Portland State University

PDXScholar

$5-14-2020$

Residence Life as Learning Organizations: an Inquiry Into Organizational Elements that Support Integration of the Residential Curriculum

Heather Kropf

Portland State University

Follow this and additional works at: https://pdxscholar.library.pdx.edu/open_access_etds

Part of the Educational Leadership Commons, and the Higher Education Commons Let us know how access to this document benefits you.

Recommended Citation

Kropf, Heather, "Residence Life as Learning Organizations: an Inquiry Into Organizational Elements that Support Integration of the Residential Curriculum" (2020). Dissertations and Theses. Paper 5464.

https://doi.org/10.15760/etd.7336

This Dissertation is brought to you for free and open access. It has been accepted for inclusion in Dissertations and Theses by an authorized administrator of PDXScholar. Please contact us if we can make this document more accessible: pdxscholar@pdx.edu. 
Residence Life as Learning Organizations: An Inquiry Into Organizational Elements that Support Integration of the Residential Curriculum

\author{
by \\ Heather Kropf \\ A dissertation submitted in partial fulfillment of the \\ requirements for the degree of
}

Doctor of Education

in

Educational Leadership: Postsecondary Education

\author{
Dissertation Committee: \\ Christine Cress, Chair \\ Karen Haley \\ Candyce Reynolds \\ Craig Shinn
}

Portland State University

2020 


\title{
LEARNING ORGANIZATIONS
}

\begin{abstract}
Student learning and success is tied to the learning goals and mission of each institution, including environments outside of the classroom. Students are more diverse than ever in terms of their lived experience and their culture, identity, and how they engage in learning. Research has indicated that students spend the majority of their time outside the classroom, where they are learning through informal and formal environments. This has significance and opportunities for student affairs practitioners who desire to create student learning environments. In fact, residence life curricular approaches have demonstrated positive learning experiences for students.

However, implementing a learning-based curricular model is fraught with organizational challenges, and little is known about how relatively successful residence life curricular model organizations adapt and modify human resources and structural, political, and symbolic elements in their quest to become learning organizations and better support student learning and success. Therefore, this inquiry investigated five residence life curricular model organizations in order to identify common best practices and strategies that can be replicated to support student learning. The findings outline a new model (curricular integration model) and eight critical components in the organizational structure and culture to operationalize the curricular approach; the model can be utilized and adapted for many organizations to support a thriving curricular model.
\end{abstract}




\section{LEARNING ORGANIZATIONS}

\section{Acknowledgements}

Thank you to my partner (Merv) whose love and support made this possible; thank you for constantly challenging me. Thank you to my family and friends for your unwavering support and understanding of this journey and season in my life. To my advisor (Dr. Christine Cress), thank you for pushing me beyond my own thoughts. To the dissertation committee members (Dr. Karen Haley, Dr. Candyce Reynolds, and Dr. Craig Shinn), thank you for your thoughtful perspectives, continued support, pushing me to dig deeper into my analysis, and a listening ear. To my mentors (Dr. Lori Lander and Sheryl Eyster), thank you for being my biggest cheerleaders. Thank you to my work colleagues for your support and encouragement throughout my doctoral journey. Thank you to the Institute on Curricular Approach faculty who have been supportive in my research; I have appreciated all of the advice and encouragement. Thank you to my dissertation editor (Jennifer Keplinger), who is beyond amazing. To my cohort mates, thank you for the group chats, beach weekends, car rides to Portland, hotel nights, holding me accountable, supporting me, and sharing your life with me through this experience. Thank you!

I am thoroughly impressed with the hall director staff who were part of this research; their pure dedication to student learning and being educators and scholar practitioners is exactly what students deserve. I additionally am moved by the staff interviewed who oversee the curricular model at their respected institutions; their students and staff are lucky to have such talented professionals. It is because of the participants' experience and sharing with me that this research was possible. Thank you 


\section{LEARNING ORGANIZATIONS}

again for your time, experience, and dedication to student learning and the curricular approach! I dedicate this research to every student who attends higher education who deserves the best in their college journey both inside and outside of the classroom! 


\section{LEARNING ORGANIZATIONS}

\section{Table of Contents}

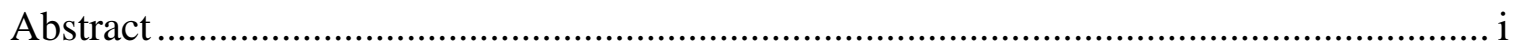

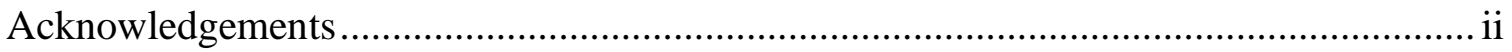

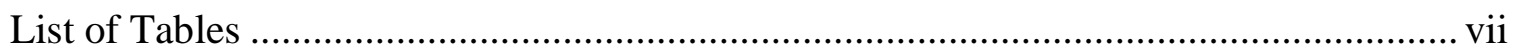

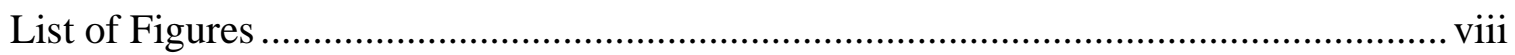

Chapter One: Introduction ................................................................................... 1

Challenges Limiting Student Success ..................................................................... 2

Student Affairs Imperative: Learning ............................................................... 3

Student Affairs Professionals as Educators ............................................................... 4

Residence Life Organizations ......................................................................... 5

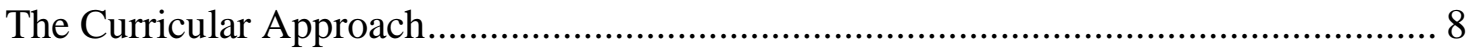

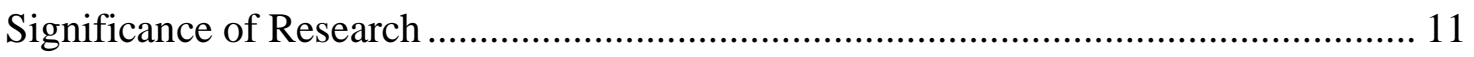

Chapter Summary ............................................................................................... 11

Chapter Two: Literature Review ................................................................................................ 13

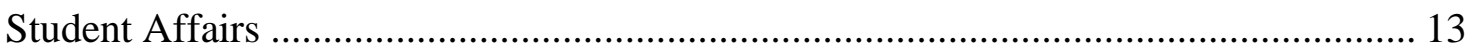

Current Landscape of Student Affairs ................................................................... 16

Climate in Higher Education ............................................................................. 16

Benefits of Residence Halls ................................................................................... 18

Curricular Approach Background ....................................................................... 22

Ten Essential Elements of a Curricular Model for Learning Beyond the Classroom 24

Residential Curricular Research …………………….................................... 25

Building Curricular Model Cultures in Organizations ................................................ 27

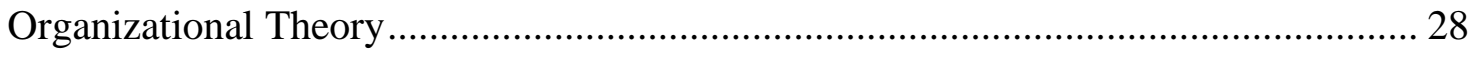

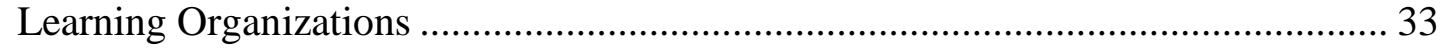

Student Affairs as Learning Organizations .......................................................... 36 


\section{LEARNING ORGANIZATIONS}

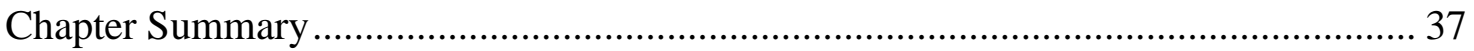

Chapter Three: Methodology ........................................................................................39

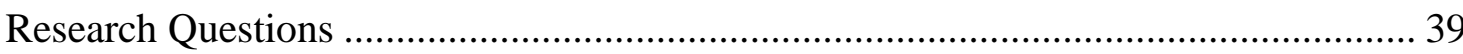

Rationale for Qualitative Research........................................................................... 40

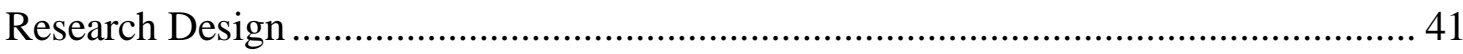

Residence Life Curricular Model Institutional Selection (Sample Selection) ........... 41

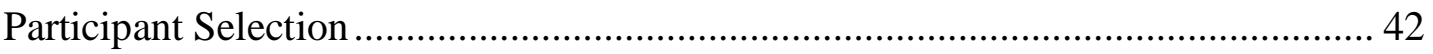

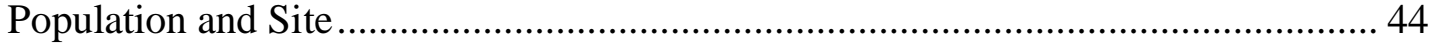

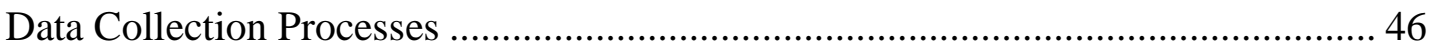

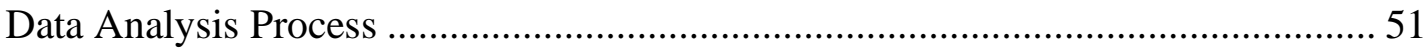

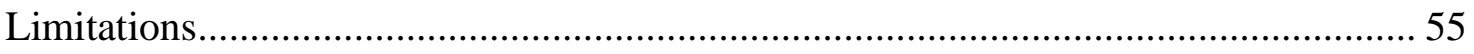

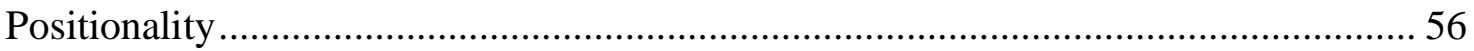

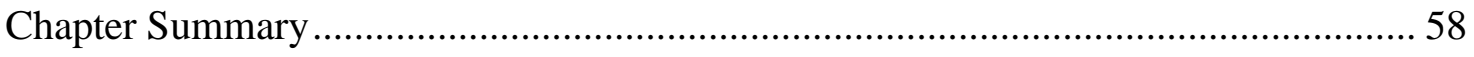

Chapter Four: Results ................................................................................................................ 60

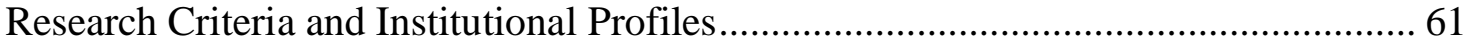

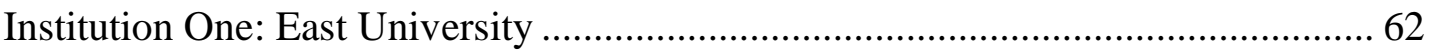

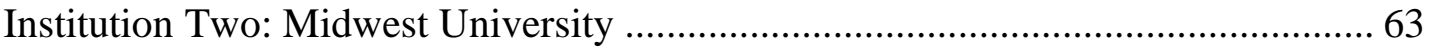

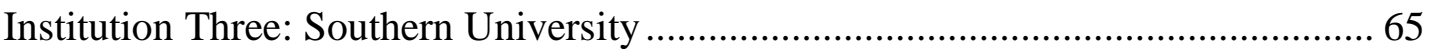

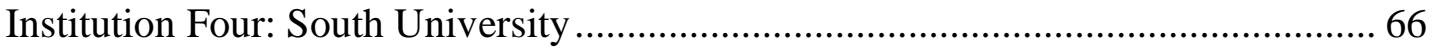

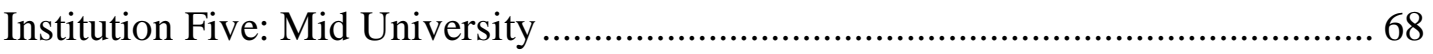

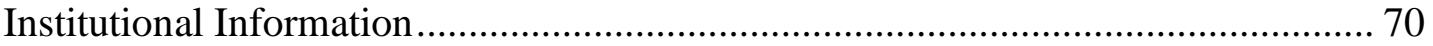

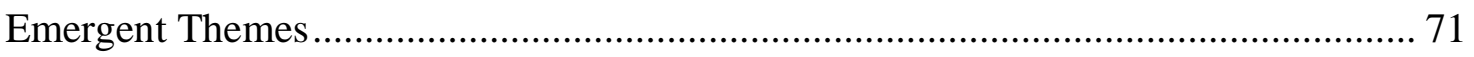

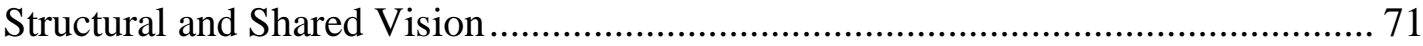

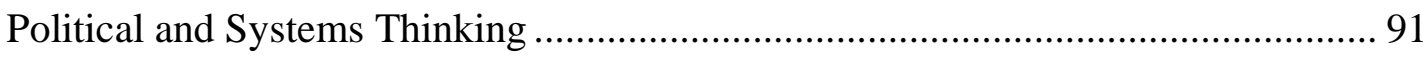

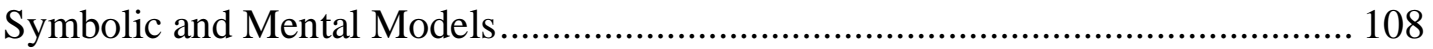

Human Resources, Personal Mastery, and Team Learning ...................................... 122 


\section{LEARNING ORGANIZATIONS}

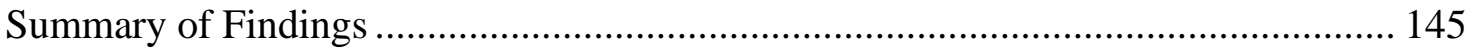

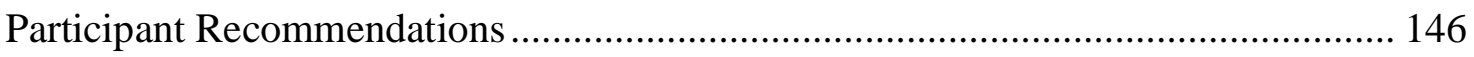

Recommendations: Creating Learning Organizations............................................ 146

Recommendations: Sustaining a Curricular Model .................................................. 148

Organizational Structure and Culture .................................................................... 150

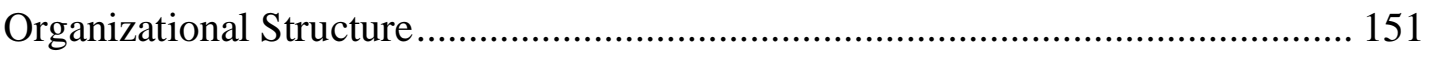

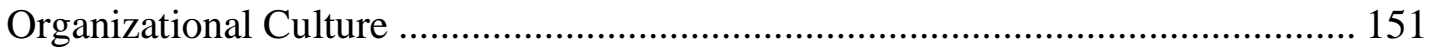

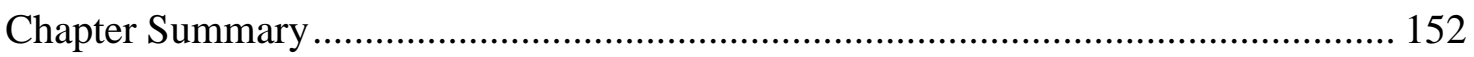

Chapter 5: Discussion ...................................................................................................................... 153

Components to Sustain a Curricular Model ................................................................. 153

Organizational Structure ................................................................................ 154

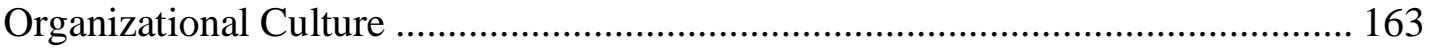

Curricular Integration Model............................................................................ 171

Strategic Steps to Curricular Model Integration: Initiating, Sustaining, and Thriving

Model of Strategic Steps to Curricular Model Integration ...................................... 180

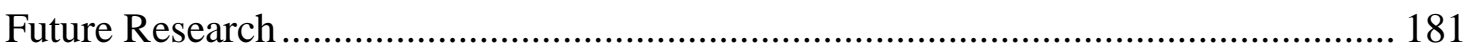

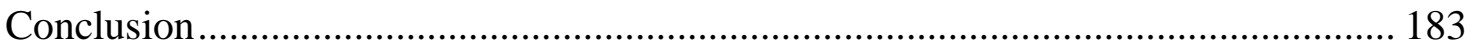

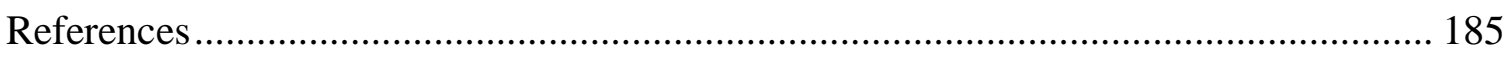

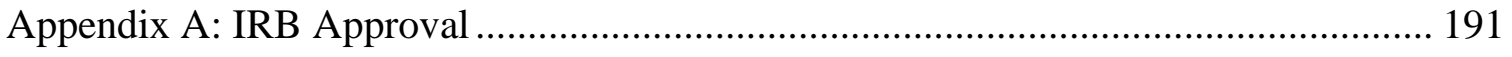

Appendix B: Email to Institutional Staff \#1 …………………….................................. 192

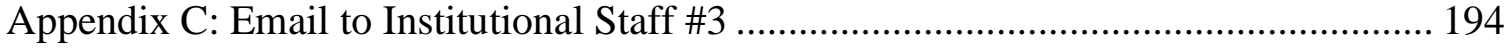

Appendix D: Email to Institutional Staff \#2 ……………………................................ 197

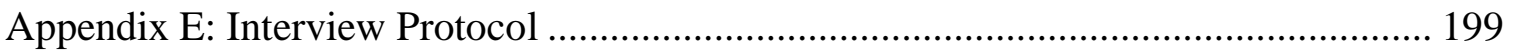

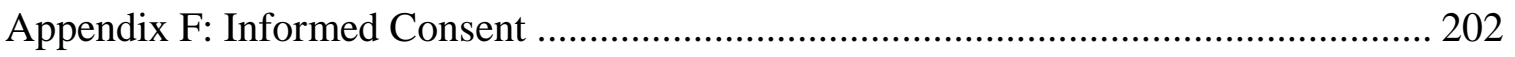




\section{LEARNING ORGANIZATIONS}

\section{List of Tables}

Table 1. Sample Interview Protocol Questions............................................................. 50

Table 2. Institution and Participant Information ............................................................ 70

Table 3. Eight Key Data Components ..................................................................... 154

Table 4. Eight Critical Concepts for Integration of an Organizational Curricular Approach 


\section{LEARNING ORGANIZATIONS}

\section{List of Figures}

Figure 1. Conceptual and Theoretical Framework Integration ...................................... 48

Figure 2. Findings Across the Areas......................................................................... 146

Figure 3. Kropf Curricular Integration Model ………................................................. 171

Figure 4. Kropf Curricular Integration Model with Temporal Considerations ............... 181 


\section{LEARNING ORGANIZATIONS}

\section{Chapter One: Introduction}

Student learning and success is tied to the learning goals and mission of each institution, including environments outside of the classroom. Students are more diverse than ever in terms of their lived experience and their culture, identity, and how they engage in learning. Research indicates that students spend the majority of their time outside the classroom where they are learning through informal and formal environments. This has significance and opportunities for student affairs practitioners who desire to create student learning environments. In fact, curricular approaches have demonstrated positive learning experiences for students. Some departments of residence life have adopted a curricular model to foster student learning tied to their institutional mission, which takes organizations multiple years to develop while adapting and changing their culture to meet the needs of their student demographics. However, implementing the learning-based curricular model has challenges, and little is known about its organizational adoption and integration.

This study explored the critical need for supporting students' co-curricular learning. Specifically, this chapter reviews contemporary complexities faced by college students, including challenges associated with engagement, retention, and learning that limit student success and graduation. Next, high-impact college practices are examined as potential intervention strategies for supporting students' co-curricular learning, including a new residential curriculum. Then, the chapter concludes by establishing the research and theoretical grounds for proposing an inquiry into organizational strategies in 


\section{LEARNING ORGANIZATIONS}

residence life departments that might be utilized to leverage student learning and academic success.

\section{Challenges Limiting Student Success}

The complexity of issues that students bring to college has increased in recent decades, including backgrounds and cultural differences, learning needs, and personal support needs. For instance, the demographic profile of students has expanded to include an increased number of students from underrepresented groups (e.g., students of color, students with disabilities, women, veterans, lower-socioeconomic status groups, and firstgeneration college students). In short, student populations on college campuses have significantly diversified. Hurtado (2007) projected that by mid-century, half of the U.S. population will be racial/ethnic minorities, with Latinx individuals representing a quarter of this demographic shift in the population. Along with a change in demographics, students increasingly face a set of challenges related to mental illness and drug and alcohol use (Tull \& Kuk, 2012). Furthermore, students on campus more often face issues related to suicide, sexual assault, and more recently, ones arising from misuses of social media (Tull \& Kuk, 2012).

Moreover, diverse students' needs have interfaced with institutions in ways that have not resulted in learning success. Cress (2008) demonstrated that students' learning environments are replete with macro- and microaggressions, creating a hostile climate that limits student achievement. Given that college can be a hostile place for students, student affairs departments can play a pivotal role in supporting the learning process if 


\section{LEARNING ORGANIZATIONS}

they integrate innovative educational outputs and adapt organizational processes and programs to attend to diverse learners' needs in supportive environments. Indeed, that is the fundamental student affairs imperative: learning.

\section{Student Affairs Imperative: Learning}

The American Council on Education hosted a conference in 1937 for educational leaders who worked with students outside of the classroom and created a report on its proceedings, The Student Personnel Point of View. The report "emphasized the importance of educating the whole student" (National Association of Student Personnel Administrators, 1987, p. 6). This document became groundwork for practitioners in student affairs.

Since then, student affairs practitioners and researchers have created student development theories and conceptual frameworks to guide professionals in their engagement with students (Patton et al., 2007). As Porterfield, Roper, and Witt (2011) explained, theories of "student development, principles of student learning, and models from management and business have been used to define student affairs purposes, tasks, and effectiveness. All of these perspectives can be used productively, particularly when taken together" (p. 2).

Moreover, nearly 50 years after The Student Personnel Point of View report was published, the American College Personnel Association (1994) released The Student Learning Imperative, which has since further shifted the focus from student development to student learning. The Student Learning Imperative urges student affairs practitioners to 


\section{LEARNING ORGANIZATIONS}

facilitate student learning and to re-examine outputs of their work as practitioners by creating learning environments for students. Outputs are educational learning moments and vary based on the institution specific initiatives. Indeed, Hurtado (2007) asserted that it is the responsibility of staff to educate and advance the learning process to better prepare students and to advance social progress during and after college. Most recently, Learning Reconsidered (Keeling, 2004) defined learning as "a comprehensive, holistic, transformative activity that integrates academic learning and student development" (p. 2). Unfortunately, some student affairs practitioners do not see themselves as educators, and at times, they continue to focus solely on student development rather than learning. Such views can further limit student success and even become a barrier to creating learning-centric environments. Instead, professional staff should have a scholarpractitioner mindset that is rooted in learning about the changing nature of student needs. In other words, student affairs professionals need to embrace their role as co-curricular educators.

\section{Student Affairs Professionals as Educators}

Student affairs professionals need to evaluate how they are shaping and engaging in learning with, for, and about students. Being a professional in student affairs is a shared responsibility with faculty and other administrators to develop themselves as educators and create learning environments for students (ACPA, 1994). As divisions of student affairs build a culture in their organization to support the changing student, the best way to engage in educating students is by focusing on student learning because it is 


\section{LEARNING ORGANIZATIONS}

tied to institutions' educational mission. Living out a mission on an organizational and institutional level can have direct gains for students because the environment outside the classroom complements what students experience inside the classroom (Porterfield et al., 2011). Being an educator can also be called being a scholar practitioner; this is when student affair professional staff are grounded in learning and developmental theory and research (McClintock, 2004)

As Blimling (2015) outlined:

In the student learning approach, student affairs administrators were focused on the creation of learning experiences that connected students to the overall educational mission of the university rather than on the individual development of students, as was the case with the student development approach. (p. 18)

To accomplish these educational learning goals, some student affairs departments such as residence life have created learning-centered programs and activities to meet the needs of diverse students. The next section gives a brief history of residence life organizations and some contemporary strategies for supporting students and introduces a new and innovative curricular approach.

\section{Residence Life Organizations}

Residence life organizations are more than a "dorm" for students who live on campus; they provide more than just sleeping quarters. The residential experience was a foundational part of the creation of higher education and a pivotal role in creating community and engaging students in learning processes (Blimling, 2015). Residence halls were part of the earlier colonial college, and they were originally known as "dormitories," which is derived from the Latin "dormire," a word meaning "to sleep" 


\section{LEARNING ORGANIZATIONS}

(Blimling, 2015). As the field of residence life has evolved to better serve student populations and student affairs divisions, dormitories have come to be called residence halls (Blimling, 2015). Whitt (2006) asserted, "The extensive body of research on college impact suggests that focusing on student engagement... what students do during college, is the best way to enhance success" (p. 2). Research studies have found that to be effective learners, students must be engaged both inside and outside the classroom. The contribution of residence life to the out-of-class experience cannot be overstated (Whitt, 2006). In other words, student engagement with all aspects of campus, both academically and socially, contributes to student success and persistence (Tinto, 1987).

Residence halls are avenues for students to continue to engage in learning outside of the classroom. According to Blimling (2015),

Residence halls contribute significantly to what they [students] learn, the friends they meet, their identities, their likelihood of graduation, and their overall satisfaction with college; residence halls are places where students make friends, connect with the larger university community, and create memories that become the foundation for meaningful college experience. (p. 179)

Student learning is defined by Blimling as the "active engagement of students in experiential programs in residence hall settings that result in measurable student learning outcomes" (p. 27).

Students who live on campus learn more than those who do not live on campus; they are retained in college at higher rates, graduate faster, and are more satisfied with their college experience (Blimling, 2015; Pascarella \& Terenzini, 2005). Students living in residence halls "report greater gains in personal growth and development than do 


\section{LEARNING ORGANIZATIONS}

commuter students" (Blimling, 2015, p. 125). Some institutions have initiated a first-year live-on requirement for all first-year full-time students because of academic advantages and an increase in retention from their first-year into their second year (Schudde, 2011), as well as because students who live on campus rather than in Greek facilities consume alcohol at lower rates (Long, 2014).

Being tied to the mission of the university provides consistency, purpose, and direction for departments. Understanding and buying in to the mission and learning is vital because it allows staff to have an understanding of how their contribution connects to the institution (Ruben, De Lisi, \& Gigliotti, 2017). When staff are mindful of the mission of the institution and goals of their department, they are better informed to make decisions and lead by example with the mission and goals in mind (Ruben et al., 2017). Sandeen (2004) urged student affairs staff to "understand and support the educational goals of their institutions and work collaboratively with academic deans and faculty to achieve these goals" (p. 32).

To that end, departments of residence life have purposefully integrated student learning through multiple avenues over the past 30 years. To name a few initiatives, departments have created living-learning programs where students live on a floor and take classes together, and at times faculty who teach in the program plan events and cocurricular activities for students outside of the classroom. In faculty-in-residence programs, a professor lives in a residence hall and engages with its community, or in themed housing, students choose their room based on a particular area of interest and live 


\section{LEARNING ORGANIZATIONS}

near people who share it. These strategies have been successful because first-year students who have more interactions with faculty have higher GPAs than those who do not (Webber et al., 2013).

Even though there have been significant efforts to integrate the mission and academic partners into residence life programs through faculty-in-residence and livinglearning programs, these strategies only affect a subset of students and often do not include the whole residential population. Furthermore, non-traditional and traditional aged students are still not being retained or achieving high levels of academic success. As such Graham, Hurtado, and Gonyea (2018) challenged residence life departments to question their programs to see if they really are creating positive interactions with students that support learning. They urged residence life programs to better assess the needs of the diverse students and their experiences and to understand the role their program plays in connecting students to positive academic outcomes. In response, some residence life departments are re-orientating and re-imagining themselves as "learning organizations," and to guide their process, they are utilizing a conceptual frame called the curricular approach.

\section{The Curricular Approach}

Some institutions have adopted a curricular approach out of a desire to engage residents and provide seamless learning opportunities for students they house. The University of Delaware created the curricular approach in early 2000s. Kerr and Tweedy (2006) wrote a residential curriculum for their institution that sequenced learning through 


\section{LEARNING ORGANIZATIONS}

learning outcomes, goals, objectives, and assessments for students living in their residence halls. The curricular approach focuses on centering the experience of student learning; the process by which institutions create this type of focus is informed by the university mission, divisional mission, then the department's learning goals and strategies to educate students (Keer \& Tweedy, 2006).

Residence life departments are shifting away from programming models where resident assistants (student staff) are asked to program around a variety of topics (wellness, diversity, or social programs). In programming models, resident assistants were often the creator of the content of the programs. Departments have been shifting from a programming model to a curricular approach, which means departments have been prioritizing learning at the forefront, focusing on a curricular learning approach outside of the classroom, and full-time staff are the creators of content (Kerr et al., 2017). They map out goals for their department that are tied to their university's mission. Institutions that have a curricular approach take the responsibility of designing programs away from student staff and shift it to professional staff, who are ultimately the educators and driving force behind the curricular model (Blimling, 2015; Kerr \& Tweedy, 2006). The curricular model should be designed so that the content is developed with "intentionality, structure, and sequencing that is applied in the design of academic majors and individual courses to college experiences beyond the classroom" (Kerr et al., 2017, p. 22). 


\section{LEARNING ORGANIZATIONS}

The curricular model connects research, learning theory, assessment, teaching strategies, learning outcomes, and much more to the student experience (Kerr et al. 2017). The curricular model is grounded in the institution's mission and focused on educating the whole student. Students engaging in the curricular approach have reported they felt more welcomed, enjoyed living on campus, had an increased sense of belonging and satisfaction, and felt an increase in their understanding of others (Brown, 2017, 2019; Kerr et al., 2017). However, the positive impacts of this model are not only experienced by student populations. Departments of residence life have also seen less strain on budgets, and fewer conduct issues and incidents, and staff have reported having a more a positive experience (Brown, 2017, 2019; Kerr et al., 2017).

To date, research studies on the curricular approach in residence life seem to be highly promising and provocative in terms of guiding student affairs work to support student learning (Lichterman, 2015; Sanders, 2018). However, re-imagining and operationalizing student affairs offices and, in particular, residence life departments is a daunting task. Tull and Kuk (2012) noted that student affairs divisions are "facing increasing challenges in terms of expanding enrollment; changing demographics; the shifting and demanding nature of responsibilities; and increased expectations related to programs and services from the greater campus community, parents, and external constituents" (p. 3). Student affairs by nature is hierarchical, and cultures of student affairs divisions and departments within them are shaped by institution type, student population size, academic programs, university's mission, president, board of directors, 


\section{LEARNING ORGANIZATIONS}

regional and state implications, donors, and types of students. Few higher education organizations have a stable environment (Manning, 2018). Therefore, the field of student affairs needs a critical and evidence-based inquiry to identify key organizational antecedents and facilitators of implementing a successful residence life curricular model.

\section{Significance of Research}

Only two dissertations (Lichterman, 2015; Sanders, 2018) and a handful of articles and resources (Kerr \& Tweedy, 2006; Kerr et al., 2017; Brown, 2017, 2019) about the residence life curricular approach have been published. This study researched how residence life organizational structures and cultures have been designed, implemented, and adapted to support and sustain a thriving curricular approach. In addition, this study examined how residence life departments have structured their organization and managed the process of becoming a learning organization to support the curricular model and ultimately focus on student learning. By identifying key elements across multiple institutions, a set of best practices and strategies may be replicated to support student learning and success.

\section{Chapter Summary}

Learning is the purpose for higher education. Students spend $80 \%$ of their time outside of the classroom (Lenz, 2015), and divisions of student affairs have a unique role to play in creating learning-centric environments that are grounded in the mission of the institution. This chapter explores students' experiences outside of the classroom, discussed the changing demographics of students, reviewed historical and contemporary 


\section{LEARNING ORGANIZATIONS}

approaches to student development and student learning, and introduced a promising way to respond to students' needs through the curricular model. Chapter 2 expands on these topics and explicates in more depth research and conceptual frames that can guide understanding of higher education and student affairs, organizational structures that inhibit and facilitate responsive adaptation to student needs. Chapter 3 outlines a methodological design for investigating strategic steps in leveraging residence life departments as learning organizations by integrating and implementing the curricular model. Chapter 4 shares the findings around the emergent themes related to the conceptual and theoretical frameworks and how departments sustain their curricular model. Chapter 5 fully explains the two major themes and eight components needed in terms of implementing a thriving curricular model in organizations for maximum efficiency and success. 


\section{LEARNING ORGANIZATIONS}

\section{Chapter Two: Literature Review}

Institutions that strive towards supporting student persistence and positive learning outcomes should encourage student affairs practitioners to actively contribute to the academic mission of the institution and assist students in reaching their potential (Whitt, 2006). Student affairs divisions play a pivotal role in educating students and creating learning environments that are rooted in the institutional mission. Unfortunately, the student affairs field has not adapted well to the changing culture of students, but some divisions have become more learning-centric in their approach by adopting a curricular model that supports learning outside of the classroom. However, little is known about how those departments have become a learning organization and integrated the curricular approach. This chapter examines the current landscape of student affairs and how residence life departments benefit students and the critical role that residence halls can play in supporting learning outside of the classroom. In addition, the curricular model is explained, including current research, and organizational theory is situated as a lens for examining strategic leverage points of the curricular model integration.

\section{Student Affairs}

The field of student affairs was formalized to educate the whole student, according to The Student Personnel Point of View (National Association of Student Personnel Administrators, 1987). Student affairs is a field that has made significant contributions to college students and their development (Porterfield et al., 2011). The profession of student affairs started at Harvard University when the president needed 


\section{LEARNING ORGANIZATIONS}

assistance with issues related to student behavior and created the first dean of men position in 1890 that was held by LeBaron Russel Briggs (Mann, 2010). The first dean of women was held by Alice Freeman Palmer at the University of Chicago in 1892 (Mann, 2010). These positions took over the day-to-day operations of advising and disciplinary duties from the president (Mann, 2010). As the profession of student affairs evolved, there were multiple deans: one for women and another for men at many institutions.

Due to increased numbers of students and changing student demographics, the current structure of student affairs at most institutions contains a vice president of student affairs, dean of students, and multiple departments, including campus life (student conduct, Greek life, leadership, community service); admissions; orientation; academic services (academic advising, tutoring services); residence life; sports and recreation; diversity and inclusion (disability, international, multicultural, and spirituality services); and counseling, health, and wellness. Student affairs as a field has been evolving since its inception and has grown and changed to meet the needs of students. As a result, the field became hierarchical and rooted in functional areas like housing, advising, counseling, and others, and when programs expanded, there was an increase in hiring mid-level managers to supervise programs and staff (Tull \& Kuk, 2012).

In a climate of decreased state and federal funding for public universities, student affairs divisions are faced with the challenge of how to carry out their mission as resources have dwindled (Tull \& Kuk, 2012). Additionally, the hierarchical structure of student affairs has had an unintended effect: a lack of intentionality on how these various 


\section{LEARNING ORGANIZATIONS}

offices meet their institutional mission and student needs and offer efficiency of resources (Bendermacher et al., 2017; Kezar \& Kinzie, 2006; Kuk \& Banning, 2009).

The growth in student affairs led to a siloed organization, where staff became more specialized in functional areas. This siloed structure resulted in duplicating efforts and competing priorities and created confusion for students if multiple departments were offering similar services (Tull \& Kuk, 2012). Often when financial resources dwindle, silos inhibit resource sharing and collaborations that could benefit students and maximize resources. If student affairs departments shared resources and staffing expertise, they could assist with increased knowledge from professionals in multiple areas.

With the changing culture of student affairs, divisions should embrace new collaborations with campus and community partners, understand competing commitments, broaden their perspectives, and recognize the changing culture of students (Porterfield et al., 2011). As budgets shrink, institutions are encouraged to move from specialist to generalist positions with crossover training in multiple functional areas (Kuk \& Banning, 2009).

Porterfield et al. (2011) explained the following:

The historic mission of student affairs has focused on providing services to support student achievement and institutional missions and creating programs and environments outside the classroom to compliment students' experiences in the curriculum. In the past four decades, that mission has been reconsidered in light of concerns about the field's centrality to the missions of higher education in general and institutions in particular. (p. 2)

Research has shown that the student affairs profession and the higher education field have been in constant change since their inception (Tull \& Kuk, 2012). 


\section{LEARNING ORGANIZATIONS}

\section{Current Landscape of Student Affairs}

Research has shown that current structures in student affairs are not able to respond to the challenges and demands of students (Kuk \& Banning, 2009; Tull \& Kuk, 2012). Manning (2018) outlined that few higher education organizations have a stable environment and they have ambiguous goals that conflict throughout the institution. In addition, divisions are guided by internal and external demands. With the new reality of divestment in state funding for public institutions and an increase in state and national politics, legislative requirements, and unfunded mandates, colleges and universities need to change their way of doing business (Tull \& Kuk, 2012). Tull and Kuk (2012) asserted the following:

Student affairs professionals are not experienced or adequately trained to address the changing climate in student affairs. Student affairs organizations are at a crossroads, faced with numerous challenges from all sides; how they respond... will ultimately affect the college students they serve. (p. 34)

Students need support that assists them towards persistence and graduation. Kuh (1996) urged student affairs staff to focus on student learning and provide classroom learning experiences outside of the class, where students are able to make a connection with their in-class learning. The ability to connect learning outside of the classroom is how seamless learning environments are formed.

\section{Climate in Higher Education}

Retention rates have been steady for first-time full-time students enrolled in a four-year institution, $81 \%$ of whom come back for their second year after completing their first-year of college (National Center for Education Statistics [NCES], 2018a). 


\section{LEARNING ORGANIZATIONS}

However, the four-year graduation rates for first-time full-time students at a four-year institution who started college in 2010 was 40\% (NCES, 2018a). The six-year graduation rate for students who started college in 2010 was $60 \%$ (NCES, 2018a), meaning that for students who entered four-year institutions in 2010 , on average $40 \%$ graduated in four years and another $20 \%$ graduated in 6 years, leaving $40 \%$ of students dropping out of college or taking longer than six years to graduate. First-generation students and students from a lower socioeconomic status graduate at far lower rates than others who do not share these backgrounds (U.S. Department of Housing and Urban Development, Office of Policy Development and Research, 2015).

Students are in need of support that assists them toward graduation, as many are dropping out and taking longer to graduate than in years before. Cost is an issue for students, as it has continually increased. From 2000-2017, public institution tuition and required fees rose $63 \%$, from $\$ 2,504$ in 2000 to $\$ 6,817$ in 2017 (NCES, 2018b). At private institutions, tuition and required fees rose $51 \%$, from $\$ 14,100$ in 2000 to $\$ 28,947$ in 2017 (NCES, 2018b). For on-campus housing and a meal plan during 2000-2017, costs rose $46 \%$ at public institutions; a meal plan was $\$ 4,804$ in 2000 and $\$ 10,402$ in 2017 (NCES, 2018b). At private institutions, housing and meal plan costs rose 51\%; the cost for a meal plan was $\$ 3,236$ in 2000 and $\$ 6,710$ in 2017 (NCES, 2018b). Cost has been a barrier to enrolling in college. In 2016, the number of students enrolling in college dropped 6\%. 


\section{LEARNING ORGANIZATIONS}

With the cost of college rising and students taking longer to graduate, students need support outside of the classroom that is tied to the academic mission to assist them in their persistence toward graduation. Some institutions have initiated a first-year live-on requirement because of the benefits that residence halls provide; the next section reviews them in detail.

\section{Benefits of Residence Halls}

Students spend $80 \%$ of their time outside of the classroom (Lenz, 2015). Campuses with on-campus living have an opportunity to engage in the learning process in residence halls. Institutions that have the highest graduation and retention rates are primarily residential (Mayhew et al., 2016), meaning institutions who have all first-year students living on campus or provide a residential experience for multiple years end up progressing students towards graduation faster than those students who live off campus. Students who live on campus for at least one year have an increase in their academic performance and positive gains in their GPA and in their college career overall (Blimling, 2015; De Araujo \& Murray, 2010; Mayhew et al., 2016). De Araujo and Murray (2010) found that when students live on campus, they have an immediate increase in their academic performance, and evidence shows that having lived on campus impacts their overall cumulative GPA for their college career.

Research has stated that students who live on campus spend on average two hours more per week on co-curricular activities, preparing for class, and relaxing and socializing than students who live off campus. Students who live on campus also feel 


\section{LEARNING ORGANIZATIONS}

more supported academically in their wellbeing and engage in campus activities (National Survey on Student Engagement [NSSE], 2014). The National Survey on Student Engagement (2014) data indicated that first-year students who live on campus engage in dialogue with others who have a different political view, religious beliefs, and come from a different socioeconomic status than their own.

The national annual satisfaction Skyfactor survey seeks to understand how satisfied students are who live on campus and how living on campus contributes to student learning. In 2017, over 300,000 undergraduate students from 300 institutions completed a survey about how living on campus "contributes to their growth in key learning areas including personal interactions, diverse interactions, self-management, risk behaviors, and overall satisfaction.... [and] also positively enhanced their overall learning experience and positively contributed to their academic performance" (Skyfactor, 2017, p. 17).

Mayhew et al. (2016) explained how living on campus promoted openness to diversity, as well as positive and inclusive racial/ethnic attitudes. These patterns were stronger within residences that were designed to foster students' interactions with people and ideas that were different from their own. Living on campus also fostered student retention, persistence, and graduation.

Living on campus has proven to be a beneficial environment for students.

Students have a meal plan and are closer to academic buildings, so they have more time because they travel less to and from their classes. They also engage with others who are 


\section{LEARNING ORGANIZATIONS}

different than they are and engage in campus events and programs. In other words, the very environment of residence life offers multiple opportunities for learning. As such, residence life departments are already situated to more fully becoming learning-centric organizations.

According to Maki (2004), "Learning is a process of constructing meaning, framing issues, drawing on strategies and abilities honed over time, reconceptualizing understanding, repositioning oneself in relation to a problem, or issue, and connecting thinking and knowing to action" (p. 2). Merriam and Bierema (2014) explained that learning is a human endeavor that is lifelong and has the ability to change someone's behavior by gaining cognitive knowledge like a new skill or emotional growth. Student learning in a residence hall provides active engagement in measurable student learning outcomes (Blimling, 2015).

Residence halls are designed to allow students to interact with others who have different lived experiences, which allows them to engage in dialogue across difference (Kerr \& Tweedy, 2006). Also, residence halls provide students direct and close contact with their peers, which encourages them to engage in conversations around difference (Keer \& Tweedy, 2006). Kerr and Tweedy (2006) asserted: "Residence hall living offers a powerful opportunity to engage young adults in learning that will improve the quality of both their campus and adult life" (p. 9). Peter Senge (2006) claimed that learning organizations are those that facilitate learning for all members and continuously seek to adapt to the needs of the student population they serve. 


\section{LEARNING ORGANIZATIONS}

The heart of residence life is learning-centric because it provides learning opportunities for all and educates residents and student staff. Indeed, residence life departments have incorporated a scholar-practitioner mindset in which professional staff are grounded in learning and developmental theory and research (McClintock, 2004). This scholar-practitioner approach has created the foundation for responding to diverse student learning needs. In other words, learning-centric environments start with residence life professionals and their adoption of a scholar-practitioner mindset. A scholarpractitioner is someone who engages in research to improve outcomes and effectiveness; they are administrators who engage in research to better their practice (Kupo, 2014). According to Kupo (2014), being a scholar-practitioner is based on a "framework of values, habits, of mind, and the ability to balance and integrate 'doing' with 'knowing"' (p. 89). Being learning centered is a personal commitment, and in order to create learning environments for students, full-time staff members need to be aware of theory and learning development (Smith \& Rodgers, 2005).

The curricular model is grounded in learning and student development theories, which serve as a foundation for professionals to gain knowledge and improve their engagement with students (Patton et al., 2007). Learning and student development theories are frameworks that help educators understand how information is absorbed and processed. They give professional staff an opportunity to be mindful and intentional about how student learning and development are integrated into their practice with the curriculum outputs they are creating. 


\section{LEARNING ORGANIZATIONS}

In a recent research study, Graham et al. (2018) found there are benefits of living on campus in regard to collaborative learning, student-faculty interactions, and discussions with diverse others. To that end, the American College Personnel Association's (1994) The Student Learning Imperative urges student affairs practitioners to focus their efforts on student learning rather than student development because a learning-focused department seeks to build out-of-class experiences that complement their institution's educational mission and ties into its academic approach (Kuh, 1996). Prior to The Student Learning Imperative, professional staff focused on student development, which was not always tied to the goals of the institution; rather, it focused on the individual needs of students. The Student Learning Imperative views student affairs staff as educators who contribute to student learning and have a shared responsibility with faculty and administrators to create learning environments that support the academic mission (ACPA, 1994). In sum, a learning-centric perspective in residence life has laid the groundwork for embracing a new curricular approach that is detailed in the following section.

\section{Curricular Approach Background}

Residential curriculum, curricular approach, and curricular model are terms used to describe the "intentional specifically structured way of promoting learning in college and university student affairs programs” (Brown, 2019, p. 9). The curricular model enhances the overall learning of the student (Kerr et al., 2017). Blimling (2015) pointed out that students will learn by simply living in a residence hall community; however, by 


\section{LEARNING ORGANIZATIONS}

intentionally framing outputs through a curricular model, learning is taken one step further, as it is rooted in the educational priority of residence life departments and is grounded in the institution's mission. This leads to more intentional learning goals and outcomes, and it is followed by strategies in a sequenced fashion to best engage students in learning processes (Kerr et al., 2017).

The residential curricular approach has been so promising that it has expanded outside of residence life to divisions of student affairs and other departments in student affairs. Annually since 2007, the American College Personnel Association (College Student Educators International) has hosted a conference called "Institute on Curricular Approach" (ICA); formerly, it was known as the Residential Curriculum Institute (RCI). The shift in the institute from RCI to ICA was intentional because learning opportunities occur beyond the classroom — not only in residence halls but also in other areas and departments on campus, even at the divisional level within student affairs. The institute is open to any institution that is interested in learning more about the curricular approach. Many institutions attend to understand how to have a curricular approach in their division of student affairs and other departments. The institute is led by faculty who are currently (or have previously been) practitioners in the field of student affairs. Some faculty also travel to institutions to teach about curricular approaches throughout the year. Many institutions that have applied the curricular model have either had campus professionals attend the institute or hosted ICA faculty on their campus. 


\section{LEARNING ORGANIZATIONS}

\section{Ten Essential Elements of a Curricular Model for Learning Beyond the Classroom}

Faculty of ICA developed a list of the 10 essential elements (10EE) of a curricular model for learning beyond the classroom. The faculty at ICA noticed either in their current institutions and or in other departments that transitioning to a curricular approach; it comes with many barriers and obstacles and they collaborated and created the 10EE to assist and clarify what components are needed to sustain the model. Kerr et al. (2017) asserted: "We see each aspect as important and have seen many approached weakened when components or elements are omitted" (p. 25). These are best practices and have been instrumental to institutions in their development of curricular models (Kerr et al., 2017); the 10 elements are as follows:

1) Directly connected to an institutional mission: Learning goals are tied to institutional and educational priorities such as general education, history, mission, and culture.

2) Learning goals and outcomes are derived from a defined educational priority: Educational aims of a unit are focused, interconnected, and clearly articulated.

3) Based on research and developmental theory: Educational content and strategies are grounded in student development theory and learning pedagogy.

4) Departmental learning outcomes drive development of educational strategies: Educational strategies are determined based on what can best facilitate each student achieving the department learning outcomes.

5) Traditional programs may be one type of strategy but not the only one: Strategies like international conversations, community and organizational meetings, service initiatives, social media engagement, and campus events are structured to help achieve the learning outcomes.

6) Student leaders and staff members play key roles in implementation but are not expected to be educational experts: Student leaders and staff members are considered to be facilitators rather than designers of educational strategies. 


\section{LEARNING ORGANIZATIONS}

7) Represents developmentally sequenced learning: Educational content and strategies build upon one another for coherent plans both across the academic year and the full college career.

8) Campus partners are identified and integrated into plans: Multiple units with intersecting goals work together to develop educational strategies that complement the student experience and advance the institution's mission.

9) Plan is developed through review processes: A regular review process (internal and/or external) is developed to get feedback from key partners and experts on content and pedagogy.

10) Customized student learning: Learning that is tailored to the individual student's needs and goals through multiple strategies. (Kerr et al., 2017, p. 25)

According to Kerr et al. (2017), departments that have a thriving curricular model have utilized the 10EE in the development and execution of their approach. They also utilize the elements throughout the assessment and evaluation of their curricular approach to ensure they are fully integrating the curriculum model. Brown $(2017,2019)$ identified an additional 11 th element, cycle of assessment for student learning and educational strategies. This element states that assessment is focused on student attainment of learning outcomes and effectiveness of strategies in a cycle of continuous improvement.

\section{Residential Curricular Research}

The 10EE of a curricular model for learning beyond the classroom have been utilized in departments to center student learning, encourage professional staff to become educators, adapt to the changing culture of students, and mapped out learning that is rooted in the institutional mission. There has been promising research in the past few years about the curricular approach through two dissertations (Lichterman, 2015; 


\section{LEARNING ORGANIZATIONS}

Sanders, 2018) and a handful of articles and resources (Kerr \& Tweedy, 2006; Kerr et al., 2017; Brown, 2017, 2019).

Lichterman (2015) researched a department's experience with adopting a residential curricular approach aligned with the 10EE, utilizing Bolman and Deal's four frames as the study's theoretical framework. Lichterman's (2015) study allowed participants to share their experiences with adopting a curricular model and found that there were challenges and gains associated with adopting the curricular approach as well as a reframing of how they viewed residential education (Lichterman, 2015; Lichterman \& Bloom, 2019). Staff perceived the gains in the shift would be positive (i.e., better for students), and they felt that they had a voice in outcomes; however, they also perceived challenges in that one approach may not meet the needs of student demographics and space limitations (Lichterman, 2015; Lichterman \& Bloom, 2019).

Sanders's (2018) research utilized Astin's Input-Environment-Outcome model to measure how the inputs of students through a residential curricular model influenced living on campus through the residential curricular survey. Sanders (2018) found that students overall during college through academic and co-curricular programs and living on campus had positive relationships when interacting with each other, and housing staff had positive gains to their personal and cultural development.

While the outcomes in research have been positive, what we do not know is how organizations have built an organizational structure to support it. Indeed, shifting from a traditional residence life student development model to a curricular approach requires a 


\section{LEARNING ORGANIZATIONS}

mindset change for staff and a cultural and organizational shift (Brown, 2017, 2019). Moreover, the 10EE are a foundational part of the curricular model, but department staff are left wondering how to operationalize them into their organization. It begs the following questions: What organizational structures and strategies are departments utilizing to support the curricular model, and how it is integrated into the organization to help it become learning centric? One possible strategy for answering these questions is to review the organizational literature.

\section{Building Curricular Model Cultures in Organizations}

Organizations over time develop values, beliefs, and patterns as both reactive and responsive activities (Bolman \& Deal, 2017). Similarly, residence life departments that are adapting the curricular approach must shift their organization to focus on student learning rather than expending all their time and energy on day-to-day student crises. Developing a curricular approach can take multiple years, and shifting to the curricular approach is as much about building the curricular model as it is cultural and organizational change (Brown, 2017, 2019). Some residence life departments have a thriving curricular model, and others have been struggling to adapt the curricular model because of their organizational structure and culture. The shift to requires a learningcentric approach in an organization, and it is vital to sustaining the curricular model; it can take nearly 2-3 years before the basis of a curricular model will be in place in each organization (Brown, 2017, 2019). 


\section{LEARNING ORGANIZATIONS}

Like any business, government office, or college unit, each division of student affairs and department has an organizational culture. In order for a culture to have significant meaning for people, it needs to be grounded in organizational values (Tierney, 2008). An organizational culture is not stagnant and can be defined as an "interpretation that takes place on a daily basis among the members of a particular group... culture is in constant flux and reinterpretation" (Tierney, 2008, p. 2). Tierney (2008) explained that organizations are socially constructed systems and their culture is reflected by "what is done, how it is done, and who is involved in doing it" (p. 24). People have different lived experiences, and how they interpret events impacts how they are involved in the culture and the decisions made by the organization (Tierney, 2008).

Ideally, residence life departments that have a thriving curricular model should have an organization that is focused on learning through their goals and values and staff that have a scholar-practitioner mindset who adapt learning environments for the changing culture of students. Learning organizations encompass a culture that creates learning environments for all people to expand their thinking and creativity, and they encourage a collaborative learning environment (Caldwell, 2005; Garvin, 1993; Henning, 2018; Senge, 2006).

\section{Organizational Theory}

Manning (2018) stated: "Organizational theory has a long history in sociology, education, psychology, and business along with other disciplines" (p. 6). Organizations are made up of people, and "organizations are collectivities oriented to the pursuit of 


\section{LEARNING ORGANIZATIONS}

relatively specific foals and exhibiting relatively highly formalized social structures" (Scott \& Davis, 2007, p. 29). Organizations are comprised of people, and they create the culture and structure of the organization (Manning, 2018). Through human interactions, "structure is reproduced, recreated, and reformed" (Manning, 2018, p. 123). Manning continued to share how humans can alter the culture and structure through their actions. Therefore, the curricular model is a choice and is implemented by humans, and interactions and commitment to support the culture and the organizational structure are needed for it to be sustained.

As student affairs and residence life departments seek to become learning organizations, various structural elements can help or hinder this process. According to Bolman and Deal (2017), organizations are complex, and dealing with challenges and changing and unstable environments has "become harder to understand and manage" ( $p$. 22). Bolman and Deal's reframing organizations model is a resource and a lens for viewing complex organizational cultures and problem solving; it details inherent elements in every organization through four different frames: structural, human resources, political, and symbolic. It will be used as the conceptual framework for this study.

Bolman and Deal's (2017) structural frame has defined rules and processes, and often culture is referred to as a factory, mostly focusing on how to allocate work and divide responsibilities. Every organization has a structure, patterns, and people who make up the organization. Manning (2018) summarized organizational structures as not always 


\section{LEARNING ORGANIZATIONS}

being concretely real but are made real by interactions between people. The structural frame focuses on the organization design, structure, policies, and finding the right roles for people in the organization (Bolman \& Deal, 2017). In residence life, for instance, the structural frame is the organizational structure itself, including restructuring, budget allocation, meeting structure, and roles and responsibilities of staff members.

Historically, the structural frame has roots from the early 1900s, starting with organizations existing to be efficient, and as the field grew, organizations were described as a monocratic bureaucracy to optimize efficiency. They formed hierarchical layers, defined positions for different tasks, and created guidelines for staff (Bolman \& Deal, 2017). The most successful organizations manage workflow through their structure vertically (hierarchy) and laterally (how work is divided through position, meetings, workflow, committees) (Bolman \& Deal, 2017). The structural frame outlines patterns in the organization along with setting strategies to direct where the organization is going (Mintzberg, 1987). Having a good strategy can assist the organization in setting direction, determining how to manage operations, assisting people with understanding what actions need to take place, and ideally, providing a sense of direction (Mintzberg, 1987). Having strategy enables the organization to expand its skills and knowledge to the fullest (Mintzberg, 1987, 1978).

The human resource frame centers the human experience, their needs, and the relationships people have with the organization (Bolman \& Deal, 2017). It seeks to motivate others and provide individuals meaning in the organization while working with 


\section{LEARNING ORGANIZATIONS}

others (Bolman \& Deal, 2017). Organizations that are human resource-focused use the talents of individuals to fulfill their mission, and they center their values on caring, taking a team approach to problem solving, and seeking to understand people's strengths, desires, fears, and emotions (Bolman \& Deal, 2017). In residence life, this means how staff are encouraged and supported in learning and how work actually gets done.

"Organizations need people (for their energy, effort, and talent), and people need organizations (for the many intrinsic and extrinsic rewards they offer), but their respective needs are not always well aligned," said Bolman and Deal (2017, p. 133), and if one is not aligned, either one or both suffer. The human resource frame has roots in the pioneer age, when the outputs of people can make or break the organization (Bolman \& Deal, 2017). People in organizations have needs in order to do their best work; an optimal environment will allow people to grow and succeed (Bolman \& Deal, 2017). Maslow's hierarchy of needs should be met, and if it is, people are able to focus on the work at hand (Bolman \& Deal, 2017).

Organizations are political in nature; the political frame views the culture of organizations as a jungle where there are shifting power dynamics and people in the organization have competing interests and priorities (Bolman \& Deal, 2017). Political organizations compete for power and resources, have different interests, form alliances, and are often organized around the positional power in the organization (Bolman \& Deal, 2017). In residence life, this means the actual culture of the organization, including the culture shifting, creating buy-in for staff, and how staff handle conflict. 


\section{LEARNING ORGANIZATIONS}

According to Bolman and Deal (2017), the political frame shares that politics are "the realistic process of making decisions and allocating resources in a context of scarcity and divergent interests. This view put politics at the heart of decision making" (p. 179). Conflict is a natural part of an organizational culture, and the effectiveness of organizational change depends on the manager's political approach (Bolman \& Deal, 2017). When conflict is handled well, it can stimulate creativity and innovation that make an organization a livelier, more adaptive, and more effective place (Kotter, 1985).

Lastly, the symbolic frame emphasizes the role people play in the organization, and it is focused on learning rooted in the history and culture of the organization's life (Bolman \& Deal, 2017). People have roles to play in the organization, and there is a shared commitment to the sense of meaning and faith that binds the organization together (Bolman \& Deal, 2017). In residence life, this means how staff are hired, trained, and developed throughout the year and how residence life works with campus partners.

The organizational culture is communicated through symbols, which take many forms and can be the vision, value, and purpose of the organization and can offer people hope and a direction (Bolman \& Deal, 2017). High-performing symbolic organizations are filled with stories to keep traditions going and balance play and humor in the workplace, as well as culture, soul, and spirit as the base of the team (Bolman \& Deal, 2017).

Bolman and Deal (2017) outlined that "organizations are open systems dealing with changing, challenging, and erratic environment(s)" (p. 31). Each organization has an 


\section{LEARNING ORGANIZATIONS}

identity and a culture; being a learning organization includes a shift in culture. Learning organizations are open and fluid. Ideally within residence life, they are focused on student learning and adapt to the changing culture of students. A strong sense of organizational identity allows staff and students to understand the purpose of the organization and to feel integrated into the organization. It encourages staff to take action in intentional and meaningful ways because people "navigate the organization from their perspective" (Manning, 2018, p. 197). Research has shown that the investment in this long-term transition, where not only the curriculum is redesigned but also the organizational structure is shifted, will result in an effective curricular approach. The next section reviews selected organizational learning frameworks.

\section{Learning Organizations}

Learning organizations develop cultures that are conducive to learning and allow people to expand their thinking, become more creative, embody a team approach, and work collaboratively toward the processes of learning and creating (Caldwell, 2005; Garvin, 1993; Henning, 2018; Senge, 2006). Senge's (2006) organizational learning model is not a structural organizational model but a process for organizations to become more learning centric, and it will be used as the study's theoretical framework. Senge's model, which has been used primarily in business sectors, can be a tool to assist higher education, student affairs, and departments of residence life to be more learning centric in their curricular approach. 


\section{LEARNING ORGANIZATIONS}

Senge (2006) claimed that learning organizations are those that facilitate learning for all members and continuously seek to adapt to the needs of the student population they serve. This is precisely the type of shift needed by residence life organizations. Learning organizations are "organizations where people continually expand their capacity to create the results they truly desire, where new and expansive patterns of thinking are nurtured, where collective aspirations are set free, and where people are continually learning how to learn together," as asserted by Senge (2009, p. 3). Senge's model encompasses five learning disciplines for organizations to follow in order to be a learning-centered organization, which include systems thinking, personal mastery, mental models, shared vision, and team learning, each of which are explicated below.

Systems thinking is the first discipline that sees the whole in an organization, and as Senge (2006) outlined, it is a "framework for seeing interrelationships rather than things, for seeing patterns of change rather than static snapshots" (p. 68). Systems thinking is a conceptual framework in organizational learning that helps organizations see patterns and a way to change them (Senge, 2006).

As the second learning discipline, personal mastery in a learning organization encompasses how people learn. Personal mastery is a choice, and without people engaging in learning, the organization will not move forward; organizations move forward through individuals who are educating themselves (Senge, 2006). Few organizations encourage growth of personal mastery, but organizations that are committed to learning will benefit from growth of their staff working (Senge, 2006). 


\section{LEARNING ORGANIZATIONS}

Building personal mastery is a discipline that deepens people's vision, energy, and outputs (Senge, 2006).

Mental models are the third learning discipline that roots an organization in a shared, genuine vision. It encourages people to excel, learn, and take action with the vision in mind (Senge, 2006). Many people stop learning after graduate school; some who continue to learn become lifelong learners because they have developed mental models for themselves through reflective practices (Senge, 2006). Learning is about action and being open to seeing new ideas and things (Senge, 2006).

Senge (2006) claimed that learning organizations are not possible without a shared vision. The fourth learning discipline of shared vision cannot be understated; it is one that provides organizations with a focus and energy for learning (Senge, 2006). Learning can be hard, and with a shared vision, people are more excited to engage in the learning process (Senge, 2006).

Team learning, the fifth learning discipline, urges organizations to move beyond individual learning to learning with each other, where team members are engaged in dialogue and grow together (Senge, 2006). Learning teams build on the vision of the organization, people's mastery, and learn how to learn together (Senge, 2006).

All disciplines rely on each other to create a learning organization. According to Senge (2006),

The heart of a learning organization is a shift in mind from seeing ourselves as separate from the world to connected to the world, from seeing problems that are caused by someone or something to seeing how our own actions created problems 


\section{LEARNING ORGANIZATIONS}

we experience. A learning organization is a place where people are continually discovering how they create their reality and how they can change it. (p. 12)

If divisions of student affairs desire to create learning opportunities for students, these organizations themselves and their staff members need to be engaged in learning as exemplified by Senge's five disciplines. Student affairs divisions that engage in a learning organization produce high-quality work and outputs (Kuh, 1996). High-quality work and outputs center student learning at the forefront of student affairs divisions. The next section reviews how some residence life departments have become learning-centric organizations with their shift to the curricular model.

\section{Student Affairs as Learning Organizations}

As noted earlier, since the early 2000s some residence life departments have adapted a curricular approach through which they center their university's mission at the core of how they educate students outside of the classroom (Kerr et al., 2017). Such residence life departments have created a curricular model and can be viewed as a learning organization by applying Senge's (2006) learning organization model, which emphasizes shared vision, a team approach to learning, encouraging staff to become educators, and creating learning environments for students.

Curricular model residence life departments center the curricular approach in their organizational structures in many ways. According to Blimling (2015),

The curricular approach is structured to engage students in activities that advance institutional learning outcomes. The integrative approach focused on connecting students' in-class and out-of-class learning, acknowledges the importance of integrated learning and the primary and complementary roles of faculty and residence life professionals in that process. (p. 241) 


\section{LEARNING ORGANIZATIONS}

The curricular approach views professional staff as educators and creators of curriculum, student learning, and development. Students who have interactions with student affairs professional staff (including residence life staff) have increased cognition and academic

motivation (Stamm, 2011), as well as positive associations and gains with their cognitive growth, more motivation towards their academics, and positive thoughts towards literacy (Martin \& Seifert, 2011).

Blimling (2015) noted:

As educators, residence life professionals plan the curriculum for the academic year in much the same way that a classroom instructor plans a syllabus. Activities are sequenced to achieve stated learning outcomes. Some programs are designed to encourage students to meet other students and make friends and thus advance the goal of fostering community development. Other programs create learning experiences designed to advance students' understanding and knowledge about topics, such as social justice or environmental stewardship. (p. 235)

Curricular model departments strive to be learning organizations because they encourage staff to become scholar-practitioners and emphasize the role of an educator in their approach to students. Learning organizations are possible because deep down people love to learn-it is in their nature to learn (Senge, 2006). Student affairs is positioned to play a pivotal role in the education of students outside of the classroom.

\section{Chapter Summary}

In summary, the research literature has demonstrated positive association and outcomes for students who engage with residence life departments that have adopted a learning-centric perspective and sustain a curricular approach. In addition, the literature has provided foundational understanding of key elements (or "disciplines," as connoted 


\section{LEARNING ORGANIZATIONS}

by Senge (2006)) of how organizations become learning organizations. In addition, Bolman and Deal (2017) offered a conceptual framework for how organizations can systematically maneuver and navigate change in order to help them realize new initiatives, for instance, implementing a curricular model.

However, missing from the literature is how residence life departments actually become learning-centric and implement a curricular approach. If student affairs organizations are to be receptive to supporting the learning needs of contemporary students, we need to carefully examine successful residence life curricular model organizations and identify strategic leverage points and processes. Therefore, as is detailed in Chapter 3, this study investigated the critical organizational factors that support and sustain residence life curricular model approaches at five different institutions. 


\section{LEARNING ORGANIZATIONS}

\section{Chapter Three: Methodology}

Students need support outside of the classroom that can assist them in their academic success and graduation. Student affairs divisions are positioned well to assist student learning outside of the classroom. To that end, some residence life departments have created and sustained a curricular approach that centers student learning in their organization, but developing a curricular approach can take multiple years, and shifting to the curricular approach is as much about building the curricular model as it is about cultural and organizational change, and it requires a mindset change in staff (Brown, 2017, 2019). Student affairs divisions have an opportunity to create a curricular approach grounded in their institution's mission to assist in learning outputs for all students. However, little is known about organizational cultures and structures that support the curricular model. Therefore, this study seeks to understand how departments with a thriving curricular model (based on the 10EE) sustain and support it through their organizational structure and foster a learning-centric environment. This chapter outlines research questions, research method, design, population and site, coding methods, positionality, and study limitations. In short, the curricular model is difficult to embed; however, some departments of residence life have implemented organizational structures and learning-centric environments that allow the curricular model to thrive.

\section{Research Questions}

This study explored how residence life departments have created a culture of learning and supported implementation of the curricular approach in their organization. 


\section{LEARNING ORGANIZATIONS}

Creswell and Creswell (2018) urged researchers to develop questions through a theoretical lens because it "becomes a transformative perspective that shapes the type of questions asked, informs how data are collected and analyzed, and provides a call for action or change" (p. 62). The research questions were created through the framework of Bolman and Deal's (2017) reframing organizations, which outlines how departments are structured through four different lenses, and Senge's (2006) learning organizational framework, which outlines a process for organizations to become more learning centric, which is explained later in this chapter.

Two overarching research questions framed this qualitative study:

1. How does the residence life department support the curricular model?

2. How does the residence life department infuse a learning-centric environment?

\section{Rationale for Qualitative Research}

The fields that most commonly use qualitative research are education and administration (Merriam \& Tisdell, 2016). According to Creswell and Creswell (2018), qualitative research is "interpretive research; the inquirer is typically involved in the sustained and intensive experience with the participant" (p. 183). Merriam and Tisdell (2016) asserted: "All qualitative research is interested in how meaning is constructed, how people make sense of their lives and their worlds. The primary goal of a qualitative study is to uncover and interpret these meanings" (p. 25). They also stated that qualitative research "is motivated by intellectual interest in a phenomenon and has as its goal the extension of knowledge. Although qualitative research may eventually inform practice, 


\section{LEARNING ORGANIZATIONS}

its primary purpose is to know more about a phenomenon" (Merriam \& Tisdell, 2016, p. 3). Qualitative studies can be found in many applied fields, but they are most commonly found in the field of education (Merriam \& Tisdell, 2016). Qualitative interviews can be focused on the internal or external of a person; they can be geared towards what is common to participants under a particular area of study (Weiss, 1995). By facilitating qualitative interviews and interviewing people in different departments of residence life, the researcher was able to understand how the organization works (Weiss, 1995).

\section{Research Design}

A qualitative interview study is best suited to the research goal of understanding how departments of residence life support the curricular model. The researcher interviewed people from different departments of residence life who have knowledge of how their organization implemented a curricular approach grounded in the 10EE, investigated how their organizational structure evolved and changed to allow the curricular model to thrive, and investigated how the organization is learning centric. This study's findings can assist departments and divisions of student affairs to understand how to structure their organization and how to become more learning centric. The next section reviews the research design process of the implementation of qualitative research.

\section{Residence Life Curricular Model Institutional Selection (Sample Selection)}

Residence life departments were selected based on faculty from the Institute on Curricular Approach (ICA) suggesting institutions that they believe have a long-standing curricular model (meaning the curricular approach has been implemented for multiple 


\section{LEARNING ORGANIZATIONS}

years and it is in line with the 10EE). The researcher asked four long-standing faculty at ICA through email if they would be willing to recommend institutions that have a thriving curricular model and were well known in the field of having a well developed curricular model. There was no criteria for "thriving" curricular models because faculty at ICA have knowledge about the good work in curriculum development at institutions. Since the researcher sent separate emails to the faculty at ICA, they had time to think about what their top recommended institutions would be. The benefit of interviewing people from multiple institutions was the ability to understand multiple institutions' perceptions of their organizational structure. Qualitative researchers are "interested in understanding in the learning people have constructed... and how they make sense of their world and the experience they have in the world" (Merriam \& Tisdell, 2016, p. 15).

\section{Participant Selection}

Departments of residence life that have a curricular model typically have one person who oversees the implementation of the curricular approach for their organization. Most residence life hall directors manage the curricular model in their building community and assist in the development of the curricular content. The researchers' interest was to hear from multiple institutions about their organizations with the intent to find commonalities.

The researcher interviewed two participants from five different institutions. One person interviewed was closely tied to and aligned with the curricular model at their respective institution. This person oversees the development and implementation of the 


\section{LEARNING ORGANIZATIONS}

curricular model. The second person was equivalent to a residence life hall director. The second person interviewed at each institution was recommended and chosen by the person who was closely tied to the curricular model at their institution. The person chosen as the residence life hall director was the person who worked closely with the institution's curricular model. The researcher contacted the person who oversaw the curricular model at their respective institution to see if they were willing to participate and asked them to confirm a residence life hall director to interview.

Participants interviewed were at different hierarchical layers within their organization, which allowed for a deeper and richer understanding of the organization's culture, structure, and learning environment. Weiss (1995) outlined that integrating multiple perspectives about an organizational culture will give more rich data to the research since there are multiple perspectives from two different layers of the organizational structure. All institutions were chosen because they had a thriving curricular model in their residence life departments based on faculty recommendations from ICA, their own assessment of their implementation based on the 10EE, and because they had a curricular model for a minimum of four years. The researcher used a video platform with semi-structured, one-to-one interviews as the interview platform and audio recording as the primary data collection tool (Creswell \& Creswell, 2018). These recordings assisted in trustworthiness of interviews for the researcher and assured those being interviewed that they would be better represented by a recording instead of handwritten notes (Sideman, 2013). Participants were asked questions about how their 


\section{LEARNING ORGANIZATIONS}

culture and organization was structured to support the curricular model itself based on Senge and Bolman and Deal's models (to be explained later).

\section{Population and Site}

Nine institutions that had a curricular model were highly recommended by faculty from ICA, who were well known and considered experts in the field of curriculum implementation. After the researcher received ICA's faculty nominations, they realized there were nine most highly nominated institutions. Eight of them were public institutions, and one was a private institution. Six of the public institutions and the one private institution had a first-year live-on requirement, meaning that all first-time fulltime enrolled students lived on campus. Two public institutions did not require first-year students to live on campus.

When the dissertation proposal was approved, the researcher finalized and submitted the Portland State University institutional review board (IRB) application with their advisor. Once the IRB application was approved (Appendix A), the researcher reached out to the six public institutions that had a first-year live-on requirement. The researcher's goal was to interview people from a similar type of institution; therefore, that is why the researcher chose public institutions with a first-year live-on requirement. By selecting like institutions, the researcher's goal was that there would be enough similarities to be able to analyze the organizational structure through Bolman and Deal's four frames and Senge's learning organization frameworks. 


\section{LEARNING ORGANIZATIONS}

The researcher emailed potential participants at each institution and indicated that their department was nominated by faculty at ICA to ensure that their department had been incorporating the $10 \mathrm{EE}$ in their curricular approach and that they had a curricular model for a minimum of four years. In this email (see Appendix B), the researcher outlined the research goals and overarching research questions. Once the person from the institution agreed to be a participant in the study, the researcher sent a second email (see Appendix C), which asked the participant who oversaw the curricular model for subsequent data to be sent before the interview, including an organizational chart of the department, training schedules and materials that showcase examples of how they trained staff on curricular models, job descriptions that talk about the curricular model, information on the curricular model itself, and any other materials about the curricular model that they were interested in sharing.

The email also asked them to identify a second participant from their institution who was a residence life hall director working closely with the curricular model at their institution. When the researcher obtained the hall director-equivalent person's contact information, they emailed them to seek their interest in participation (see Appendix D). When both participants at the institution were confirmed, the researcher sent them an additional email (see Appendix C) that contained the interview protocol (see Appendix E), the informed consent form (Appendix F), and the scheduled date and time for their interview. Informed consent is the first step in minimizing risk for participants (Seidman, 2013). The informed consent form outlined the risks, confidentially, and other elements 


\section{LEARNING ORGANIZATIONS}

of the research. Informed consent allows potential participants to understand enough about the research to make an informed decision on if they want to be a participant (Seidman, 2013).

Five institutions met the research criteria. The researcher interviewed two people from the five different institutions. The first public institution, which is located in the Northeast, provides on-campus housing for $40 \%$ (total number: 7,578) of its undergraduate students. It has 18,946 undergraduates enrolled and has a first-year live-on requirement. The second public institution is located in the Midwest and houses 31\% (total number: 7,096) of its undergraduates on campus; it has 22,819 undergraduates enrolled and has a first-year live-on requirement. The third public institution is located in the Southeast and houses on campus $28 \%$ (total number: 7,381) of its 26,362 undergraduate students; it also has a first-year live-on requirement. The fourth public institution is a land-grant institution located in the Southeast that houses $41 \%$ (total number: 7,954$)$ of students on campus. It has 19,402 undergrad students enrolled; they too have a first-year live-on requirement. The fifth public institution, which is located in the Midwest, has 11,591 undergraduate students, 36\% (total number: 4,172) of whom live on campus with a first-year live-on requirement.

\section{Data Collection Processes}

The semi-structured interviews were facilitated via an online video platform (Google Meet). The interview protocol was designed to gather participants' perspectives about the process and strategies through which their residence life departments have 


\section{LEARNING ORGANIZATIONS}

supported and adapted the curricular model. Selecting the five institutions assisted in generating a clear sense of the variation across residence life departments in terms of their processes, implementation, structure, and learning environment. Selecting two participants from each institution assisted in generating multiple perspectives from different hierarchical layers of the organizational structure.

Educational strategies in the curricular model vary by institution because they are unique and tied to each individual campus. Each residence life department is autonomous in the curricular model and chooses different outputs to create learning for students. Therefore, the researcher did not ask participants about what strategies were working in their respective institution's curricular model. The researcher did ask openly about the shift in culture and structure in their organization and different components in the 10EE that are not focused on educational strategies. In addition, the researcher asked what structural components support an effective curricular model, gathered data about their assessment process, and sought to understand how they shaped and constructed their organizational processes.

During the interview, the researcher reviewed the two research questions, then asked the interview questions, followed by sub-questions and probes. The goal of the interview questions was to assess the culture, structural support, organizational culture, and learning environment. More specific interview questions were related to how the department gathered buy-in from staff, how they trained and developed staff, how they structured committees, how they assessed the curricular model, how they integrated 


\section{LEARNING ORGANIZATIONS}

campus partners, and how they created a learning-centric environment in their organization. The researcher created interview questions within four areas that are related to this study's conceptual framework, which is Bolman and Deal's (2017) reframing organizations, and the theoretical framework, which is Senge's (2006) learning organization framework. The researcher also reviewed the 10EE to generate thoughtful questions to gain more insights into the four areas of questions. Figure 1 shows how the researcher broke down the interview questions in relation to the frameworks.

Figure 1

Conceptual and Theoretical Framework Integration
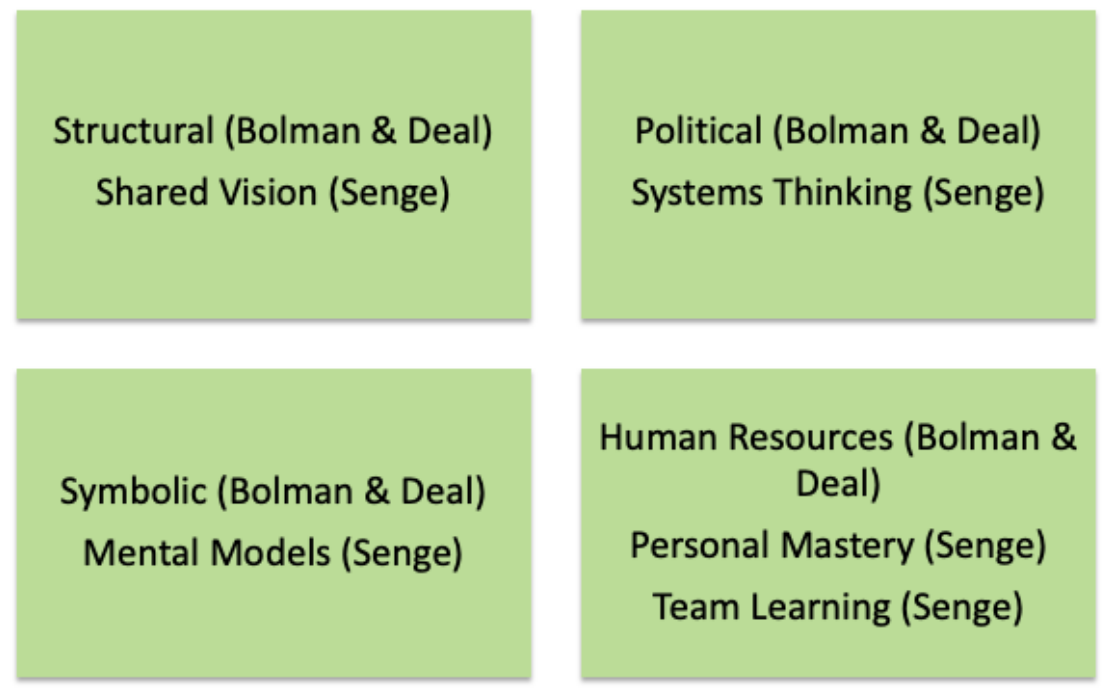


\section{LEARNING ORGANIZATIONS}

Interview questions that were structural were also in line with shared vision and asked how the organizational structure shifted to support the curricular model, how the vision of the curricular model was created and rolled out, how funding changed, and what elements in the organization allowed the curricular model to thrive. Interview questions that were political were also line with systems thinking and focused on how the organizational culture shifted to support the curricular model, how live-in residence hall directors were integrated into the creation of the curricular model, how the organization created buy-in from staff, and how the department learned about the changing culture of students. Interview questions that were symbolic were also in line with mental model, asking what the impact had been on staffing, what hiring and training were like, and what was successful while working with campus partners. Interview questions related to human resources were also in line with team learning and personal mastery, asking how the organization focused on learning, how staff learned about and engaged in the curricular model, how full-time staff were empowered and developed to be scholarpractitioners, and how the organization created assessment, review, and editing processes for the curricular model. Table 1 lists some of this study's interview questions. 


\section{LEARNING ORGANIZATIONS}

Table 1

Sample Interview Protocol Questions

\begin{tabular}{|c|c|}
\hline Frameworks & Questions \\
\hline $\begin{array}{l}\text { Structural (Bolman \& Deal); } \\
\text { Shared Vision (Senge) }\end{array}$ & $\begin{array}{l}\text { - How has the organizational structure changed since the } \\
\text { implementation of the curricular model? } \\
\text { - Describe how the organization created a vision for the } \\
\text { curricular model. } \\
\text { - Please share how funding and budgets changed to } \\
\text { support the curricular model. }\end{array}$ \\
\hline $\begin{array}{l}\text { Political (Bolman \& Deal); } \\
\text { Systems Thinking (Senge) }\end{array}$ & $\begin{array}{l}\text { - How does the culture of the department support the } \\
\text { curricular model? } \\
\text { - Tell me how your department is a learning } \\
\text { organization. }\end{array}$ \\
\hline $\begin{array}{l}\text { Symbolic (Bolman \& Deal); } \\
\text { Mental Models (Senge) }\end{array}$ & $\begin{array}{l}\text { Describe how you leverage recruitment, onboarding, } \\
\text { training and continued development to educate } \\
\text { professional staff on the curricular model. } \\
\text { - How has the department integrated campus partners } \\
\text { into the curricular model? }\end{array}$ \\
\hline $\begin{array}{l}\text { Human Resources (Bolman } \\
\& \text { Deal); Personal Mastery } \\
\text { and Team Learning (Senge) }\end{array}$ & $\begin{array}{l}\text { - How does the organization train and empower staff to } \\
\text { be scholar-practitioners/educators? } \\
\text { - Can you explain how the group (committee, full } \\
\text { department, etc.) that works on the curricular model is } \\
\text { structured? } \\
\text { - How have you found joy in the curricular model? }\end{array}$ \\
\hline
\end{tabular}

Note. See Appendix E for a full list of interview questions. 


\section{LEARNING ORGANIZATIONS}

The researcher also asked very broad probing questions following the interview questions. To finalize the questions, the researcher worked with one faculty member from ICA to gather their feedback on the initial questions derived; this person was not a part of the interview process. The researcher integrated their feedback into the interview protocol. Weiss (1995) outlined how to extend questions, which allows the researcher to understand what is being talked about. Some of the questions the researcher adapted were as follows: "What happened then?" "How did that start?" "What led to that?" Weiss (1995) outlined that pilot interviews allow the researcher to clarify the aims of the study before the actual interview; this is a way that the researcher can test their questions. The researcher hosted a pilot interview with a residence life colleague at a different institution than the ones being interviewed in the study to test the interview protocol. The researcher adapted the participant's feedback and adjusted the interview protocol to assist in the formal interview processes.

\section{Data Analysis Process}

Merriam and Tisdell (2016), Maxwell (2013), and Saldaña (2016) urged researchers to collect and analyze the data simultaneously and encouraged them to begin analysis early and often. Therefore, the researcher blocked off two hours per interview session in order to utilize a research journal after the interviews to reflect and take notes. The interviews lasted 75-90 minutes each, and the researcher took preliminary notes during and after the interview in a research journal, where they highlighted key findings that were shared in the interview. After each interview, the researcher took time to reflect 


\section{LEARNING ORGANIZATIONS}

on what they heard and wrote follow-up notes of what stood out to them in a research journal. They wrote their initial reflections, reactions, and insights; the journal was also used in the coding process (Merriam \& Tisdell, 2016; Saldaña, 2016). The researcher used the journal for outlining the ideas and stories shared that were interesting, noteworthy, would hold an audience's attention, and would be meaningful to departments of residence life that implement a curricular model (Weiss, 1995). Since the interviews were conducted through an online platform and were audio recorded, the researcher actively listened and asked probing questions that were rooted in the theoretical and conceptual framework of the research.

The researcher used a transcribing app called Otter, which recorded the voices and transcribed in real time. Researchers who transcribe their own notes come to know their data more intimately (Seidman, 2013). Knowing this, the researcher edited all of the transcriptions by listening to the recordings while reading and editing to ensure the transcriptions were correct.

As Merriam and Tisdell (2016) outlined: "Data analysis is the process used to answer your research questions(s)" (p. 202); and "Qualitative data analysis is about identifying themes, categories, patterns, or answers to your research questions" (p. 216). Organization is key to analysis processes, and researchers get to create their own coding processes that work for them. Merriam and Tisdell (2016) urged researchers to code to the chosen theoretical framework and to map the codes into broad categories. Creswell and Creswell (2018) asserted: "Coding is the process of organizing the data by bracketing 


\section{LEARNING ORGANIZATIONS}

chunks" (p. 193). Sideman (2013) urged researchers to "come to the transcripts with an open attitude, seeking what emerges is important and of interest from the text" (p. 119).

The researcher coded after all of the interviews were facilitated and transcripts were completed. The researcher used an online coding platform called Dedoose. They were able to pull the transcribed interviews from Otter and seamlessly upload them to Dedoose. The researcher began the coding process by reviewing their research journal; they reviewed their initial highlights from each interview before they coded to inform their positionality and to assist them in keeping themselves as separate from the data as possible. Additionally, by reviewing the journal they ensured the highlights of what they valued and learned throughout the interviews was incorporated in the coding process.

The researcher set up the Dedoose system to code by the four areas related to the conceptual and theoretical framework utilized for this research: (a) Structural (Bolman \& Deal) and Shared Vision (Senge); (b) Political (Bolman \& Deal) and Systems Thinking (Senge); (c) Symbolic (Bolman \& Deal) and Mental Models (Senge); and (d) Human Resources (Bolman \& Deal) and Personal Mastery and Team Learning (Senge). The researcher also added sub codes from highlights related to the journal content underneath the four areas.

Coding was a three-stage process utilizing structural coding, open coding, and holistic coding. First, the researcher utilized structural coding, which can be used in all qualitative studies and is best for interview transcripts to generate a list of categories of themes (Saldaña, 2016). They used structural coding to code by the four areas related to 


\section{LEARNING ORGANIZATIONS}

the conceptual and theoretical framework and by salient ideas and grouped the data into the four categories. The researcher coded by institution; therefore, they had two interviews back to back to code before moving on to another institution's transcriptions. Saldaña (2016) outlined that coding "requires that you wear your research analytical lens" (p. 7). As the researcher coded, they highlighted things relevant to the four area codes created.

Throughout the coding processes, the researcher realized that not all data fit into the four categories easily; rather, some fit into multiple areas. Realizing this, the researcher facilitated open coding (as a second stage to coding) to ensure they did not miss data that did not easily fit within the four categories. Open coding (initial coding process) is appropriate for all qualitative studies and assists the researcher to break down data into parts as they code (Saldaña, 2016). The researcher used the four themes and integrated the data into the category that it fit into the best. During open coding, the researcher ensured that nothing relevant was left out. The researcher coded notable quotes, interesting highlights, data that would be beneficial for other institutions to understand in relation to the research questions, and data they knew they would want to write about after reflecting from their research journal.

The third step in coding utilized holistic coding where once the two transcripts were coded per institution, the researcher analyzed the data and coded by preliminary codes and by similarities (things that happen the same way or when the participants were talking about the same topic in the four areas); difference (things that were different from 


\section{LEARNING ORGANIZATIONS}

each other); and unique attributes that other departments would be interested in learning about in relation to the overarching research questions. Saldaña (2016) outlined that this type of coding is holistic coding, which is appropriate for researchers who have a "general idea of what to investigate in the data, or to 'chunk' the text into broad topics as a preliminary step before mode detailed analysis" (p. 166).

This process was facilitated with each set of transcripts per institution, then replicated for all the transcripts together. After all of the transcripts were coded, the researcher mapped out the large four areas and the initial findings that the institutions had in common, as well as interesting data about their organizational structure and culture. Lastly, the researcher took the categories and mapped them under the research questions to ensure the data answered the overarching research questions. Once the researcher had listed categories under the four sections, they moved on to writing the narratives and pulled quotes for the findings.

\section{Limitations}

The goal of this study was to understand how residence life departments supported the curricular model and created a learning-centric environment. There was a limited amount of research on curricular models, and this study's research limitations were not numerous. However, there were a few. Not everyone in participating institutions' residence life departments were interviewed, just two people from each institution. The researcher decided to interview two people rather than one person per institution to ensure more depth was uncovered about the organization. However, by 


\section{LEARNING ORGANIZATIONS}

interviewing only two people the full dynamics of the politics and power in the organizational structure may not have been uncovered. The researcher interviewed staff from five different residence life departments with the goal that the findings would be relevant and applied to divisions of student affairs. The additional component was that at each institution, one person interviewed served as faculty from ICA, which is something to note. The researcher interviewed people with different identities, and this can illuminate how participants' perspectives can impact their view and experience of the curricular model. The researcher also had experience with the curricular model, which can be both a strength and limitation to the study. The researcher's positionality is described next.

\section{Positionality}

Merriam and Tisdell (2016) outlined that in qualitative data, the researcher is the key instrument to the qualitative study, meaning they are the ones collecting the data, interviewing participants, and analyzing the data. Recognition of bias is important; a researcher should name what biases they might have before they start conducting interviews and analyzing the data. I addressed trustworthiness and my own perception and position in my study along with the analysis processes (Creswell \& Creswell, 2018; Merriam \& Tisdell, 2016). I created a document with the purpose statement, theoretical framework, conceptual framework, research questions, goals, and other relevant information that framed the research (Saldaña, 2016). I printed the document as a visual reference and a resource during the interview process along with the analysis process to 


\section{LEARNING ORGANIZATIONS}

reframe my thoughts and center myself on the goal of the research. This topic was very personal to me, and I first started the coding process by reading my research journal; the goal in reading the journal before coding the transcripts was first to understand my biases and recognize what I heard in the interviews. After I reviewed my research journal, I was positioned to be more open to hearing what the participants were saying about their organizations because I has already reflected on the notes in my journal.

As an undergraduate student, I lived in campus housing for four years and benefited greatly from my residence hall college experience. While I was finishing graduate school, I knew that I wanted to start my career as a residence life hall director. As a hall director, I planned programs related to the interests of my resident assistants and educational events for students to engage in learning; they were not tied to anything in relation to the mission of the university. As my career advanced, I learned of the curricular model and ICA. I had colleagues from other institutions who shared benefits of this approach, including lowered conduct numbers, hall directors finding meaning in their work, resident assistants spending more time with residents than planning programs, and students living on campus feeling more connected than previous cohorts of students. For the past six years, I have overseen the learning model in my department where resident assistants have one-to-one conversations, host community meetings, and facilitate roommate agreements with residents rather than planning large-scale programs. The outputs are rooted in our organization's learning goals. As our department attempted to expand the model to create an approach that was more curricular in nature, there were 


\section{LEARNING ORGANIZATIONS}

many barriers and challenges. I have a deep-rooted interest in the curricular model and hope to engage as a scholar to learn from institutions who have facilitated this model for multiple years.

I attended ICA and hosted two ICA faculty at my campus to facilitate a mini-ICA for the residence life department I worked in. The work in residence life is different each day. Residence life professionals respond to student crises, student conduct issues, partner with faculty, and develop and supervise students. I saw firsthand how curricular development can be pushed aside due to the high level of crisis work associated with the function of residence life. I have a vested interest in learning from departments and showcasing the amazing work they have done for the profession. Therefore, I have been interested in learning the common themes and trends that longstanding curricular model departments have integrated to allow the curricular model to be at the forefront of their department and integrated into its culture.

\section{Chapter Summary}

Throughout this chapter, research questions, rationale for qualitative methods, site population, research design, and analysis are discussed. The researcher also shared their bias in the research design process. Five public institutions that have a first-year live-on requirement were a part of this research. Two people per institution were interviewed: one person who oversaw the curricular model and another who was a residence life hall director. The qualitative research was facilitated by one-to-one semi-structured interviews conducted through a video platform. The purpose and significance of this research was to 


\section{LEARNING ORGANIZATIONS}

understand how departments with a thriving curricular model (based on the 10EE) sustained and supported the curricular model through their organizational structure and infused a learning-centric environment. Chapter 4 shares findings around the emergent themes related to the conceptual and theoretical frameworks and how departments were a learning organization and their organization has sustained their curricular model. 


\section{LEARNING ORGANIZATIONS}

\section{Chapter Four: Results}

The purpose and significance of this research is to understand how departments with a thriving curricular model (based on the 10EE) sustain and support the curricular model through their organizational structure and infuse it into a learning-centric environment. Residential curriculum, curricular approach, and curricular model are terms used to describe the "intentional specifically structured way of promoting learning in college and university student affairs programs" (Brown, 2019, p. 9). The curricular model enhances the overall learning of students by intentionally framing outputs (which are educational learning moments and vary based on institution-specific initiatives) through a curricular model (Kerr et al., 2017); learning is taken one step further as it is rooted in the educational priority of residence life departments and is grounded in the institution's mission. This leads to more intentional learning goals and outcomes, and it is followed by strategies in a sequenced fashion to best engage students in learning processes (Kerr et al., 2017). The 10 essential elements (10EE) of a curricular model for learning beyond the classroom have been instrumental to institutions in their development of curricular models (Kerr et al., 2017). A list of the 10EE can be found in Chapter 2.

The first part of this chapter reviews the research criteria, outlines a profile for each institution that was a part of the research, and highlights the findings around the emergent themes related to the conceptual frame from Bolman and Deal's (2017) reframing organizations, which outlines how departments are structured through four 


\section{LEARNING ORGANIZATIONS}

different lenses, and the theoretical framework from Senge's (2006) learning organizational framework. The researcher pulled salient themes related to the theoretical and conceptual framework. While analyzing the data, the researcher also kept in mind the two research questions that frame this study, which are:

1. How does the residence life department support the curricular model?

2. How does the residence life department infuse a learning-centric environment?

Through the analysis processes, most of the data fell into the conceptual and theoretical frameworks. However, at times the researcher realized that since departments are structurally and culturally complex, there were times when the data fell into multiple categories. For the simplicity of the analysis, the researcher continued to code to the four categories and ensured that the most relevant data pieces were discussed in the area of most relevance. All of the thematic categories are represented by most institutions.

The last part of this chapter reviews recommendations to other institutions that participants shared during the interview related to creating a learning organization and sustaining a curricular model.

\section{Research Criteria and Institutional Profiles}

Institutional criteria were that each institution was a state school; initiated a firstyear live-on requirement, where all first-year students needed to live on campus; had a curricular model that followed the 10EE; and had the curricular model for a minimum of four years. All institutions met the research criteria. This study interviewed 10 people from five different institutions, with two people per institution. One person is the person 


\section{LEARNING ORGANIZATIONS}

who oversees the curricular model, and the second person is a person who is a hall director staff member. The next section reviews a profile for each institution.

\section{Institution One: East University}

The first public, semester-based institution is called East University, which is located in the Northeast and provides on-campus housing for $40 \%$ (total number: 7,578) of its undergraduate students, with a total enrollment of 18,946 undergraduates. This organization has a director who has multiple direct reports in residence life and housing, including communication, assignments, business administration, and conduct. The director also supervises residence life, which includes one associate director of residence life, who oversees student engagement and assessment, including the curricular model. The director and associate director supervise a coordinator who assists in this work. The director also supervises three assistant directors of residence life, who supervise a total of 16 hall coordinators. The director and one hall coordinator were interviewed for this research.

One of the first shifts this organization went through was moving from graduate hall directors to full-time professional hall coordinators to assist with the design work needed throughout the academic year for the curricular model. Budgetarily, this shift also allowed the organization to create one position that has evolved into the associate director, who oversees student engagement and assessment and is known in the department for being a curriculum specialist. Even though everyone has a role in the curricular model, this position is the primary person who oversees it; they supervise one 


\section{LEARNING ORGANIZATIONS}

coordinator and two graduate assistants. They provide functional supervision to the hall coordinators in areas of student engagement and assessment, oversee assessment for the department, develop living-learning communities, and lead other various initiatives.

Nearly two years ago, the director noticed that there was a need for specific jobs to be responsible for functional areas in residence life, so they eliminated upwards to eight positions called the complex coordinator and created three assistant director positions with different functional areas that included resident assistant selection and training, leadership development, and equity and inclusion. Creating these positions allowed one of each of the four learning goals to be assigned to folks to ensure tasks were facilitated in the goals through their curricular model. The current organization has also built a functional organization chart, where four people have indirect supervision with the hall coordinators. This has been helpful because accountability is built in since they have different oversights in the curricular work. This organization has had their curricular model for over 10 years, and it has a first-year and upper-division educational plan.

\section{Institution Two: Midwest University}

The second public, semester-based institution, which is located in the Midwest, is called Midwest University and houses 31\% (total number: 7,096) of its undergraduates on campus; it has 22,819 undergraduates enrolled. This organization has an associate director of housing and food services and a director of residence life. The director has multiple reports, including three assistant directors of residence life, and oversees residential colleges and international student services. The three assistant directors all 


\section{LEARNING ORGANIZATIONS}

supervise the center/community coordinators and resident directors (who are graduate students). There are eight center/community coordinators and nearly 25 graduate staff who serve in various roles (assistantship with the curricular model, occupancy, programming, advising hall council, resident assistant class, and building management oversight). One assistant director oversees the curriculum coordinator, who oversees the day-to-day operations of the curricular model. The curriculum coordinator supervises three graduate students who work with residential curriculum. The curriculum coordinator and one center coordinator were interviewed for this research. This department has had a curricular model for six years.

They started their curricular model journey when the assistant director heard of the curricular approach and attended their first Institute on Curricular Approach (ICA); when they returned, they were encouraged by the vice president to implement it in their department. After they attended, they began to implement the curriculum model and launched very fast as the resident assistants did not have buy in. The department had a hard start to their curricular efforts because of this culture shift. However, moving forward this department has had success with their curricular model by adding positions. In recent years, they have added two to three graduate staff, who assist with the residential curriculum, and one full-time staff, who is the curriculum coordinator who oversees the curricular model. This coordinator works collaboratively with all three assistant directors who oversee a piece of the curricular model. The curriculum coordinator oversees the day-to-day operations of the curricular model, training and 


\section{LEARNING ORGANIZATIONS}

assessment related to it, and researches best practices to ensure the curricular model is improving and creating learning opportunities for students. They have two educational plans, one for first-year students and one for upper-division students.

Recently, this organization has had a few assistant directors move on to other positions and into upper management. There have also been changes at the presidential level; all of this has created some instability for the organization. Additionally, since becoming understaffed the curriculum coordinator has taken on the responsibility of overseeing a small residential community during the transition period.

\section{Institution Three: Southern University}

The third public, semester-based institution, which is called Southern University, is located in the Southeast and houses on campus $28 \%$ (total number: 7,381) of its 26,362 undergraduate students. This organization has a director of residence life, who supervises two associate directors (one oversees the service operation team and the other oversees the student learning and academics team). The associate director who oversees the student learning and academics team and supervises two assistant directors (one who oversees leadership and another who oversees the curricular model). The assistant director who oversees the curricular model has one full-time coordinator and two graduate staff who assist in this area. The director also supervises three assistant directors, who supervise hall director staff (residence life coordinators and area coordinators who supervise full-time and graduate staff). The associate director who oversees student learning and academics and one area coordinator were interviewed. 


\section{LEARNING ORGANIZATIONS}

This institution is steeped in tradition and has a very strong student affairs

division. Ten years ago, the associate director position was newly created, and the person was hired to improve outputs in student learning and academics and now oversees the curricular model. Once hired, this staff member was asked to attend the Institute on the Curricular Approach to start the curricular model at their institution. There was a structural addition to support the creation of the curricular model and academic and leadership initiatives. After 10 years of having a curricular approach, there are three fulltime staff who work on the curricular model. The department expanded to have an assistant director and a coordinator assist on the curricular model implementation for the department. The department also added graduate staff in the residence life area, and one of them is dedicated to the curricular model. These positions do not oversee the day-today operations or residence hall director staff, but they do work closely with them as both areas report to the same director. They have one educational plan in their curricular model that is scaffolded centrally with multiple facilitation guides per strategy that are utilized per community. Hall director staff are able to adapt and add to some of the facilitation guides per their academic communities.

\section{Institution Four: South University}

The fourth public, semester-based institution, which is called South University, is a land-grant institution located in the Southeast that houses $41 \%$ (total number: 7,954) of students on campus with a total undergraduate enrollment of 19,402. This organization has a director of residential living, who oversees the day-to-day operations of the 


\section{LEARNING ORGANIZATIONS}

residence halls and hall director staff. In residential living, there are three associate directors who supervise community directors and a coordinator for fraternity and sorority life. There are multiple graduate students, who are supervised by the community directors. Additionally, there are two assistant directors of residential living who report to the director of residential living. This organization also has a director of residential learning who supervises two associate directors of residential learning and multiple faculty in residents and faculty partners. One of the associate directors of residential learning (who oversees the curricular model) supervises an assistant director and graduate students. The associate director of student learning who oversees the curricular model and one community director were interviewed.

The associate director interviewed was hired nine years ago to create academic living-learning programs and oversee the resident assistant academic class and programming model. After they started, there was a structural change in the department where the former director moved into an executive director role and promoted the then two associate directors into two different director positions (living and learning). After the structural shift, the organization moved from an area coordinator model to content expert assistant directors in residential living. Staff who oversee the curricular model talked about the culture they created in their department: "We take advantage of teachable moments." They continued to say, "We're not doing radically different things; we're doing things radically different." 


\section{LEARNING ORGANIZATIONS}

The person who oversees the curricular model reflected about the shift to the curricular approach. When they first arrived at the institution, there were a few different initiatives for different populations of students, some of them being first-year, sophomore, and honors models; this became a bit bifurcated and didn't necessarily flow from year to year. There was also feedback about how resident assistants perceive their role to be a programmer and a policy enforcer. The person who oversees the curricular model talked with their supervisor at the time and asked, "Why are we doing this? And what would happen if we got rid of resident assistants and did things completely different?" They asked thoughtful questions to get other people to "flip the script" on what they have always known. The professional staff had worked at a curricular model institution before and saw the potential to completely shift to a different framework of outputs and how resident assistants perceived and engaged in their role. This was their journey to a curricular approach, which has been in place for roughly six years and has one educational plan for all students that utilizes very robust rubrics to engage in student learning as they house all first-year students and a large population of second-year students.

\section{Institution Five: Mid University}

The fifth public, semester-based institution, which is called Mid University, is located in the Midwest and has 11,591 undergraduate students, 36\% (total number: 4,172 ) of whom live on campus. This organization has an executive director or residence life who has multiple areas they supervise, including business operations (including 


\section{LEARNING ORGANIZATIONS}

marketing and desk operations), technology, central administration, residential education, and academic initiatives. The residential education area has one associate director and two assistant directors, who supervise multiple area coordinators. The area coordinators supervise hall directors, and the hall directors supervise graduate students. The executive director also supervises an associate director of academic initiatives who implements the residential curriculum, living-learning communities, and assessment. The associate director who oversees the residential curriculum and one area coordinator were interviewed.

Nearly two years ago, there was one associate director of residential education who was supervising the live-in team and managing and implementing the curricular model and living-learning programs. Two years ago, they created a second associate director position and split the work. With two associate directors, this allowed the new associate director to oversee the live-in staff and managing the day-to-day operations of residence life stayed with the current associate director. In addition, the newly created associate director position was able to focus time on the curricular model, create livinglearning communities, and oversee assessment for the department. The area coordinator position was newly created a few years ago with the need to have more structural support for the curricular model and long-term commitment to the institution. There are three levels of live-in staff: graduate students, hall directors, and area coordinators. This organization has had their curricular model in place for nearly six years, with one 


\section{LEARNING ORGANIZATIONS}

educational plan for their first-year students. It is revamping and creating their educational plan for returning students, which they have had in the past.

\section{Institutional Information}

Institutions were assigned names, and Table 2 indicates them and institutionspecific information, including enrollment numbers, percentages of students who live on campus, and other information relevant to the study.

\section{Table 2}

Institution and Participant Information

\begin{tabular}{lccll}
\hline \multicolumn{1}{c}{$\begin{array}{c}\text { Institution } \\
\text { Name }\end{array}$} & $\begin{array}{c}\text { Percent (and } \\
\text { Number) } \\
\text { Enrollment } \\
\text { Students Living } \\
\text { on Campus }\end{array}$ & $\begin{array}{c}\text { Position of Participant } \\
\text { with Curricular Model } \\
\text { Oversight }\end{array}$ & $\begin{array}{c}\text { Participant with Role } \\
\text { Equivalent to Hall } \\
\text { Director }\end{array}$ \\
\hline $\begin{array}{l}\text { East University } \\
\text { Midwest }\end{array}$ & 18,946 & $40 \%(7,578)$ & Director & Hall Coordinator \\
$\begin{array}{l}\text { University } \\
\begin{array}{l}\text { Southern } \\
\text { University }\end{array}\end{array}$ & 22,819 & $31 \%(7,096)$ & $\begin{array}{c}\text { Curriculum } \\
\text { Coordinator }\end{array}$ & Center Coordinator \\
$\begin{array}{l}\text { South } \\
\text { University }\end{array}$ & 19,402 & $41 \%(7,954)$ & Associate Director & Area Coordinator \\
Mid University & 11,591 & $36 \%(4,172)$ & Associate Director & Area Coordinator \\
\hline
\end{tabular}

Note. All institutions were public ones with a first-year, live-on requirement and had implemented the curricular approach for at least 4 years. 


\section{LEARNING ORGANIZATIONS}

\section{Emergent Themes}

After the participants were interviewed, the researcher coded the interviews in the four areas relating to the conceptual and theoretical framework utilized for this research; the next section outlines the emergent themes per four areas: (a) Structural (Bolman \& Deal) and Shared Vision (Senge); (b) Political (Bolman \& Deal) and Systems Thinking (Senge); (c) Symbolic (Bolman \& Deal) and Mental Models (Senge); and (d) Human Resources (Bolman \& Deal) and Personal Mastery and Team Learning (Senge). Throughout the coding processes, the researcher realized that not all data fit into the four categories easily; rather, it fit into multiple areas because organizational cultures and structures blend together and impact one another. Knowing this, the researcher facilitated open coding to ensure they did not miss data that did not easily fit within the four categories. The researcher did use the four themes and integrated the data into the category that it fits into the best. There were two people interviewed per institution, all with different titles but somewhat equivalent in roles.

\section{Structural and Shared Vision}

Organizations are complex, surprising, deceptive, and ambiguous because of the people who comprise them. No one can predict their actions and outcomes, as outlined by Bolman and Deal (2017); they stated: "Organizations are open systems dealing with a changing, challenging, and erratic environment" (p. 31). The structural frame looks at putting people in roles where they can thrive and have the most productivity, and it outlines the structural design for allocation of work and coordinating responsibilities 


\section{LEARNING ORGANIZATIONS}

along with understanding that organizational structures are complex but can be changed (Bolman \& Deal, 2017). Having a shared vision is vital to any organization because with one, people are able to see the future they are creating, and when there is a genuine shared vision, people are inclined to have more ownership in the organization (Senge, 2006).

During the interview processes, the interview questions that were related to structural and shared vision asked participants about the structural components and vision. This section reviews the organizational structures, change in roles, support of the curricular model, buy-in from top levels of the organization, and budgetary structures. In addition to the research criteria, there ended up being many similarities between the institutions. All institutions were on a semester-based academic calendar, had a graduate program in student affairs, and utilized graduate students in their residence life organizations.

Department Organizational Structure. One of the unique aspects of all of the organizations was that there was at least one person who oversaw the curricular model in each department. This position in all five of the organizations did not supervise the dayto-day operations of a residence life department, including conduct, crisis management, or supervision of hall director staff. Rather, if the person who oversaw the curricular model supervised other areas, they included ones such as assessment, academic programs, and/or leadership and advising. 


\section{LEARNING ORGANIZATIONS}

The area coordinator from Southern University shared that part of the success of the curricular model is having dedicated staff for the curricular implementation. They shared that at previous institutions they worked at, the curricular model was an addition to an assistant director's role, who also supervised hall director staff; they shared that this structure did not work. In this department, the area coordinator shared that having dedicated staff to the curricular model and not having them oversee the day-to-day operations of residence life has been a success for implementation and creation. The area coordinator also shared that the associate director who oversees the curricular model is a champion for the work and has really shifted the organization to become a learning organization and have a vision for the curricular model.

Since the inception and creation of the curricular model, all of these departments have added positions. The center coordinator from Midwest University said, "So (for) organizational structure, it's mostly been adding positions. That's been crucial to the way that we have functional with residential curriculum." This organization now has multiple graduate students and a curriculum coordinator who oversees the curricular model. Other institutions have an assistant or associate director who oversees the curricular model, and most have one to three staff who report to them to assist in the curricular outputs. Two years ago, Mid University created the associate director position, who oversees the curricular model, assessment, and academic programs; this position does not supervise any additional staff. 


\section{LEARNING ORGANIZATIONS}

In addition to institutional profiles that outline the organizational roles and functions, the institutions had separate areas in their organization where the curricular model was managed by staff who did not have any responsibility for the day-to-day operations in the residence halls. East University has an associate director who supervises a coordinator who assists them on the curricular model and assessment. This position works collaboratively with the assistant director team, who supervised the hall staff, and they all collaborate to complete the model. Midwest University did not have a separate area in their department, but it has a curriculum coordinator who is supervised by one of the three assistant directors. The curriculum coordinator works with multiple graduate students, center coordinators, and the assistant directors to finalize the curricular model. Southern University has a separate area in residence life where the associate director overseas leadership and student learning. They supervised an assistant director of residential curricular initiatives and supervised a coordinator and a graduate student. Together, they work with a committee that includes hall staff to implement the curriculum model. South University has two separate departments (residential learning and residential living). One area of residential learning has an associate director who oversees the curriculum model with a few graduate staff and a committee made up of hall staff from the department of residential living; this position also supervised an assistant director of residential living. Lastly, Mid University has an associate director who oversees the curricular model, academic programs, and assessment. They work collaboratively with other hall director staff on a committee to implement the curricular 


\section{LEARNING ORGANIZATIONS}

model. The committee in the past included the director and the second associate director who supervised the day-to-day operations of residence life.

Roles Change. The structural changes that are listed above assisted each residence life department to allow the curricular model to have movement and assisted with the culture change. Throughout the years, departments with a curricular model have different functions and role changes for their staff, which have allowed them to spend more time on the curricular model. Resident assistant roles have also changed in the curricular approach. This section outlines a few of those role changes.

South University recently shifted how they facilitated conduct for first-time offenders; this shift led to hall staff spending less time facilitating conduct meetings. They also streamlined paperwork to an online platform. Both of these shifts have allowed hall staff to spend more time in the curricular model. The associate director reflected on the shift with the resident assistants and said, "It's way more important for an RA to be accessible and available and interested in their residence lives versus this is something I

googled last night, and I'm going to talk about it for 20 minutes to people that showed up in a lounge."

Mid University's associate director reflected on how the shift to the curricular model allowed the department to question what the hall director staff were doing. The curricular approach has encouraged the staff to hone in on what they really would like their hall directors to be doing in their work outputs; the associate director shared how they sought to learn about all of the specific things hall directors were doing, and they 


\section{LEARNING ORGANIZATIONS}

were able to shift some of those responsibilities and clarify their role. They created an assistant director position to oversee operations and the desks, which removed this administrative piece from the hall staff. Hall staff no longer oversee desk operations. Another shift was to move away from paperwork to an online platform for system management. The paperwork was taking an extreme amount of time, and using an online platform has really increased productivity and given time back to staff.

Throughout the years, the director from East University has taken calculated steps to ensure that the staff within residence life have time to be educators and that their work is tied into their learning goals and outcomes. For example, the organization has reassigned $40 \%$ of their conduct cases to the office of student conduct, where the graduate students in the office facilitate the conduct meetings for pre-conduct and alcohol. This has allowed the hall coordinators to be more focused on efforts related to student learning in the curricular model. The organization hired an office manager, which was an additional responsibility of one returning resident assistant per hall who managed the keys and on-call schedule; this has taken some administration tasks off of hall coordinators. The director has created a space where hall coordinators have little to no role in summer conferences since the summertime is spent in final design work for curricular implementation. The department also realized that resident assistants were dedicating many hours to room condition reports and health and safety inspections, and it had become the resident assistants' priority rather than focusing on student learning, so they removed this from their job duties. The communications team in the department 


\section{LEARNING ORGANIZATIONS}

creates newsletters and visual items related to their learning goals that are distributed in the residence halls, which is another structural piece that has shifted.

Since the curricular model has been implemented, there have been a few changes on job functions of the center coordinator and graduate staff at Midwest University. The hall staff reflected that their conduct load has drastically decreased since the curricular model has been in place; they went from 136 cases before the curricular model to 22 cases this past year (with a curricular model in place). Also, processes for building management have been streamlined from a paper process to an online management system and online platforms. Because of these two shifts, the staff have been able to dedicate more time to the curricular model than in years past. The center coordinator interviewed has been at the institution since 2011, when they started as a graduate student. They saw the shift to a curricular model and shared that they spend much more intentional time getting to know graduate students and the resident assistants than they did before; this is because they have more time. Seeing this shift created a draw for this staff member to stay at the institution because they believe in the approach.

Within the past few years, there has been an addition to the residence life department at Southern University where they hired full-time staff to manage desk operations. The live-in staff no longer had a role in assignments or facilities, and they do not oversee desk operations. The outcome has been that they have dedicated time to think about work related to the learning goals. This shift of job responsibilities has given them 


\section{LEARNING ORGANIZATIONS}

time to become educators. The curricular model is not added to the role; it has become the role of the live-in staff, and they are expected to be educators.

A unique strategy that the director from East University has utilized is an equation for changes. They obtained a report on how much their employees cost and noted that nearly $40 \%$ was related to benefits. Another additional cost is the apartment given to the residence hall coordinator, which could generate revenue if residents lived in it. With this equation, the total cost is added up, and an hourly rate is given per staff member. These figures can be used to understand the hourly rate a hall director costs, which enables the department to decide if it would rather have the hall director doing the work for their hourly rate or a student to perform the job for a lower rate. This has been used as a costsavings argument to hire students and shift responsibilities off the hall coordinator staff, thus allowing more time for them to be educators and focus on student learning.

Support and Vision of the Curricular Model. There are many outputs of the organization and institution that have supported the curricular model. Some institutions have a very strong student affairs division or strong support from the director and/or the vice president of student affairs, a few institutions have an introductory course for all incoming students that has allowed staff to be involved in learning and teaching outside of residence life, and some have a resident assistant course.

Mid University outlined that the best support for their organization was having multiple people in their department who served as faculty at ICA. The associate directors, director, and other central staff are willing to assist with curricular model implementation 


\section{LEARNING ORGANIZATIONS}

and writing lesson plans; this assisted in gaining buy-in from the hall director staff. When it was needed, a small group edited the educational priorities and learning outcomes and scaffolded the curricular model; membership included the director and two associate directors (one of whom was the person who oversees the curricular model).

The area coordinator said:

We make it a point to know who our students are. Not just as a department, but as a division and as an institution. We're very intentional about knowing individual students, how their days are going, what they're interested in, what their perspectives are, what their lived experiences are, and what they're not getting enough of.

The supportive institution, individual approach, and division structure has allowed the curricular model to thrive.

Staff from Southern University shared that there has been a commitment from the division and department of housing, and residence life is a strong learning organization. There is a commitment at the divisional level for all staff to be learning and to be educators; examples of this are the summit for new professionals, having staff teach the introductory class for students, and monthly training for all student affairs staff about students and their development. The current associate vice president was the person who tasked the associate director with creating the curricular model and funded staff to attend the institute on the curricular approach the first eight years; the curricular model is fully supported at the top level.

The structural support of the division of student affairs has reinforced the integration of the curricular model in residence life. The vice president of student affairs has created many outputs for the division that are highly attended and a part of the culture 


\section{LEARNING ORGANIZATIONS}

of student affairs. The vice president has hosted events for staff to share what they are learning and reading about (trends in student affairs); they invite the full division and have high staff attendance. The division has a monthly meeting where staff learn about different topics related to students, trends in student affairs, and what students are experiencing in college, and they hear from experts at the institution about their office support of students. Residence life staff continually learn from these structured meetings and implement what they learn in their work.

The division has also hosted a summit for new professionals geared towards graduate students and staff who are in their first and second years as professionals. Staff are encouraged to attend and present. It has been a space where people learn from each other. Co-curricular transcripts have been another output the division has been working on. The unique structural outputs and people from higher levels of the division have created learning opportunities that have allowed the curricular model to be supported within residence life. Many staff teach in the institution's introductory class for incoming students, and the training to become faculty for the course is a three-day program on pedagogy and classroom teaching techniques. Staff who have taught the course have shared that this training and teaching experience has been a very helpful tool to apply for the curricular model.

There are many structured opportunities in the division to allow the curricular model to be well supported. Both staff interviewed highlighted how the curricular model has had an advantage to be supported by the division and staff because there is support 


\section{LEARNING ORGANIZATIONS}

from the structural learning-centered division. The area coordinator shared that there has been a clear vision of the department's learning-centered approach, and it is reinforced in its supervision lines. Department committees have also encouraged people to learn new skills.

South University has ownership and buy-in from the top level, who have pushed staff and supported student learning and the curricular model. Culture has trickled down to where directors are very focused on student learning, and as you move down the organizational hierarchy, supervisors are very supportive of the curricular model. Recently, a new assistant director joined this organization who previously worked at an institution with a curricular approach, and this has reinforced the culture of curriculum, where it has been talked about on a regular basis with live-in staff, and they have felt more supported, have been more engaged, and have more understanding of the importance of the curricular model.

Midwest University and South University participants reflected on their resident assistant class. In the class, resident assistants are trained on the curricular model. They review all aspects of the curriculum and the course content is based on the theoretical framework, learning goals, and outcomes. This shift has been a good tool and strategy for resident assistants to understand the curricular model and what is expected of them as well as the importance of creating learning environments. South University has been training resident assistants to be peer educators, and they have been trained on intergroup dialogue, which is a tool that is incorporated in the curricular model. The resident 


\section{LEARNING ORGANIZATIONS}

assistant class assisted multiple departments in sharing the why behind the curricular model and really assisted people in understanding their role for the upcoming academic year.

At East University, the curricular model has become a part of everyone's job, and collectively as a department, they have worked on the curricular model together. The director has ensured that there are very clear expectations for staff, and they are held accountable for being educators and the executors of the curricular model.

The director shared that each hall director staff

must gain new knowledge and skills every year, but you're not allowed to go to an academic year, simply improving, you must obtain a skill that you don't have, you must obtain knowledge that you do not have, that's part of their whole individual plan... they have to highlight, get it approved. (It is) approved all the way through me... they actually have to do an interview with me.

This interview has been a time for hall staff to share how they are going to gain new knowledge and how they are going to tie it back to their work. There has been a requirement for staff to learn and teach others.

The hall coordinator from East University shared:

We have created a vision for their curricular model. It's giving everybody in our department an opportunity to have a say in the process. We all as staff, especially more so the residence hall coordinator staff, assistant director staff, we all take ownership in writing some element of our (curricular model). And we all come together for feedback for assessment of that. And it's a very collaborative process.... It's really grounded in best practices and research and how we know what we want our students to gain out of their experience.

This institution has focused on a sense of belonging, and the hall coordinator reflected,

"We know that all of our for learning (outcomes, they) should somehow contribute to a 


\section{LEARNING ORGANIZATIONS}

student's sense of belonging... putting it into the student experience that they're going to get from those learning experiences."

Institute on Curricular Approach. All institutions have staff who serve as faculty of the annual institute on the curricular approach (ICA). ICA is an annual institute (started in 2007) that was created by the American College Personnel Association (College Student Educators International). The institute is called "Institute on Curricular Approach" (ICA); formerly, named the Residential Curriculum Institute (RCI). The shift from RCI to ICA was an intentional shift because there are multiple learning opportunities outside of residence life and more institutions were expanding their curricular approach to multiple departments and divisional levels of student affairs. The institute is open to any institution that is interested in learning more about the curricular approach. Having this added knowledge has been beneficial for the departments since they train staff on the curricular model. Staff shared from all institutions that they have staff attend the institute which has been a benefit for all of the organizations because the institute is in the fall and it serves as an extension of training and immersion of the curricular model.

South University staff utilize their professional development allotted to attend the institute. They shared that after attending the institute it allowed them to understand the right questions to ask and it clicked because they were able to become an advocate for the curricular model in their department and it helped the two departments communication flow; ideally the staff felt more connected to the curricular model. The associate director 


\section{LEARNING ORGANIZATIONS}

reflected, "I never would have anticipated the excitement and motivation (from the community director who attended the institute); they came away with that mirrored the excitement that I have. It was so cool to see; and to hear them say this is the most impactful institute that I've ever gone to. I forget about how valuable (the institute) is."

Midwest, Southern, and Mid University would send all of their new staff to the institute each year; this has shifted to staff using their own professional development funds. Southern University shared that the current associate vice president used to be the executive director for their housing department who charged the department to have a curricular model and funded all new staff to attend the institute for nearly eight years. Returning staff are using their own professional development to attend the institute because they found it so valuable; this has become part of the department's culture.

East University will send staff to the institute when they are working on larger shifts of their curricular model. For instance, this past year they sent three people to the institute to reflect on the core parts of their curricular model and to assess if they are missing elements. The director shared that in future years they are planning to carve out enough budget to send multiple people each year; most likely being the associate director and the assistant director team since these staff oversee the curricular model plans for the department and the timing of the institute works with their curricular model creation process.

Department Meetings. Multiple people reflected on their department meetings as a tool to support the curricular model. Mid University's monthly meetings include the full 


\section{LEARNING ORGANIZATIONS}

department of housing and have a form of professional development around in the learning goals; they are a good reminder for the full department that they are all tied into the learning outcomes. There are department of residential education meetings that serve as an extension of training where there is professional development that happen once a month as well as every other week they are dedicated to education around the curricular model. There is conversation around how people learn, what are students learning, and how do people know and assess learning; this has been a time for people to watch different videos and be in discussion together around what people are learning.

Midwest University's department meetings are a fascinating part of the organization culture. The weekly department meetings are for all professional staff (including graduate employees) which is 40 people. During the meetings there are functional updates, a review of community concerns, and an ability to review upcoming curricular model information, and receive feedback around the curricular model. Staff carve out intentional time to reflect how the curricular model is doing in individual communities. This feedback and information is used as they review and improve the model for years to come. This department has theory to practice moments where all full time and graduate staff research and present on an aspect of professional development. These topics can be an area of interest, something related to what they are working on, or related to students. Typically, staff will choose and actively and then have a discussion on it. The department meetings also outline what students are going through each week in 


\section{LEARNING ORGANIZATIONS}

order to assist the staff to learn more about the student experience in order to best support them; this has been extremely beneficial for graduate staff.

South University department meetings are an extension of training and are used as a platform to train staff on the curricular model, they are focused on student learning and have opportunities for staff to discuss different articles or common reading books. This organization sees department meetings an opportunity to build what they want staff to learn, they view the time as an opportunity to revise and remember what curriculum is, discuss the learning outcomes and what they want students to learn along with what they want resident assistants to experience. Upon further reflection the person who oversees the curricular model shared, "And recognize that for a lot of our learning outcomes, these are things that we're all dealing with, and we're all kind of working towards." The living and learning departments will meet periodically together.

The community director said:

There's always a learning component in our meetings....We focus on our students, but there's always a learning component for us as well. We're lifelong learners and that's part of the culture. We're constantly trying to learn and grow as well. And we see that in our meetings, because there's always a piece of learning for us as well for professional development.

Lastly, East University department meetings are a fascinating part of the organizational culture in the development of the curricular model. The director shared that, "You have to throw out a lot of the (old) way we do meetings." Department meetings are structured to be $70 \%$ professional development throughout the year. Utilizing the department time for curricular model design work is so important that the 


\section{LEARNING ORGANIZATIONS}

director will only allow upwards of 15 minutes to agenda items related to opening, closing, resident assistant hiring, etc. The department meetings throughout the month of November to February are purely dedicated to the curricular model design work. The director shares that most hall coordinators are working 55 hours per week and recognizes how precious time is; therefore, they want to spend time efficiently in department meetings and wanted to challenge the ways the normal residence life department meetings operate. They shared that there is no toleration for individuals reflecting about opening for two hours or non-residence life staff wanting to have time in front of the hall coordinators; they recognized different ways to run department meetings. This year the director worked with the assistant director team and they prepopulated agenda items for the year and recognized they were over time on content and the assistant directors were asked to cut $25 \%$ of their content and figure out a different way to deliver the information to the team.

Budget. When asking about how budgets have changed with the curricular approach; most institutions shared that their budget amount has stayed the same, but they use budgets in different ways. The difference in spending comes down to departments being more intentional related to spending money related to the outcomes and student learning highlighted Southern University. Mid University stated that if there is a central curricular output where everyone is using the same items in a lesson plan; this is something that is ordered centrally for all of the live-in staff to utilize rather than in a budget that the hall staff use. 


\section{LEARNING ORGANIZATIONS}

South University does spend less money with their curricular model; and they push staff to spend $60-70 \%$ of their budget in the fall semester in order to get students engaged early. Their live-in staff create a community plan and request a budget for the year based on assessment and they present this to the department where campus partners are invited. This community plan is an opportunity for live-in staff to create ways they will support learning in their role and a budget is given to live-in staff with campus partner input.

Funds are primarily used for educational programs that are a part of the curricular model at Midwest University. Budgets are allocated centrally for coordinators and graduate staff and resident assistants are no longer given a budget. The center coordinator reflected on the budget change:

Beforehand, it felt like we were telling the resident assistants; you have this great idea for a program. Sure, you have the budget, just go do it. Now, it's really having those conversations and questioning: Does this program makes sense for your community?; Is this something your students asked for?; Is this something you want to do? And (talking through) those pieces help our students. Personally, I've seen nothing but growth in our department, in the way that we're all thinkers, and doers. Before we were just doers. And I think now we really think through the process before we go do anything.

With the change to the curricular model the department one spent half of the budget in what they used to spend when they had a programming model at East University. This allowed the department to shift how they used their budget and now are able to bring in speakers and experts to facilitate learning. The department also has a strategic initiatives budget where the money is used for staff travel in order to be educated around the area of diversity and inclusion work; the staff chosen are the ones 


\section{LEARNING ORGANIZATIONS}

who have a demonstrated skill in this area and are able to learn and then implement what they learned back in the department. The director noticed a need to develop people in this area and decided to invest the additional resources in this way.

Based on research around positive gains of community ownership and engagement the department developed an opportunity that empowers students who live in the residence halls to contribute to their communities. Therefore, in this structure the resident assistants are not given a budget like most other institutions. The budgets are given to the residents in the community to develop initiatives for the residence hall communities. These residents in the community are given time at their floor meeting to co-facilitate the meeting with the resident assistant. There are roughly 400 students engaged in the community roles who are planning activities and social connections for other residents in the community.

Summary of Structural and Shared Vision. Structures change in organizations because of leadership, technology and environment (Bolman and Deal, 2017). "Structural change invariably produces confusion and resistance; things get worse before they get better," said Bolman and Deal (2017, p 92). Structures can be machine line and within the structural frame it centers the job responsibilities roles, organization design and streamlines policies. Furthermore, learning organizations are impossible without a shared vision. When there is a shared vision people are more excited about the learning processes and the outcomes. The five institutions shared how their organizational structure has evolved to support the curricular model, how positions have changed to 


\section{LEARNING ORGANIZATIONS}

allow staff dedicated time to execute the curricular model, and a shared vision of some form was present at each institution.

The data above merge into six thematic categories: department organizational structure, roles change, support and vision of the curricular model, ICA, department meetings, and budget. Analysis of the data using the substantiated quotes and organizational descriptions further categorized into five primary outcomes that have implications for how other institutions might successfully implement and support the curricular model. First, and foremost, the curricular model must have support and be legitimized by upper level leaders and administrators. There must be a clear directive, vision, and ongoing support from higher administrators including directors and even vice presidents at times depending on the organizational structure. Second, who oversee the curricular model and implementation must be identified and positioned within the departmental structure and the primary role does not oversee the day to day operations of the residence halls. Third, the role of residence hall staff including hall directors and resident assistants must shift from being reactive to proactive (addressing student learning and integrating the curricular model); being proactive in the approach has assisted with the reactive side of residence life that is inevitable. Fourth, staff must be continually engaged in professional development around the curricular model and could include their own research and building knowledge through articles, attend the institute on curricular approach, training and department meetings and ongoing professional communication. Finally, there must be adequate resources to support these efforts. 


\section{LEARNING ORGANIZATIONS}

\section{Political and Systems Thinking}

Organizations are political at their core, and according to Bolman and Deal (2017), they are "lively arenas for internal politics" (p. 223). Also, they are "powerful tools for achieving the purposes of whoever controls them" (Bolman \& Deal, 2017, p. 234). Organizations have conflict, and groups form as a way to control conflict; this happens at every layer of an organization (Bolman \& Deal, 2017). Bolman and Deal (2017) shared that having clear goals come from the top of an organization will assist the rest of the organization; however, the political frame views authority as only one form of power. Even though organizations are political, what can assist is to have a discipline for systems thinking that is a frame through which to see the whole, as Senge (2006)

outlined. Senge shared that systems thinking is "needed more than ever because we are becoming overwhelmed by complexity" (p. 69).

During interviews, participants were asked questions related to political and systems thinking. This section reviews the cultural and organizational support for the curricular model, how staff have shifted culture, and concepts of a learning organization. In addition, it addresses concerns related to conflict and how organizations address them. Structural changes to organizations and shifts in positions helped the cultural shift in all organizations.

Cultural Support for the Curricular Model. Part of creating culture for all institutions was the ability to attend ICA. Multiple participants shared that having people 


\section{LEARNING ORGANIZATIONS}

attend ICA assisted in the culture of their organization. and it benefited staff to have additional knowledge.

Part of organization culture at East University has been to make mistakes, be open and name them, be humble in their approach, and move on. The director shared, "We really try to have that embedded in the culture: that discovering the fallacy of your ways is a thrilling thing. And that's something that is super proud of; it's something to be acknowledged as something to be rewarded."

In regard to their curricular model, the department tries new ideas, shifts often, sees what works, and integrates well-researched practices. The vision is set by the director of the department, which impacts the culture. The culture of the department is embedded in doing research to better inform their practice. All people's suggestions need to be backed up by research and frameworks; they cannot just suggest things based on lived experiences. Even the director does not mandate things related to the curricular model; they wait for buy-in from the team and perform research in order to share best practices. Ingrained in the culture is an expectation that people are well researched about the culture of students and what students are learning in their respective communities. The hall coordinator shared that the culture was "very collaborative, and that everyone is in the know about what's going on. So, they're able to support all different levels of how we implement our [curricular] initiatives." Additionally, the director reflected that the resident assistant staff were invested in learning and the goals of the department; and they were not taught about curriculum, nor would they even know they were at a curricular- 


\section{LEARNING ORGANIZATIONS}

based institution. This institution has not experienced what can happen at other institutions, where there are morale or motivation issues with resident assistants. The resident assistant group was not trained in the concepts of residential curriculum and did not know what a curricular model is; rather, they knew what the learning goals and outcomes of the department were and that the department was dedicated to student learning. The director shared how the staff were competent professionals and all had specialties in addition to being generalists. This allowed them to be more employable later even outside of residence life. Since they moved to the curricular approach, staff in the past years after leaving the institution have done very well in their career; the director told staff if they commit to the work, it will work out better for them, and it does.

The organization utilized the eight-step processes for leading change by Dr. John Kotter. Each new staff member receives a book when they arrive, and it is expected that everyone in the department reads the book and understands how change happens, and the culture of the department continues to enforce the change model by ensuring that this framework of change is utilized.

Staff interviewed from Midwest University talked about how the curricular model is fully ingrained in their culture. Their theoretical framework used the curricular model as a base and casted a vision for staff during training, the resident assistant class, and graduate staff series that is facilitated throughout the year. The organization has been open to feedback from its own staff, resident assistants, graduate staff, and students. The

coordinator who participated in this study said they valued the perspective of the graduate 


\section{LEARNING ORGANIZATIONS}

students and resident assistants because it helped keep them grounded in the student experience since they are more removed from the student experience; it helps them stay relevant. The coordinator reflected on the shift to the curricular model, stating that it "really feels like we knew what we were doing in terms of helping students. And that's what we wanted to do is help them thrive. But it really has felt like there's been a sense of purpose attached to it now. And I think that's huge."

Failing and making mistakes have become ingrained in the Southern University's culture. The department has been open to growth and learning and has continually strived to do better. Staff have regularly discussed and reflected on the curricular model and thinking of student learning. The department's culture has encouraged people to be educators, be creative, create new ideas, and have autonomy. For example, the area coordinator created a rubric for bulletin boards that was very successful, and they shared the tool with the associate director. It was so impressive that they were able to share broadly within the department that the rubric has been a resource utilized department wide. The area coordinator also incorporated the learning goals into their team meeting agendas for their student staff as a reminder about the work the department does. At every level of the organization, people have been made aware of the learning goals; it has been infused into the culture of the department.

The department has encouraged growth and skill development in staff. One staff member wanted to create a podcast series about learning, and the training committee empowered them to do this. The staff learned the skills of creating a podcast; in the end, 


\section{LEARNING ORGANIZATIONS}

it was not the most effective way to train on learning, and the department didn't continue the podcast. However, the department encouraged creativity, trying things, skill development, and was ok with things when they do not work out because people are learning, being creative, and assessing their outputs.

Ingrained in the culture is a supportive connection from the staff who oversee the curricular model; both participants interviewed talked about having people stop into their offices to talk about the curricular model and that the person overseeing the curricular model was open to feedback and could continually change things to best meet the needs of students.

The associate director from South University said:

The culture has supported [the curricular model in a] sense that that we have really asked the "why." Why are we doing some of the things that we're doing? We have been willing to drop things from the work that we do as a result of it.

That's a common trend among other institutions that have adopted a curricular approach. This organization has sought to be transparent and open about where they are headed; this created buy-in from all levels of the organization and has aided the culture to be more learning centric. Even though there are two different departments, the culture has been open between them, and they have talked openly about what is working and not working well. The associate director recently put into place a committee and realized that expanding the curricular model committee across the two departments has been very beneficial. Before, they were hesitant to do so as they did not want to burden staff with 


\section{LEARNING ORGANIZATIONS}

the work; however, they have found that people are more engaged in the curricular outputs.

The associate director from Mid University reflected that it can be exhausting if you are the only one brought into the curricular model. When they arrived at the institution, there was buy-in from the executive director and a push to continue the curricular model, but the live-in staff needed to have a mindset shift, and they did not see the curricular model as their primary responsibility. The associate director shared that the resident assistants along with the hall staff saw the curricular work as checkboxes to mark off rather than a focusing on student learning. The curricular model was a very siloed piece of people's work, but now, it has been integrated in people's day-to-day work and they understand it differently; they recognize how students learn through the curricular process and realize their role in it.

There were many things that led to the culture shift, and in the end, it allowed people to be brought into and understand the curriculum. People became open to change. This started at the top, and now openness to change is common for staff. As people were hired with an understanding of the curricular model, the culture shifted. It helped to create full-time staff positions (creation of the area coordinator role); this allowed having more full-time staff with longevity in the department to understand and support the curricular model. Another output the director has been working on is a guide for supervision meetings to assist supervisors in their one-on-one meetings. This would 


\section{LEARNING ORGANIZATIONS}

include staff from graduates all the way up to the assistant director team; the goal would be to encourage lifelong learning.

The associate director said: "We can ask the question of "What have you learned this week, personally? Trying to continue to situate people as both lifelong learners.' But if you aren't situated yourself as a learner, how can you then be the best teacher or educator for your students?" They also reflected on moving to a curricular model and shared that it has

started to permeate other aspects of our organization. I'm really excited to see how the kind of culture continues to shift. And there are some folks that they're realizing, "This really isn't my jam, I want to search." [They respond:] "What can we do to help you be ready for that?" That's good to see some of that coming around.

Learning Organizations. Learning organizations develop cultures that are conducive to learning and allow people to expand their thinking, become more creative, embody a team approach, and work collaboratively toward the processes of learning and creating (Caldwell, 2005; Garvin, 1993; Henning, 2018; Senge, 2006). All organizations create opportunities for staff to be engaged learners and have a learning-centric approach, and staff are engaged in research to better their practice. All of the institutions interviewed shared an openness to learning from mistakes and making things better as the years go on. They shared an openness to growing in assessment and improving on their curricular outputs. The hall director staff (at most institutions) shared that the person who oversees the curricular model is open to feedback, willing to listen, and also has created a structure for feedback on the model itself. The majority of institutions outlined how they 


\section{LEARNING ORGANIZATIONS}

are open to failing, learning, and making their outputs better. Part of the curricular approach is trying new things and learning and growing. If institutions are striving to implement the 10EE, they will be learning, engaging in research, and constantly striving to do better. The institutions, East and Southern University, have the longest curricular models compared to the other institutions; they shared that they enjoy failing and making things better because that is what a curricular model is about.

For the purpose of this research, the researcher defined learning organization as adapted by Senge's (2009) work: Learning organizations encompass a culture that creates learning environments for all people to expand their thinking and creativity, and they encourage a collaborative learning environment. The researcher asked each participant how their department is a learning organization in relation to the named definition. It is evident that these departments have been striving towards constant implementation of the $10 \mathrm{EE}$, and having the curricular model for multiple years has improved the learningcentered culture in their organization.

East University has a unique learning-centric environment where the expectation of being learning-centered comes from the director of the department, and all staff are expected to engage in this process. The director expects this of staff, engages them, and leads by example, and this has shaped the culture of the department to create a learning environment. Staff at Mid University have attempted to develop relevant outputs for students based on Generation Z, incoming student, and first-generation data, as well as 


\section{LEARNING ORGANIZATIONS}

retention rates. Hall director staff interviewed said it is very important to understand students' experiences.

The associate director from Southern University shared their perspective on a

learning organization:

I truly believe in the spirit of learning organization, and one of the most effective pieces has been showing where we are... part of the learning organization definition is that things aren't always going to be perfect. But how do you have this culture where they're constantly able to look at the good, the bad, the ugly? In there and make meaning of it and do something with it. So for us, it's helped us in a backwards way of realizing our curricular model is 10 years old now... it's okay for us to embrace the approach but redefine.

The area coordinator from Southern University shared:

I think people in a programming model tend to not see themselves as part of the overall mission of the institution from a learning perspective. I don't think they see how they're a part of that learning. In a curricular approach, you see yourself as deeply committed and intertwined with the learning goals of the institution. That is what inspired me and got me excited. I want[ed] to learn about the curricular approach when I was job searching and when I was in college and grad school, but when I got to [work in a department with a] curricular approach, I was hooked from the beginning.

Staff at all of the institutions shared how there has been an expectation that people are researching to better inform their practice, and multiple people shared how they are heavily researching Generation Z. Southern University demonstrated this, as its staff have recently been reading about Generation $\mathrm{Z}$, and the department is open to integrating new technology and trends to best engage their outputs in student learning. The committee has also worked with the marketing staff in the department to assist with making structured floor visuals and digital images online with the curricular model and make them look professional. The department provides materials to incoming students; when they move 


\section{LEARNING ORGANIZATIONS}

into their room, they get a brochure that highlights elements of the curricular model. This allows incoming students to learn more about opportunities in the residence halls.

South University has a strong commitment to learning for staff. Staff are encouraged to use their professional development funds to attend conferences, including ICA, they participate in common reads, and they take turns training others on content areas they are researching. People attend conferences often outside of higher education; some of the conferences they attend are content-specific ones that assist them in the dayto-day functions of their role.

The associate director at South University said:

There is space for open-ended topics, and where someone could say, "Okay, this is something that we need to discuss. And so I'm going to prep [a] presentation or an interactive activity for us to do." So, I would say that's the biggest thing is carving time out of that, to anticipate that during this month or during this week, we need to talk about this topic or process after a group of people have just come back from a conference or something like that they can share and allowing different people to take the lead on how that information is conveyed.

At Mid University, the department is very open to promoting professional development in residential education and outside of residential education in the department of residence life (which includes multiple units). They recognized there are opportunities outside of residential education to advance other staff in their learning to better inform their practice. There are informal times when staff are encouraged to engage in taking StrengthsQuest, and it created a team site where the full department can learn and read articles and review PowerPoints. 


\section{LEARNING ORGANIZATIONS}

The residential education area at Mid University is committed to people's passion areas, professional development, and future careers. For example, one live-in staff was very interested in operations, and they were allowed to be on a business operations committee; the department is open to training and educating others. There have been very small outputs that have impacted this culture. The associate director added learning outcomes related to the circular model in all of the professional staff training. Staff take time to learn from each other, and the department regularly talks about theory and gives resources to one another. Graduate students regularly share what they are learning, and full-time staff are open to learning from graduate students about class content. The department has come from a state of being very understaffed for a number of years, and when fully staffed, the culture is really rooted in work being distributed, people having time to engage in the curriculum, and be excited.

As Mid University's area coordinator reinforced,

You get called out if you're not thinking about things in ways that are up to date with the current trends, the current expectations, best practice. You're going to get called on it really quickly. And that's really great to me because I worked in environments in the past that were very apathetic, very much like, "This is how we've always done things. And so we're going to continue to do them this way."

East University shared openly about being a learning organization. The director reflected that their departments do the same outputs like other institutions do with common reads, webinars, development training in department meetings, or having staff share what they learned after they attend a conference for others to learn, etc. However, 


\section{LEARNING ORGANIZATIONS}

the department is very intentional in requiring staff to create a professional development plan each year that highlights their intentions of learning.

The East University director shared that staff present on

frameworks that they're looking at and their poof [of a] new skill. And so they're often using their proof of a skill by trying to train your colleagues on a certain construct. So those things happen as a regular part of our [department].... They're brought back in again, from a basic foundation, as some of the best way to learn is to teach so part of their job on their own learning is to help teach each other people.

The staff in the past years have done really well in applying what they learn at the institution to their future careers. They are "more competent.... All have specialties and things they can do... This plays out in [that] their employability later is much higher and not necessarily even in residence life but in terms of other careers within student affairs.... I can promise them that if they commit to us and work that really will work out better for them.

Another way this department is a learning organization is that they have initiated and host assessment retreats twice a year that are described later.

Navigating Conflict. All of the institutions interviewed shared some form of conflict within their organizations regarding the curricular model and/or its implementation. Some participants shared that staff were not bought into the curricular model; therefore, their institutions have changed the way they hire and train people.

Some participants talked about different reporting lines in an organizational structure, as staff who did not oversee the curricular model may not have felt ownership in it and have not wanted to give staff false information; therefore, their institutions have talked more regularly about the outputs of the curricular model to empower people to understand it better. Some institutions shared that when implementing changes, it was hard because 


\section{LEARNING ORGANIZATIONS}

student resident assistants or professional staff were not bought into the shifts. Some staff who oversee the curricular model shared that they feel if they left there was a fear that the curricular model would suffer because of lack of oversight. Some participants shared that learning is centered into conversation when there is a director in a room or the person who oversees the curricular model; and when they are not in the room, the conversation shifts to not being centered on student learning. These conflicts represent some but not all of the institutions reviewed in this study.

Some departments have different reporting lines for the hall director staff and the curricular model staff. South University shared openly about this. Having two distinct directors for living and learning created some isolation between the two departments, and what evolved were consultant meetings between the person who oversees the curricular model and the live-in staff and graduate students to seek to understand what was working, what was not working, and what could be changed. These consultant meetings happened as often as needed and at minimum once a semester. The curricular model committee was also started to include members of both areas and at all departmental levels.

The associate director from South University shared openly about the structure of having two departments:

We found some success with that change, that shift in the sense that we have dedicated people that are focusing on things and not necessarily the reactive, or this is what we need to do exactly in the moment. That's really been positive to have staff members learning to go in and assist and take things back and think through and plan things out and design resources. Over the years, there's kind of become more of a disconnect between the two departments that there are topics 


\section{LEARNING ORGANIZATIONS}

where we don't ask our grad students to sit in during the training of the res learning grads because a lot of is not applicable.... Sometimes, our grad struggle with defining roles and what that looks like. As a whole, it has pushed us in directions that we probably couldn't have gone before and allowed us to build some resources that we hadn't already done. That was a huge shift to be two distinct departments with [two] directors that work closely together. At the associate and assistant director level, we still meet all together. But as you go down the list, the interaction I have with resident assistants has diminished over time, the interaction that we can have. Even some of the res living grads, I don't see them quite as much.

The associate director and the graduate staff regularly have noticed this shift in their organization and conflict and started to attend the resident assistant meetings to gather feedback. Recently, they initiated consulting meetings with each community director throughout the year. These were put in place for an opportunity for feedback and understanding of the staff's perspective, a training opportunity where they could assist people learning more about the curricular model, and an opportunity to address any conflict the staff was having in the curricular model. They also initiated web-based video check-in times with staff to answer any questions.

The area coordinator from Mid University shared:

[The] thing I noticed about this department is, we're always asking: "How can we make it better? How can I make it better?" Which, honestly, is the source of what causes some of the conflict over curriculum.... Sometimes, there's folks on the outside looking in and thinking, "What would be different if I had done this lesson plan? I would have written it better." Which can be a really positive thing because you have those people that have those ideas that are passionate about them and willing to bring them to the table.

The area coordinator talked openly about a recent conflict when the central leadership team was taking longer than anticipated to share out the final curricular model for the upcoming year. It was taking longer than anticipated because it was after they had the full 


\section{LEARNING ORGANIZATIONS}

department write lesson plans and sequence the curricular model. This led to having facilitation guides written in 30-plus different voices. While the central staff were working on the final curricular model, some of the live-in staff shared that they wanted the content even though it was not perfect. The conflict came about because live-in staff felt like they were not going to be prepared and would not understand their role.

However, the committee was not finished with the content, and it ended up getting shared later than anticipated.

The Mid University area coordinator reflected on this conflict:

Sometimes, when you get that conflict in that outrage and that frustration, it comes from a place of not understanding because people, when they know specifically what they're doing, they're confident in knowledge. A lot of times dissonance comes.... I don't necessarily understand this because I had some folks that would complain about the curriculum. But once I explained why something was happening or the reasoning behind it, they were suddenly like, "Oh, okay, oh, I can do this." And so just getting to [where the] frustration really coming from.

The annual cycle of residence life also impacts the curricular model

implementation because the nature of residence life is in crisis mode and responding to student needs, which is very important. East University ensured that their curricular model was completed by February for the next year because they approved theirs through the division of student life, general education committee, and faculty senate. Part of the creation processes outlined by their director is that staff have three opportunities for feedback on the curricular model, and they do not change it after this three-step process.

The East University director shared:

You cannot change midstream.... You have failed [to give feedback] whether it's because you weren't mentally present, because you weren't managing your time, because you didn't want to make interpersonal waves. Your voice was gone from 


\section{LEARNING ORGANIZATIONS}

that; it doesn't get a comeback later. You only get to come back in the next cycle. It can wait till November; your voice can come back then. Until then, this is how we're going.

Staff's role is to support the institution, and at times, there are competing priorities when staff like to have their own personal platform take precedence over the institution's goals. The director reflected that this happens once every few years, mostly in the recreation processes of the curricular model; if their platform is not connected to the institution, it will not be successful. Lastly, another conflict that happens is how staff agendas are created because the majority of the department meeting time is for the curricular model processes. If people want an hour on the agenda, they have to find other ways to share their information since their meeting time is very limited. The East University director shared they have debated this with staff in the past:

About how I do staff agendas. Because I won't tolerate certain things being on that agenda until you find another way. I don't have to direct it, you know, just find another way, it still has to happen. We have open. We have to do all these things every residence hall program has to do. It doesn't have to take an hour of my staff meeting, and I can't. We will give you 5 minutes.

Many participants reflected on how important the role of a supervisor is.

Supervisors hold much power in making the curricular model thrive, and at times, there

was a disconnect with their role in supervising hall director staff. There is an opportunity for all supervisors of hall director staff to notice the importance of talking with their staff about the curricular model where this might make a connection between the live-in staff and the curricular model; this also provides an example of how the conversation can be replicated with resident assistant staff and hall director staff. At times when there are 


\section{LEARNING ORGANIZATIONS}

different reporting lines, when the curricular model is managed in a different area outside of the supervising lines, there can be a lack of discussion and understanding of the curricular model. One staff shared that the supervisors of the hall director staff had discomfort in talking about the curricular model since it is not theirs to manage. However, some departments have seen great benefits in hiring supervisors of hall directors who understand and have worked in a curricular model department because they understand the importance and lead with that in their supervision meetings. Secondarily, this translates to hall directors (as supervisors) taking the time to educate their resident assistants in supervision meetings and resident assistant staff meetings.

Summary of Political and Systems Thinking. Bolman and Deal (2017) said:

"Organizational change and effectiveness depend on manager's political skills" (p. 216). Senge (2006) outlined that "feedback processes are the engines of growth" (p. 79). The political frame recognizes that power shifts happen, and people have competing priorities and resources and form alliances to ensure work is done. The political frame recognizes the culture of the organization and that culture shifts over time, conflict happens, and buy-in from staff is very important. Systems thinking moves the organization forward by encouraging people to see the whole and interpret the culture; people will be able to change culture when they see the patterns. All organizations have opportunities for participants to give feedback and have structures in place to support the curricular model and create a learning-centered environment. 


\section{LEARNING ORGANIZATIONS}

The data above merged into three thematic categories: cultural support for the curricular model, learning organizations, and conflict. Analysis of the data using the substantiated quotes and organizational descriptions was further categorized into three primary outcomes that have implications for how other institutions might successfully implement and support the curricular model. First, being fully familiar with the research on student learning and student success and how factors that facilitate student learning and success created the cultural context for the curricular model. This is a pivotal and important first step in creating the cultural environment for sustaining the curricular model. Second, having a learning-centric approach creates the context for residence life departments to operate as a learning organization. Specifically, this approach requires staff to be learning focused with an openness to new information and a tolerance for failure and feedback that may be critically constructive. Third, communication is central to integrating and sustaining the curricular model. If decision-making excludes voices and perspectives, then misunderstanding and conflict is likely to arise.

\section{Symbolic and Mental Models}

Bolman and Deal (2017) outlined that the symbolic frame focuses on how people make sense of the organization they work in. Symbols are basic elements of circumstances, are a part of everyday life, and the "symbolic frame interprets and illuminates the basic issues of meaning and belief that makes symbols so potent" (Bolman \& Deal, 2017, p. 241). Over time, organizations adopt values, beliefs, and activities that develop the culture of the organization (Bolman \& Deal, 2017). Senge 


\section{LEARNING ORGANIZATIONS}

(2006) outlined that mental models are "deeply ingrained assumptions, generalizations, or even pictures or images that influence how we understand the world and how we take action," (p. 8). Implementing mental models is a breakthrough for any organization that moves them to be learning centered because they teach people that learning is action. The symbolic ways an organization hires and trains staff can impact the way a person engages in their learning and growth process in their individual mental models.

During the interview processes, the interview questions that were related to symbolic and mental models asked participants what the impact has been on staffing and hiring, what training has been like, and what has been successful while working with campus partners. This section outlines the shift in hiring and training, as well as campus partner integration in their departments.

Shift in Recruitment and Hiring. Institutions used the recruitment process as a way to teach people about their departments' curricular model and culture. The organizations were interested in hiring people who had an educator and learner mindset and were committed to growth and learning for students. All institutions in this study completely overhauled their recruitment and hiring processes and have noticed how these processes can be ones that teach applicants about their institution's curricular model. The vision of the curricular model is set during the hiring stage, where the institutions are sharing early and openly about their curricular model and the role the candidate would play. Marketing materials have been infiltrated with information on the curricular model, 


\section{LEARNING ORGANIZATIONS}

educational priority, and learning goals and outcomes, and they have been used as a platform to educate candidates on how staff are educators in their community.

Interview questions have shifted to be rooted in how participants are educators and were related to the institution's curricular model, specifically their learning goals and outcomes. Rubrics related to the theoretical framework have been utilized at some institutions in the evaluation processes of each candidate. During the on-campus interview, some institutions have incorporated discussion times when people are discussing articles related to the curricular model and/or theoretical framework or they utilize articles as a tool for candidates to read before their on-campus interview.

East University's director views selection as being $20 \%$ screening of candidates and $80 \%$ training processes; they utilize the hiring processes as a training opportunity. The director reflected how when a person is first looking for a job, a person's brain is wired to learn. Part of their hiring processes is to have the candidates be a part of a case study with other live-in staff. The live-in staff shared one of the questions they ask candidates was: "We embrace debate. How are you going to deal with that?" The culture is designed to challenge and push people to be better professionals by being well researched and making decisions based on assessment.

The director met with each candidate individually and uses this time as a primer for the curricular approach. The director asked a few introductory questions, then they moved to asking them to identify a student population: "They can talk first year or upper

division, then [they ask], 'What would all of your first-year students learn as a result of 


\section{LEARNING ORGANIZATIONS}

residence halls... and convert that into at least one outcome." The director gave them the revised Bloom's taxonomy chart and asked them to design an outcome. They asked the candidate "to design a fall semester residence hall experience that is going to give up to 600 people achieving that outcome." Then, they move into the design phase of the curricular model, where the candidate is asked to design learning and strategies that will meet the outcome. The director would push back on some of their ideas and challenge the candidate to think critically about redesigning a community meeting or resident assistant training, or how to partner with offices on campus. This is the full-hour interview, and while some candidates struggle with the approach, others are intrigued. The director is not looking for perfection in the outcomes; rather, they are looking for candidates who are willing to be challenged and become excited about the processes.

The live-in staff member shared that this interview was the most intimidating part of the process, where they were asked to

create learning outcomes and [the director pushed me] and... I remember being petrified during that interview. And then afterwards [they asked], "How do you feel? Well, that's what it's like to work here." And I was like.... this is really cool. And I think that kind of [what drives] us to be successful and how we all kind of take on that learning opportunity.

As part of the interview process, Mid University selected a different article each

year to incorporate into the interview process. The article was either related to the theoretical framework or curricular model, and they asked each candidate to facilitate a presentation as if they were teaching the content to a group of students or resident assistants. The associate director said, "We want to see if you can engage with us and 


\section{LEARNING ORGANIZATIONS}

think because ultimately, we are more practitioners, but we're going to be scholars

together as well. And we're going to talk about these things and theories."

The interview questions changed to focus on learning and being an educator

rather than a crisis responder or conduct officer. The live-in staff reflected on this change:

I'm not gonna lie, I was a little nervous when we did some of the interviews because we stopped asking things about how our new folks handle crisis and we started asking questions about how they can educate and teach and how they can challenge a departmental goal that [staff are not buying in to]. We asked a lot of questions about how they're going to navigate that in order to still accomplish things.... Then we're going to do the evaluation sheets, and they're really, they have a really good understanding of pedagogy, they have a really understanding of this; but I'm worried that they don't have a ton of crisis experience. And I was told, "Hang on now, crisis response is teachable... but if they don't have that educator-learner mindset from the get go, that's not something we can really teach.... We can teach tasks of the 12 steps you need to respond to this incident.... We can't teach that we can teach people to enjoy learning and educating. You can theoretically, but that's not where we want to spend our time." That was honestly a bit of a shake up for me because we have all these new staff coming in that have never handled a Title IX or a suicide ideation [situation].... But I've noticed the difference in them being able to articulate the importance of what we're doing and the ability to think about different learning styles and think about the needs of our students and student staff. That was a big change we made that we're still making to our culture.

South University's associate director outlined that during interviews,

There's a question where we asked them to actually look at the learning outcomes and either identify an opportunity where they've experienced learning and that were identify an opportunity where they could structure some kind of a learning experience for their residents.

This organization hires people who like to learn because the department can teach the curricular approach; they need people who enjoy learning to be successful working in the department. Recently, they added an interview with the director where each candidate talks through a learning outcome and how they would create a learning experience for 


\section{LEARNING ORGANIZATIONS}

their community. "We've hired staff that are doing things for the right reasons more often.... They have that interest and connecting with their residents; that's been important," said the associate director.

These institutions have shifted recruitment and hiring processes and are hiring people who have a greater understanding of their curricular model and understand their role as educators.

Shift in Training. These organizations have seen a shift in hiring people with an educator's mindset after changing their recruitment and hiring processes. All departments have changed their training to be focused on the circular model, and throughout the training, they shared that staff were expected to be educators and were asked to be relevant and ensure they are doing research to learn about trends in students. Training has changed to be rooted in learning and reflective practices.

During summer training, the departments host at minimum a full day where they go over information given at ICA so staff have a base knowledge of the curricular model. Most institutions call this a "mini" ICA, where they walk staff through the history of their model, review the 10EE, discuss their institution-specific goals and outcomes, train on how to write a learning outcome and lesson plan, read articles related to the curricular model, and go through the model for the upcoming year (including tools, resources, and expectations).

Southern and Mid University moved their training to be scaffolded per position as they have three layers of hall staff. There are different tracks for returning staff, new 


\section{LEARNING ORGANIZATIONS}

staff, and different levels of training. Mid University started this year with the big picture of asking large questions related to what does learning mean and what does being an educator mean. They trained on mindset shifts, reviewed articles, and held large group and small group discussions, and staff were paired together with a learning partner to reflect with each other in a one-on-one setting. All of their training schedules have learning outcomes related to the learning goals, and this included what they hoped people would gain from the training and questions they wanted to answer from the outcome. This has shifted staff understanding of their role in the training and what is expected for them to learn. Southern University has incorporated the concept of flipped classroom in training, where at the end of each session the presenters gave out resources for participants to continue their learning on the topic presented; the resources included links to articles, books, Ted talks, and websites. Knowledge is shared throughout the year, as staff send articles and information to each other. Faculty are also brought in, and they train staff on how to write a lesson plan.

East University's training is learning focused and incorporates the core concepts

of the 10EE and the ICA model. The director shared that they shifted training to be more focused on the basic elements of the curricular model because staff started to drift away from the curricular model. Previous training did not do in-depth training on the curricular model, and when staff were not learning about the curricular model, the director noticed live-in staff drifting back to programming origins instead of a curricular basis. Talking about the curricular model is covered in roughly 10 hours in the summer training and 


\section{LEARNING ORGANIZATIONS}

revisited throughout the year as professional development in department meetings. Training covers the core rubrics used, explains how the change process works for the curricular model, and the basics of the 10EE. The live-in staff shared that it feels like graduate school, where you are given books, there are common readings, and staff are expected to read articles and discuss them in large groups or structured discussion with partners. Training is continued throughout the year in the department meetings.

Midwest University has upwards of 25 graduate students in their department, more of them than full-time staff. Knowing this, they have focused training to emphasize the why behind shifting to a curricular model. In the past, it has been nearly five days of training related to the curricular model, and in summer 2019, training was three days. The new staff learn about the 10EE and the curricular model. They go through a simulation of a made-up university, where they review the made-up institution's mission and create learning goals, outcomes, strategies, lesson plans, and even an assessment plan. Once this is created, they review their department mission and share the evolution of their curricular model. This has assisted new staff in understanding how and why they moved to a curricular model and allowed incoming staff to have more buy-in with the added context. In the past when they did not go through this much history, they realized new staff did not understand the why behind the curricular model and did not see themselves as part of the department's curriculum. During training, the curriculum coordinator shared openly about the changes for the upcoming year and reviewed past years' 


\section{LEARNING ORGANIZATIONS}

assessment on the curricular model; this too has helped people understand their role, and they had more buy-in to the approach and understood why changes happened.

This organization also has a graduate curriculum that is an extension of training. The residence life staff oversees the graduate curriculum for the institution since they have more graduate staff than other departments. This is an extended curricular approach training that helps graduate students have a deeper understanding on learning outside of the classroom and the theoretical framework used in the curricular model; it is relevant to all graduate students outside of residence life.

The center coordinator shared how they talk with the resident assistants about the curricular model:

We want to bring hard topics to the forefront. We want to have conversations with students, we want to be able to have a model to help them with the resources and making sure that I told my staff this for the first time this year. And I saw some eyes just open really big to remind them that we're all just a resource; we're not the resource. And that is a big part of the curricular approach is that we are a resource.

South University's associate director said:

We've really gotten back to the why of what we do... we can much better articulate the importance of and value of our work, so that's been a huge gain.... As a result, we're much more willing to be flexible to try things and new ways; we're willing to shed things that we just did because we've always done it. But really ask... "Is this a value? Is this core to what we're about?"

Their training has moved to a more skill development-related focus and to the curricular approach. The associate director at South University stated that the organization viewed the big picture of the curriculum model and student learning and asked questions: 


\section{LEARNING ORGANIZATIONS}

What do we believe about student learning? What do we believe about the potential of our residential environments to be places of learning? How can we reflect on learning that we have had? What do we think students learn from living on campus and get students to students and staff to kind of talk a little bit about what they think?

These questions ideally set the stage for the learning goals of the department because most of what was talked about in the answers to these questions was related to the learning goals, and there was a connection that happened for staff who are going through training. It ended with staff feeling more connected to the learning goals and finding relationship and congruence in them. All staff are given a binder with resources related to expectations of the curricular model, articles, and examples of well-designed bulletin boards. They trained on all aspects of the curricular model and followed up with feedback sessions throughout the year as well as web-based video check ins, which has been very successful.

Campus Partner Integration. All of the organizations included campus partners in different ways. Campus partners were other departments at their institution in student affairs, academic departments, and faculty partners. Some of the integration included meeting with partners regularly, sharing information about the student experience, having them come in as content experts to train staff on content related to the curricular model, having them come to facilitate parts of the curriculum model to residential students, and/or utilizing them as a vetting board for their curricular model.

Most of the residence life staff met with campus partners regularly. These meetings were a platform for sharing information with campus partners to help them 


\section{LEARNING ORGANIZATIONS}

understand the changes in the curricular model and highlights of student learning. They also were used as a platform to understand how campus partners were working with students to understand their goals and outputs so residence life staff can best support their program or initiative. South University sent out regular monthly reports highlighting student learning in the residence halls to campus partners. Mid University invited campus partners in to train their live-in staff on bystander intervention; afterwards, the live-in staff facilitated this session in their community as part of the curricular model.

Midwest University is shifting to a department collaboration with campus partners rather than an individual partnership. It has been noticed that when staff leave, if the partnership was with an individual, it is harder to sustain the initiative than when it was a department-driven partnership initiative. The curriculum coordinator regularly met with campus partners to share about their outputs as well as learn about initiatives that will impact students, understand completion requirements for students, and gather dates on campus traditions for the upcoming year. The staff uses what they learn to create a map of what is happening on campus and ensures that their curricular model is building off of and supporting other initiatives that partners are working on.

The residence life staff at Southern University work with campus partners and use campus resources and data to understand the student experience, and it is incorporated to enhance the outputs of the curricular model. As the institution has expanded living learning communities and academic programs, the curricular model has been adapted to allow the academic programs to be better integrated. The curricular model structure gives 


\section{LEARNING ORGANIZATIONS}

staff options of different facilitation guides per strategy, and the structure has allowed the facilitation guides to be adapted for hall director staff working with faculty. The full curricular model is structured and sequenced with strategies, and there is some flexibility with upwards of four different options per facilitation guide. They have found this to be very beneficial for living-learning community integration, where part of the facilitation guide can be adapted per community by the academic partner or the area coordinator.

The department from East University methodically and strategically build partnerships where both are able to fully focus on student learning and success. A unique strategy that East University has put into place is to have their curricular model approved by the university faculty senate. A positive gain has been that this deadline of approval by the senate has reinforced the idea that the curricular model needs to be complete by a certain date.

The East University director of the department shared:

Residence life organization will always kick things down the road because we're in crisis mode. We're always in response mode. And if we don't have any kind of those forced deadlines on us, I don't know that our profession is able to respond appropriately when we have the ability to not.

The department has the curricular model completed by February, where the vice president of the student life council reviews the proposed curricular model, and the department of residence life incorporates feedback before presenting it to the faculty senate in May. The faculty senate will approve, reject, or make modifications on the curricular model. The department views this approval as an ability to continue the 


\section{LEARNING ORGANIZATIONS}

curricular model for the new year. This timeline allows the department to create a backwards timeline to work from.

The residential curricular approach has been so promising that it has expanded outside of residence life to divisions of student affairs and other departments in student affairs. Four of the institutions that have been a part of this research have been at the starting stages of expanding their curricular approach beyond residence life. South University has recently been seeking ways to incorporate the curricular model to custodial and dining staff.

Three other institutions are at the starting stages of moving to a division-wide curricular approach. East University has recently restructured pasts of their division of student affairs units, and underneath one umbrella related to student engagement and the multiple units are now writing educational priorities and outcomes. The director from East University also has co-facilitated training on the curricular model for other campus departments who are interested in a curricular approach. Midwest University's residence life department has done an outstanding job; their work has been noticed by the vice president, who recently sent a number of directors to the ICA to learn more about creating a division-wide curriculum. A committee has formed that has six different people, and the curriculum coordinator is one of the members. Mid University's student affairs division is interested in a curricular approach because of the impact that the residence life curricular model has had on students. The division is moving towards a cocurricular learning model because of how impressed and inspirational residence life has 


\section{LEARNING ORGANIZATIONS}

been in their approach. Additionally, the executive director has been working on expanding the curricular model to other areas in the residence life department and has been working on a first-year experience curriculum at the institution.

Summary of Symbolic and Mental Models. All of the departments have vastly changed their hiring and training methods to be rooted in hiring people with a learners mindset, as related to mental models that Senge (2006) outlined. Training has become a symbolic way to dedicate time to teaching and training staff on the curricular model. The symbolic frame encourages departments to focus on the roles people play and teach and create a culture of learning and encourage a shared vision; this will assist staff in feeling a part of the overarching goals and bring people together. Additionally, with mental models staff who understand their department goals and their role are able to recognize their role. Those who are life-long learners will take action through a reflective practice as described in mental models. Institutions have integrated campus partners methodically. According to Bolman and Deal (2017), "Stories are deeply rooted in the human experience. It is through story that we can see into each other's souls, and apprehend the soul of the organization" (p. 247). Institutions hone in to equip staff and campus partners to understand the curricular model, to show that students are impacted and learning, and assist them in understanding their role and the benefit of the curricular model.

The data above merged into three thematic categories: shift in recruitment and hiring, shift in training, and campus partner integration. Analysis of the data using the substantiated quotes and organizational descriptions was further categorized into two 


\section{LEARNING ORGANIZATIONS}

primary outcomes that have implications for how other institutions might successfully implement and support the curricular model. First was educational alignment with hiring and training. Staff are selected and supported intentionally around the curricular model elements and specific learning goals and outcomes of the institution. Second, the curricular model is extended and integrated with on-campus partners intentionally with the output of each unique institution's curriculum.

\section{Human Resources, Personal Mastery, and Team Learning}

According to Bolman and Deal (2017), the human resources frame

highlights the relationship between people and organizations; organizations need people, and people need organizations, but their respective needs are not always well aligned... [If it is a] good fit [it] benefits both: individuals find meaningful and satisfying work, and organizations get the talent and energy they need to succeed. (p. 133)

Groups operate at two different levels, which include tasks and then processes, and the "human resource frame centers on what people do to and for one another" (Bolman \& Deal, 2017, p. 113). Personal mastery, which is an individual discipline, is when someone goes beyond understanding skills and building competence but continually learns (Senge, 2006). Senge (2006) said, "Organizations can get into considerable difficulty if they become too aggressive in promoting personal mastery for their members" (p. 161). Organizations can only learn when people in organizations learn, and team learning benefits personal mastery (Senge, 2006). According to Senge, "Team learning is the process of aligning and developing the capacity of a team to create the results its members truly desire" (p. 218). 


\section{LEARNING ORGANIZATIONS}

During the interview process, participants were asked questions that were related to human resources, personal mastery, and team learning, specifically how the organization focused on learning, how staff were scholar practitioners, how the department implements the curricular model, and how people have found joy in the curricular model. This section outlines how departments structure their curricular model creation, outlines a few institutional review processes and assessment strategies, showcases how staff are educators and find joy in the curricular model, and how some institutions are moving beyond a residence life curricular model.

Curricular Model Implementation. All institutions shared about how they supported the implementation of their curricular model. Three of the five institutions have assembled a departmental committee that edits and creates the curricular components. The committee's membership is comprised of all layers of the organization. East University initiated a full department approach to the creation of the curricular model. Midwest University has a small group assembled with the curriculum coordinator/grads in combination with the assistant directors and center coordinators.

The creation and revision of the curricular model at East University is not a committee's responsibility; it is everyone's role. Between the months of November to February, nearly $70 \%$ of the weekly department meetings are focused on curricular model design work. The live-in team along with the assistant directors are able to use data from the fall survey, their own analysis, a SWOT (strengths, weaknesses, opportunities, threats) assessment, and other data and research to pitch new ideas for the curricular 


\section{LEARNING ORGANIZATIONS}

model for the upcoming year. Based on proposals, small working groups were assigned for the design processes. These working groups consisted of the live-in staff and assistant directors, with about 2-3 people per group. The curricular model edits and revisions go through a three-step process in which the full department has three opportunities to have a voice in each proposal. First, people give feedback on their vision of the proposal, ideas for change, shares their wish list and it is the working group's responsibility to incorporate their feedback. Second, the working group gathers feedback, makes edits and presents it to the department for final feedback. Lastly, by the end of the academic year the working group shares the final product based on their vision and the feedback from the department.

The department has two plans: one for first-year and another for upper-division students. The department makes informed decisions based on assessment of student learning, not student satisfaction, and utilizes national data to inform practices. The department utilizes rubrics in the design processes, not a metric of assessment; each learning outcomes has its own rubric. They utilize (with permission) already vetted rubrics from AAC\&U along with sense of belonging and self-efficacy rubrics. They modify rubrics when needed but choose to use premade ones.

Their review process happens every four years. They start with their archaeological dig, host interviews with key stakeholders to learn more about outputs that will inform their model, and spends upwards of eight months rebuilding the entire educational priority, learning goals, and outcomes. Throughout the processes, they have 


\section{LEARNING ORGANIZATIONS}

shifted to align their curricular model to the general education outputs. The four-year review cycle has allowed the department to better meet the needs of students, revamp their outputs, and correct their mistakes.

Midwest University has created a culture where the curricular model is ingrained in all the department outputs. Part of the department's culture of creating a sustained curriculum is how the curriculum coordinator and graduate assistants engage the department. They gather feedback from department meetings and work collaboratively to ensure the curricular model is updated and ready for the next academic year. The curriculum coordinator emphasizes the strong importance of buying in and listening to the coordinators who are implementing the curriculum in their residence halls.

The review process happens centrally with the curriculum coordinator and graduate students. They gather feedback throughout the year through surveys and facilitate research on best practices of the curricular approach. The curricular coordinator facilitates term check-ins on the curricular model with all full-time staff. The curricular model has first-year and upper-division plans, and both are reviewed during these structured check-ins. The term check-ins happen once or twice a term to review what has happened so far (e.g., within the first eight weeks) and what is to come with the curricular model. They review what is currently happening with the curricular model and see if there are any changes that need to be made. The team will break out into first-year and upper-division areas and work together to ensure the scaffolding is working and the plans' curriculum complements each other. They use rubrics as part of their design phase. 


\section{LEARNING ORGANIZATIONS}

During these term check-ins, feedback from the department meetings is brought in to include feedback from the graduate staff.

The organization of Southern University has a committee with 7-8 people who oversee the curricular model. The committee is comprised of all levels of the organization, and its function is to gather feedback, make adjustments and changes, and innovate new ideas; it is charged with gathering all voices in the department to make changes to the curricular model. Both people interviewed have served on the curricular committee.

The committee is very open to feedback throughout the year and is flexible to make changes when needed. There are multiple ways the committee interacts with the overall department. During the monthly full department meeting (upwards of 45 people, including graduate staff and full-time staff), there are committee updates, and this is a time when the curricular model committee will share updates, solicit feedback, and present on any new information. The committee also solicits feedback on the curricular model from staff on what worked, what went well, what needs to change, and what can be adapted or improved through an online platform throughout the year. They have found this means as the best way to hear feedback from the majority of people.

The three professional staff who have been hired to implement the curriculum model hold tight to the 10EE and continue to review the outputs of the curricular model compared to the 10EE. This has provided a consistent framework to improve the curricular model. The committee is constantly gathering feedback and meeting together 


\section{LEARNING ORGANIZATIONS}

regularly to make changes and edits. The committee uses rubrics that guide their overall work with the curricular model. At the end of each year, there is a full day when the livein staff meet to prepare and plan or the next year's curricular model.

Both participants from Southern University shared that this is an exciting time for the institution because their curricular model is reaching its 10-year anniversary, and this upcoming year, they are going through a full review processes and overhaul of their curricular model, which is still in development. The area coordinator said:

And as we've hit a decade, we are deciding how do we review our curriculum to make sure that it is still true to our educational priorities and still true to the mission of the institution but adapted for today's students. So, we're very exciting time where we get to explore that.

The review process will consist of outside stakeholders for feedback and include multiple people in the changes. Up until this point, the committee and staff who oversee the curricular model have implemented assessment strategies to improve and make changes to the model.

The committee from South University, which was recently assembled, has members from both areas of residential learning and residential living and encompass all levels of both departments. Before, the group working on the curriculum model was the residential learning staff, and now, they have included staff from residential living, including the area coordinator interviewed. This committee was charged with the development of the curricular model but also provided members of the group training around the 10EE and the curricular approach. What this committee created is staff who ended up feeling more connected to the curricular model, and it ideally helped the two 


\section{LEARNING ORGANIZATIONS}

departments' communication flow better. There was a culture shift when the committee started meeting: There was more cross collaboration, understanding of the curricular model, and buy-in. The committee meets every other week, when they review their model, review examples of other institutions, evaluate their curricular model in relation to the 10EE, and implement change. The outputs of the curricular model use assessment trends to inform their practice. They utilize Generation $\mathrm{Z}$ data as well as assessment collected throughout the year to change for the year to come. Both directors of living and learning sign off on the curricular model for the next year.

They recently changed the outputs of the curricular model structure. They used to have a curricular model for the first four semesters, but they simplified the model and now have a rubric for a peer learning outcome. This simplified shift happened because some students were not ready for the third semester curriculum, and the clearly defined rubrics allow staff to determine if a student was at the beginning or advanced portion. This rubric is used to teach resident assistants to be aware of different levels of learning based on the rubric. Resident assistants are not asked to rank residents on the rubric; however, they do rank their community as a whole on a monthly report that they turn in. In the report, they are asked to report what learning happens on their floor and how they assist in it. Once the report is submitted, the residential learning staff utilize the submission and send a monthly report to the two departments (living and learning) and campus partners. The general overall report highlights the rubric, identifying where communities are at in their learning. The associate director and graduate students also 


\section{LEARNING ORGANIZATIONS}

created the consultation meetings and focus groups, where they meet with area coordinators and resident assistants to learn more about the curricular model to assist with the shifts in its development.

Mid University shared that their department and institution functions as a hierarchy, and the curricular committee felt different, which allowed all people (at different levels of the organization) to be able to openly contribute despite the role they held. The area coordinator shared that positions do not matter in the committee. The committee spent time processing, assessing, researching, and preparing to better improve their outputs. The associate director who oversaw the curricular model shared that since their two years of being there, they have been able to have the right people on the committee: ones whose mindset is primed to create curriculum. The associate director reflected on the committee being new this past year. The year before last, they had the full department be a part of the creation of the curriculum and realized that there were too many voices, then shifted to a smaller committee because with 30 people contributing to the scaffolding, multiple voices in writing the lesson plans was a barrier. The committee allowed the organization to create more consistency and one voice in the lesson plans.

Their curriculum is centrally structured with one plan. Now that the one curriculum is scaffolded the committee is spending time editing, tweaking, and now creating a second- and third-year plan for students who live on campus for multiple years. The committee also works on feedback on the curricular model; they send out a survey to staff to learn more about what is working, not working, and what could be improved. 


\section{LEARNING ORGANIZATIONS}

They also have a survey that they ask each hall director to review and contribute to in their resident assistant team meetings. The committee is currently updating their rubric and has built in focus groups to review the first five weeks of the fall semester for feedback; they have found this to be very valuable.

Assessment. Departments have outlined different techniques utilized to enhance assessment and understand student learning. Most institutions shared that this area is a growth one for them. However, two institutions (East University and Southern University) have a unique structure in their department that ensures assessment is at the forefront for staff.

East University's department incorporates assessment in everyone's job description. Even though there is an assessment committee, everyone has a role in producing reports, making assessment-informed decisions, and giving reports and presentations on their areas. The reports turned in are a replication of a publication with a title, literature review, findings, and recommendations. Additionally, the person who coordinates housing management systems has $30 \%$ of assessment in their position to provide the department with reports, analytics, and deeper assessment work within their systems to share out to others with the goal of using this data for the curricular model design. There are two large surveys that are developed at the department level and sent out in the fall and spring semesters. Both of the survey results are used to plan for the upcoming year's curricular model design. Each live-in staff member is required to do assessment and share out what students are learning in their areas. Twice a year, the 


\section{LEARNING ORGANIZATIONS}

department hosts assessment retreats facilitated by the assessment committee. At these retreats, everyone is required to attend and present on assessment they facilitated; this allows people to experience professional development, both by learning from others and presenting on learning by sharing on their assessment findings. Each person is also required to create a report (like a journal article or publication) on assessment and make recommendations for the future. This initiative has assisted staff in growth and learning about making research-informed decisions. There is also one graduate assistant who provides assessment support and runs reports and analyzes the data.

This department has very innovative ways of equipping hall staff to make datainformed decisions because the residence life staff have the same permissions as academic advisors and each live-in staff pulls reports on their residential community, and the information found is used to inform their practice. The systems showcase predictive analytics about students based on where they are struggling or failing classes, and the director shared that it will predict a student's percentage of graduating based on what the student is currently doing. One staff in residence life pulled detailed reports, and from the reports they were able to build in their own warning systems to better support students and create intervention for ones who were more at risk than others. The director shared that they can

tailor some of our outreach part for the students on those kinds of components. So those [reports] have helped out quite a bit terms of institutional data gathering. That's also kind of your philosophy about using numbers to give yourself action rather than just doing it. 


\section{LEARNING ORGANIZATIONS}

"Our department is steeped in assessment," shared the associate director of residence life from Southern University. The housing department has two full-time staff dedicated to assessment in the department. They assist with assessment efforts for the curricular model. The staff working on the curricular model have partnered with two people who are managing assessment for the department.

The curricular model committee incorporates classroom assessment techniques and focus groups as a part of their curricular model to assess student learning. An innovative way they assess student learning is to send a survey to students who attend a program a few weeks after the event to learn about their continued learning and the significance of the experience. It has been a great tool to engage in understanding about the outputs of learning that the program had on their development. The committee also uses university assessment from different departments to inform the outputs of the curricular model. Live-in staff create quarterly reports and are expected to learn new skills and do research to inform outputs in their community and on committees. The livein staff shared that assessment is not extra. The area coordinator stated: "It is your job to do assessment and to do it well and to learn how to incorporate classroom assessment techniques... and because we have clearly defined that and we have supervisors who get to support us full time, we are able to learn and grow." The structure of supervision meetings and the relationships that supervisors have with live-in staff reinforce the curricular model and asking people to be educators. 


\section{LEARNING ORGANIZATIONS}

The department from Midwest University mostly gathers qualitative assessment. They started a hashtag campaign and micro surveys via text message this past year to get information from students. Within the first few weeks of school, they asked (via text) how students were doing with hashtag good or bad, and if students replied with bad, their resident assistant checked in on them. They recently took all of the logged one-on-one conversations that resident assistants have implemented and used a simple coding method to create a resource guide on what students were struggling with. This resource guide is given to resident assistants to help residents. They also have initiated resident assistant and resident focus groups as part of their assessment.

Mid University has introduced creative assessment techniques; one example is where they asked students to paint what conflict looks like to them. They also utilized a note card assessment, where each resident would fill out a note card, and the resident assistant would compile them for their floor, then hall staff completed them for their hall and gave them to one central person to compile. They also utilized a white board assessment at the front desk.

Residential learning staff from South University pulled one-on-one submission logs to learn more about trends of their students. The logs indicated how a student was doing by the use of a hashtag and asked resident assistants to imitate where they referred a student to. This information is also outlined on the monthly report as well as used for the curricular model committee to review the high stress points for students and imitate 


\section{LEARNING ORGANIZATIONS}

positive and negative trends that inform their upcoming curricular model work and upcoming year's strategies.

The curricular committee also streamlined their assessment strategies to be more central and utilize classroom assessment techniques. Before the centralization of assessment, there were different options for assessment strategies, but now each lesson plan has one means of assessment. This shift has assisted the committee to centrally review learning and has assisted in the development of curriculum for the next year.

Being an Educator. Each department encourages a learners mindset and has outputs where staff can be scholar practitioners and educators, and each hall director shared that staff are educators. The researcher defined scholar practitioner as someone who engages in research to improve outcomes and effectiveness; they are administrators who engage in research to better their practice. The majority of the institutions have common readings for the department, where staff read a book together and discuss ways to integrate content.

The staff at East University are expected to be educators and scholar practitioners who take ownership in the curricular model and their professional development. The hall coordinator shared: "I've been able to take more ownership of what I'm doing in my community." Each hall coordinator is expected to be an expert in a chosen professional development area. Hall coordinators' professional development funds are based on their goals for the year, which are specifically crafted and created by their desires and areas of interest. Each hall coordinator is expected to research and present their findings. For 


\section{LEARNING ORGANIZATIONS}

example, two hall coordinators who were trained through Gallup Strengths have created a pilot program related to strengths and infused strengths into the curricular model. The department used their strategic initiative funds to assist the staff to attend the institute. The hall coordinator shared that the "culture is built [in] a way that we know what other people's interests are... it's not uncommon to go to your mailbox and see an article printed out or a magazine from a colleague that they think you'll be interested in or get an article forwarded [through email]."

The live-in team knows the reason and why behind the curricular model, and they are expected to embrace their role as educators. Each hall coordinator is expected to design outcomes and goals for their own resident assistant staff meetings; this does not come centrally from the department. The department outputs are designing student learning pieces, and hall coordinators are expected to be educators for their resident assistants. The hall coordinator shared that they "are encouraged... to have some type of framework that informs the [curricular model] that we're doing." The hall coordinator oversees the resident assistant hiring committee and reviews research and articles to inform outputs and ensure best practices are integrated into the processes.

The hall coordinator stated:

I think our students are gaining tangible life skills... every curricular model is built differently, but many of them start with looking at institutional context, department context, and past/prior experience. Ours are have direct connections to our university's general education requirements, and we can make those connections.... We are giving students direct life skills that they can use when they graduate and clearly articulating that to students. 


\section{LEARNING ORGANIZATIONS}

An example they shared is when they mediate a roommate conflict, they are talking about how conflict is giving them life skills, and they share an example of their own experience and how these skills are going to be constantly used in their everyday life. During conduct meetings, the staff reflect with students about their future careers and talk about the conduct violation and what they will learn that will assist them in their future careers. They have found a lot of meaning and growth in students when providing this reflection when they tie it back to the goals of the curricular model.

Being an educator is modeled by all levels in the division at Southern University, especially in the department of housing and residence life. The department is learning and adapting their approach to meet the needs of the changing student population. The area coordinator shared, "I think in a curricular approach... you see yourself as deeply committed and intertwined with the learning goals of the institution. So I think that that is what inspired me and got me excited."

The area coordinator from Southern University shared that this was the best culture they have ever worked in, they felt empowered to be an educator, and they were able to be innovative in their work. The area coordinator interviewed shared that they feel like an educator, I feel like I'm able to put my education to work... we really talk about lifelong learning from the beginning and end in our trainings.... We have really strong educators... who are really good at modeling the way for us.

The area coordinator continued:

I look at the curricular approach to our student learning, and I'm able to apply that as a supervisor and as an advisor to a student organizations. These are things that you should learn in a master's program on education but you oftentimes don't.... We might have had one class on assessment where they talked about learning 


\section{LEARNING ORGANIZATIONS}

outcomes, but you really learn how to write learning about classroom assessment techniques and scaffolding learning in my master's program.... So, I think that being able to learn from the curriculum approach, you're like, "Wow, I really am an educator," in a way that, like, I thought I was, but now I can see that I'm able to scaffold the learning of my graduate students. And I'm able to think about what they need to learn and when they need to learn it, and I never would have known how to do that without the curricular approach.

Staff felt like educators, and they shared knowledge with each other. Staff regularly sent out articles to each other, took classes on campus to engage in learning, and participated in broader university and divisional outputs like teaching university introductory courses and summits. Staff routinely researched and infused what they were learning into the outputs of their job, and they were excited to share what they were learning. Talking about learning, being educators, and the curricular model was a daily occurrence for staff in this department.

The curriculum coordinator at Midwest University said:

We had the conversation about how a practice that is not informed by theories is a little dangerous... [we] tie into with the training session that I lead in terms of.... Consider yourself in the role of an educator; how do you know that you're educating effectively? We learn both in terms of what are some pedagogical approach and how to design educational content.

The staff viewed themselves as educators, and the culture was still shifting to where staff were encouraged to be well researched. This was showcased by the department asking staff to research and teach others (called theory to practice), where staff research areas they are passionate about and learn about them and create outputs to teach others about their areas of passion. 


\section{LEARNING ORGANIZATIONS}

The curriculum coordinator read about the curricular approach and current students and shared about best practices that are happening. For example, they recently read a book about Generation z students and created a first-year map based on theories of what first-year students experience. They looked at research to inform their practice and utilized the map created to think about the student experience. Being learning-centric is ingrained in the culture, as staff are constantly educating themselves. Staff are humble and open to learning about the incoming students, they are able to ask for help from the team, and the culture is a constant learning environment.

The center coordinator shared that the curricular approach is the thing that has kept them at the institution and reflected:

Once curriculum really kicked in here, it just kept flourishing, of like, "Yeah, we want you to keep reading; we want you to guide [the curriculum]." So, it's made me become even more of a better scholar-practitioner, and then just a practitioner.

The community director at South University took the initiative and saw it as their

job to be an educator and prepare their team to facilitate the curricular model. The staff said, "I love learning," and often asked the associate director:

What more can I learn about, about curriculum? .... I decided on my own to attend a free drive-in conference, which was solely on curriculum and living-learning communities.... I'll find a really cheap flight, which is what I did, and I just gotta soak up this knowledge.... [I need] to be the best that I can be for my students.... I love receiving the knowledge and like inputting the knowledge. I would probably say I need to do a little bit more when it comes to, like, researching and, like, really taking/digging apart what we're doing. I think that's one thing that I don't do often. [For example,] I like assessment, I like to read it, but that's it, just read it, and I'm not doing anything else with it. But I'm hoping this year to actually really dissect it and really put in that practitioner piece this upcoming year. 


\section{LEARNING ORGANIZATIONS}

They enjoyed learning and teaching others, and this was shown by how they equipped their resident assistant team to understand their role in facilitation and ensure they were familiar with the facilitation guide and implementation. As the area coordinator shared while reflecting on a recent video check-in time, they were the only one on the video chat who was taking the time to openly talk with their resident assistant team about their role in the facilitation of the curricular model and ensured that they knew what was required of them and how to facilitate the content. The area coordinator openly talked with the graduate students they supervised about what they were learning from the monthly report submitted by the resident assistants. The area coordinator felt like they had autonomy and used the resident assistant team meetings to scaffold learning and ensure their staff are equipped to facilitate the curricular model. This staff had the opportunity to attend ICA, and after the institute, they were better equipped to train other colleagues at their institution on the curricular approach.

The staff shared that it

was really intentional for me and my job search to try and work for a school that was focused on student learning. I remember being in graduate school and [the department was] a programming model, and I think our students did way too much. And I don't think this is what we're supposed to be doing.... I remember sitting in my graduate classes, and I was often the only person that [felt like] I'm an educator, I'm here to help students become better citizens after they leave. And some of my colleagues are like "No, I don't think so; I'm just a practitioner...." We were in class or even after class [talking about] practitioner versus educator. For me, I valued what students were learning and the conversations I was having. I knew that I was making an impact that would change their life. I desired to be a part of.

The area coordinator at Mid University also utilized the resident assistant team meetings as a platform for training. They led the floor meeting, but the resident assistants 


\section{LEARNING ORGANIZATIONS}

facilitated it to ensure that they were aware of the activity. The area coordinator reviewed with them to ensure they were ready, set expectations, and answered questions.

The area coordinator said:

For some of the bigger events, there's an expectation that we need to be educating them on how to have those. So .... I did the floor meeting with them during a meeting. I went over every bit of the lesson plan as if I were in RA [resident assistant], ask them what questions they had. I have materials ready, and I think that helps them understand a little bit better how they should be doing it. So, it shouldn't be a thing where we're just handing them a lesson plan and telling them to have a nice day.

The area coordinator, who had an education background, pushed people to be creative in the curricular model approach. They shared that "you can't just ask them what your values are... ask them what they would do with a million dollars, right? We have a lot of those conversations; let's make it fun conversations." They see the value of relating to students and believe in their ability to educate others, and they take the initiative to pull in articles from different mediums and ask the question, "How can I make this relevant to students?"

The live-in staff reflected on how after their first year at the institution, they did a soft search for a different job, and through this process, they realized the importance of curricular approach and the educator mindset and recognized that at other institutions there was not intentional learning happening. They reflected:

After being trained in a curricular environment, it seems backwards to me, to be honest, it just seemed like something was missing [at the other institutions].... I wouldn't have very much of a voice there, and I felt like the environment would be challenging but not in the way that I wanted to be challenged. Because I like to engage with scholarship; I like to think about education. I see myself as an educator... We've been trying to make that argument as a field for decades, that 


\section{LEARNING ORGANIZATIONS}

we are educators, we aren't just, like, cruise ship directors, right? And residential education, if we want to make that argument, that's going to be the way to do it, is to have a residential experience, because we are then engaging with the faculty side of the house in those conversations about student learning. And if we can get them [faculty] on board with some of the stuff we're doing... by having those conversations and having that open relationship, then the students are having a better experience because then they're seeing that collaboration, and they're not seeing that weird, siloed culture.

Being an educator is a mindset, and it seems from the researcher's perspective that

the participants who were hall director staff viewed themselves as educators, took time to research, created opportunities for the resident assistant team to learn and engage in the curricular model, and performed research on their own to better inform their practice.

Sense of Purpose and Joy. The researcher inquired about the sense of purpose that individuals felt regarding the curricular approach; hall director staff at each institution spoke how they found joy in the curricular model. The area coordinator from Southern University shared:

I find joy in everyday moments of student learning. The curricular model allows you to explore what you're passionate about and what is valuable to you and incorporate in different ways. Continuous learning is important to me, and allowing flexibility in that way is important to me. I find joy in being able to learn alongside my students every day; I find joy that I'm empowered to learn new things. So, I can give that to my students. I find joy when, when my students, like, especially [with] my resident assistants [when] I see the light bulb with them because they're the people I'm closest to. It's really valuable to know that you're part of something that is deeper than just building a community on campus. It's really advancing the goals of the organization, the university, and field, and [being] part of that is really valuable. And allowing our students to see what's important to them, and seeing that the structure, seeing that it works, is really great."

When asking the hall coordinator from East University how they found joy in the curricular model, they shared the following: 


\section{LEARNING ORGANIZATIONS}

I find joy when we are able to... read so much. And you learn so much in higher education master's programs about academic affairs and student affairs kind of becoming at odds. But I think the curricular model is one of many ways that can kind of work toward that collaboration and show that we're all learners, are students, the learners on campus. My master's thesis was all on organizational collaboration. I think this kind of influences that that way, in that we have this opportunity to work with faculty and other folks who do learning on campus or do teach here on campus to be those facilitators of education as well. Our students experience campus in a very different way than we implement it. And I think we need to consider that, that they might have their own preconceptions of what to experience when they go into a residence hall. But at the end of the day, they're on a college campus. And if we show them that education happens at all elements and all spaces here, and they're going to want to learn and be eager to learn. So the more that we are bought in, the more that we're motivated to do it, the more that we see students being bought into it as well.

The community director at South University shared, "I love helping," as they

reflected on working with a graduate student they supervise who has never worked in

residence life. The area coordinator has processed with the graduate student about

working in residence life, assisted them when things were challenging as they were first

on call. They said:

You have to think about the student and what learning is happening in that moment. We have these emotions, but how are you helping that student learn through this? How are you making every moment a teachable moment?

Sometimes, they're not going to be. But overall, how can you make this a teachable moment for the student? And I find joy in that; I find joy in challenging Ras, to [ask them,] "What are they learning?"

They went on to discuss how they challenge resident assistants to think critically about

how students are learning and the process of learning.

The center coordinator from Midwest University reflected:

It goes back to that purpose thing. I think it's also the strategic piece of it. There's something about having a plan and goals that really make me thrive and push myself to do something a little different or push something elsewhere....

Personally, as well, I've seen nothing but growth in our department in the way that 


\section{LEARNING ORGANIZATIONS}

we're all thinkers and doers. Before, we were just doers. Now we really think through the process before we go do anything, with the exception of crisis management. You still have to be a doer in those senses.

The staff also reflected on how before the curricular model it

felt like we were telling the RAs, "Oh, you have this great idea for a program? Sure, you have the budget, just go do it." And now, it's really having those conversations and questioning like, "Does this program makes sense for your community? Is this something your students asked for? Is this something you want to do?" ...and put those pieces together to help our students.

The area coordinator from Mid University used an analogy to explain curriculum;

they talked about construction work underground when people see a big hole from the street but not the work going on underground. The people who view the construction work from above ground may be irritated with the impact that the construction has on them, as they may have to take a different route to work. They may get mad or wonder what is going on underground. The area coordinator sees their work on the curriculum committee as being the people who are underground, doing the work, and making sure things go smoothly for the people using the road. They are repairing damages and supporting the road. The area coordinator said:

We are making sure all of the gas pipes aren't going to erupt, so we're, we're doing all that work. And with curriculum, if you let yourself get defeated and you stop at that point, where [there is still] a hole in the road, you're not going to see the moment where it's repaired in that first car drives over it. And curriculum is one of those things [where] one day it was a giant hole [and] the next day I drove there, and it was flat, it was repaired.... And, like, there's a lot of work that goes into it. And so the most joy I received really was sticking it out through all of those times where it just felt like it was never going to end. All everyone saw was the hole. They were complaining... and they had to drive the long way around. But being able to say, "I was there when we put the rest of that blacktop on, and I was there when I saw that first car drive over it, and I was there when people said it was a really nice repair and like it looked." It was a better road, you know. It 


\section{LEARNING ORGANIZATIONS}

was a road that was easier for people to travel on than it was before. It was a clear road with, like, nicer paint. You know, all of those things.

When reflecting further on joy, the area coordinator said:

That's really what brings me joy is the fact that I know I stuck with it even when it was hard, even when it wasn't popular, even when people were complaining. And I got to see that final project, that final product, and we're still working on it, you know. It's not ever going to be something that's perfect. But even going to that first board meeting knowing that I helped revised it.... I've seen all the lesson plans before; I helped write all these lesson plans. I helped review all these lesson plans, and so putting it into a student staff member's hands, and watching them kill it at a community meeting, watching them follow the lesson plans, watching the residents engage, watching it go as planned, that was enough for me.

\section{Summary of Human Resources, Personal Mastery, and Team Learning.}

Bolman and Deal (2017) said: "People want things that go beyond money, such as doing good work, getting better at what they do, bonding with other people, and finding meaning and purpose" (p. 120). Organizations have an opportunity to ensure that they are set up to encourage others for personal mastery and team learning, and this happens when there is a common purpose, a shared understanding, vision, and an understanding how to complement one another (Senge, 2006). The human experience needs people in relationships within the organizations: people who care for one another and encourage talent development. Personal mastery is a choice, and an organization's commitment to learning will benefit from the growth of the team. The departments who were a part of the study have moved beyond individual learning to team learning, where they dialogue together and are all a part of the learning processes.

The data above merged into four thematic categories: curricular model implementation, assessment, being an educator, and sense of purpose and joy. Analysis of 


\section{LEARNING ORGANIZATIONS}

the data using the substantiated quotes and organizational descriptions further categorized into three primary outcomes that have implications for how other institutions might successfully implement and support the curricular model. First, the curricular model is implemented utilizing strategic planning and the 10EE as a guide. Departments develop incremental goals and processes to ensure that they have the structure and timeline to execute the curricular model planning process. Second, research design methods and analysis of assessment and feedback are intentionally integrated into the strategic planning and revision process. In other words, implementation is viewed as an iterative process. Third, the staff are expected to think and behave like scholar-practitioners. Reflection activities are incorporated into professional development activities and an expectation that staff are incorporating assessment, research, and reflective practice. The result is that staff come to realize a sense of purposefulness and joy.

\section{Summary of Findings}

This qualitative research was applied through the conceptual and theoretical framework integration defined by Bolman and Deal (2017) and Senge (2006). Figure 2 outlines the 16 core findings across the four areas. 


\section{LEARNING ORGANIZATIONS}

Figure 2

Findings Across the Areas

\begin{tabular}{|l|l|}
\hline $\begin{array}{l}\text { Structural and Shared Vision } \\
\text { - Department Organizational Structure }\end{array}$ & $\begin{array}{l}\text { Political and Systems Thinking } \\
\text { - Cultural Support for the Curricular } \\
\text { - Roles Change }\end{array}$ \\
$\begin{array}{l}\text { - Support and Vision of the Curricular } \\
\text { Model }\end{array}$ & - Learning Organizations \\
- Institute on Curricular Approach & \\
- Department Meetings & \\
- Budget & \\
\hline Symbolic and Mental Models & Human Resources, Personal Mastery \\
- Shift in Recruitment and Hiring & and Team Learning \\
- Shift in Training & - Curricular Model Implementation \\
- Campus Partner Integration & - Assessment \\
& - Being an Educator \\
& - Sense of Purpose and Joy \\
\hline
\end{tabular}

\section{Participant Recommendations}

The researcher asked each participant to give recommendations to other institutions. The following section highlights the participants' recommendations to others about creating a learning organization and sustaining a curricular approach.

Recommendations: Creating Learning Organizations

Participants were asked, "What recommendations do you have for others about creating learning organizations?" Learning organizations encompass a culture that creates learning environments for all people to expand their thinking and creativity, and they 


\section{LEARNING ORGANIZATIONS}

encourage a collaborative learning environment (Caldwell, 2005; Garvin, 1993; Henning, 2018; Senge, 2006). This section highlights a few select recommendations about creating, integrating, and sustaining a curricular model. The most salient recommendations were focused on creating a learning organization, shift in curricular output, and being open to feedback.

The first main recommendation was that everything within the curricular model should be about learning and focused on learning. Learning organizations can start with the top leadership in the department researching and facilitating reading groups and discussing articles. This practice of doing research can be replicated in committees, supervision meetings, department meetings, training, and other areas of the department. Three participants interviewed said it starts with the top leader in the department setting the tone for others. If an organization wants to be a learning organization, then it must be a teaching organization. It must teach others and make work challenging. Staff should be encouraged to create learning outcomes for resident staff meetings or one-on-one supervision meetings to encourage a learners' mindset. Staff should be encouraged to back up ideas and initiatives with research and best practices. Staff should also be required to be educators and held to the standard of being a learner. One suggestion was adjusting training to be replicated like graduate school, where staff are reading and discussing together relevant books and articles. One staff member shared how their department focused on teaching about learning and teaching strategies through reading books. 


\section{LEARNING ORGANIZATIONS}

Secondly, adopting a curricular approach means that there is a shift in outputs to be more learning centric. Two people interviewed shared how operations, room assignments, and applications can be centered in learning and be a learning process. This can happen easily by asking questions about what is one's capacity to learn from others in addition to learning about complementary personal attributes and preferences. Multiple hall directors encouraged others to make learning fun and to talk about social justice and diversity as key elements in the curriculum model because this generation of students are eager to discuss this. One staff member shared that curriculum is a proactive rather than reactive way of educating students. Curriculum is simple to understand because it is a way of organizing learning: what you want students to learn and what conversations resident assistants should be having. Using a backward design approach to develop what a department based on what you want students to learn is a strategy for developing curriculum (Wiggins \& McTighe, 2005).

Being open to feedback and learning from others will create a learning centered organization was the last recommendation. One participant shared that listening is a crucial skill, and learning from students' perspectives is valuable to curriculum development. Creating a learning organization takes time, and culture shifts take time; both require more than one person.

\section{Recommendations: Sustaining a Curricular Model}

Participants were asked: "What recommendations do you have for others about how to sustain a curricular model?" Sustaining a curricular model is rooted in the 


\section{LEARNING ORGANIZATIONS}

organizational culture. Tierney (2008) said that for culture to have meaning for people, it needs to be founded in organizational values. This section outlines salient recommendations related to intentional integration, conflicting priorities, and being open to learning.

The first recommendation is related to being intentional while there is integration of a curricular approach. Starting a curricular model is the hardest part because it takes multiple years to create, and it is a phased process. One participant shared that people should not bite off more than they can chew. It is important to remember that it will never be perfect as the curricular model evolves, develops, and changes. Departments should be encouraged to move towards implementation of the 10 essential elements of learning beyond the classroom (10 EE), and this takes multiple years. If staff are educated on the $10 \mathrm{EE}$, they will better understand where curriculum development is headed. In a simplistic way, curricular model is built on collaboration that includes literature, assessment and organizational change. When creating facilitation guides, a few shared that it is vital to have a small group review the content and give feedback to ensure consistency; members of this small group are not the ones creating the content; rather, the rest of the department does. It is the nature of residence life to be in reactive mode, and a curricular model can be sustained by having very strict deadlines when work needs to be completed.

Secondly, there will be conflicting priorities, and at times, some people may shift back to a programming model or the "way things were done before"; it is imperative for 


\section{LEARNING ORGANIZATIONS}

staff to be challenged to continue to have a learner mindset and implement a curricular approach. Staff buy-in is important in sustaining a curricular model. Leadership needs to be behind the approach, and staff need to learn about the student population to ensure that they are equipped to create learning environments.

Being open to learning is a valuable recommendation. One staff interviewed reflected about a situation that happened years back; their perspective was that one-onone conversations should happen organically, with no structured questions. As they listened to feedback from their staff, they realized there was a benefit in having structured one-on-one questions. Therefore, their recommendation to others was being open and listening to staff's ideas. Ideally, the educational priority and learning goals are set, and there is a lot of flexibility on the strategies and facilitation guides that can positively impact student learning. The point of curriculum is that it can shift, it can change, it doesn't have to stay stagnant. Talking about the curricular model, gathering feedback, and checking in on what is working and not working is imperative to the success of sustaining a curricular model. The next section reviews the overarching themes and key components found in the data.

\section{Organizational Structure and Culture}

Using Bolman and Deal (2017) and Senge (2006), the data fell relatively neatly into four main categories that highlighted the 16 core findings. However, after the participants shared recommendations for other institutions for creating a learning-centric environment and sustaining a curricular model, their comments and suggestions in 


\section{LEARNING ORGANIZATIONS}

addition to the 16 core findings highlighted two overarching themes, which were the structural and cultural aspects of their organizations and were key cornerstones in supporting the curricular model.

The additional analysis based on participants' recommendations revealed the two large overarching themes (structural and cultural), each with four key principles (that integrated the 16 core findings) for framing and operationalizing the curricular model, which can guide organizations toward effective and efficient integration and sustaining the curricular model in their organization. Organizations need a structure and culture to support the curricular model. Institutions should consider the eight key data components defined below, which are fully explored in Chapter 5 .

\section{Organizational Structure}

- Leader Legitimization: Need leaders who articulate vision and authorize resources.

- Strategic Design: Need stakeholders to collaborate on principles, policies, and outputs.

- Campus Integration: Need other student affairs staff and faculty to understand priorities and progress so they connect engagement and meaningful ways to their own work.

- Assessment Process: Need data informed feedback and decision making to remain responsible, accountable, and effective.

\section{Organizational Culture}

- Learner Centric: Integrating to facilitate student learning and success.

- Learning Organization: Integrating to generate employee and organizational performance.

- Empowered Communication: Integrating inclusive practices that support equity 


\section{LEARNING ORGANIZATIONS}

and capacity building.

- Iterative Adaptation: Integrating inclusive practices into the department and institution's culture in ways that are socially and academically responsive.

\section{Chapter Summary}

The purpose of this research was to understand how departments with a thriving curricular model have sustained and supported it through their organizational structure and infused it into a learning-centric environment. The two research questions were: How does the residence life department support the curricular model? How does the residence life department infuse a learning-centric environment? The participants shared experiences related to how their culture and structure has supported a curricular model, and the emergent themes were shared in relation to the conceptual and theoretical framework. Chapter 5 reviews key findings through the eight principles to sustain a curricular model through the organizational structure and culture, implications for future practice, and recommendations for future research. 


\section{LEARNING ORGANIZATIONS}

\section{Chapter 5: Discussion}

This study explored residence life departments with a thriving curricular model to investigate how they sustained and supported the curricular model through their organizational structure and enabled a learning-centric environment to flourish. Two central research questions framed this study:

1. How does the residence life department support the curricular model?

2. How does the residence life department infuse a learning-centric environment?

This qualitative research study interviewed 10 people from five different departments of residence life who have knowledge on their organizational curricular approach. Two people were interviewed at each institution: one person who oversees the curricular model and another person who held a role equivalent to hall director. This study investigated how their organizational structure evolved and changed to allow the curricular model to thrive and how the organization was learning centric. Findings were eight key components to sustain a curricular model through the organizational structure and culture. This chapter fully explains two themes and the eight components in terms of how to sustain the curricular model for maximum efficiency and success. Additionally, this chapter reviews recommendations for future research.

\section{Components to Sustain a Curricular Model}

Through this study, the researcher found two salient themes, organizational structure and organizational culture, which contain eight key components for framing and operationalizing the curricular model, which can guide institutions towards effectively 


\section{LEARNING ORGANIZATIONS}

and efficiently integrating and sustaining the curricular approach in their organizational structure and culture. The next section reviews the implications for action on how to best support the curricular model; institutions should consider the following eight components to sustain a curricular model from Table 3 .

Table 3

Eight Key Data Components

Organizational Structure

Leader Legitimization

Strategic Design

Campus Integration

Assessment Process

\section{Organizational Culture}

Learner Centric

Learning Organization

Empowered Communication

Iterative Adaptation

\section{Organizational Structure}

The organizational structure, which is the first theme, cannot be understated. How the organization is constructed is a pillar in sustaining the curricular model and supporting a learning-centric environment. This starts with the director and positional leader in the department, including resources, followed by a clear plan for the curricular implementation, continued expansion with campus partners, and a clear assessment process. The next section reviews each of these components.

Leader Legitimization. Leader legitimization, where leaders can articulate and authorize resources, is needed. Institutions have always faced change, and obstacles to 


\section{LEARNING ORGANIZATIONS}

change have been overwhelming to leaders (Kezar, 2018). However, change is needed from higher-level administrators to enact the curricular model. Enacting change is different in today's society, and Kezar (2018) asserted that leaders should "choose changes and initiatives that are based on evidence and research" (p. 6). The curricular model has roots in student development theory, and each organization that implements the 10EE bases their approach on research related to their student population, student learning, and growth.

Positional leaders play a pivotal role in the vision, outputs of the curricular model, and allocation of resources to support efforts. For the curricular model to be sustained, it has to be legitimized and have strong support by upper-level leaders and administrators. There must be a clear directive, vision, and ongoing support from higher-level administrators, including directors and at times even vice presidents depending on the organization's structure. This structural support will allow all staff in the unit to understand how the curricular model is vital to student success and ideally root their efforts in student learning. Positional leaders need to be aware of structures and situations in relation to the four frames that Bolman and Deal (2017) outlined; depending on the situation, positional leaders need to operate and respond under different approaches and analyze the organization's needs in order to identify the best action steps (Kezar at el., 2006).

Additionally, there should be one lead curriculum coordinator identified in the organization. This person should not oversee or supervise the day-to-day operations of a 


\section{LEARNING ORGANIZATIONS}

residence life department, including conduct, crisis management, and supervision of hall director staff. Rather, this person should oversee the curricular model, and it can be in combination with assessment and/or academic living-learning programs. As the curricular model evolves, there could be additional positions created that report to this position, including an assessment coordinator, academic living-learning program coordinator, or an additional curriculum coordinator, all dependent on organizational needs. The positional leader does not have to be the person who is the lead coordinator; the positional leader simply needs to support and legitimize the work of the lead curriculum coordinator to ensure everyone is working towards a common goal of student learning and success.

There must be adequate resources to support the curricular approach; this includes time and financial resources. Resources are needed to sustain the curricular model. Having staff either attend the Institute on Curricular Approach (ICA) or host ICA faculty on campus is needed for additional education and support of the outputs of the curricular model. By having staff attend ICA, new staff of the institution can have extended training to enhance their skill set and knowledge of the curricular approach. Staff can also attend ICA when the institution is in need of revamping parts of the 10EE. Additionally, if attending ICA or hosting ICA faculty on campus is not something that can financially happen on an annual basis, it is vital and important for staff to be well educated on the curricular model. There are many online resources, videos, publications, and tools for self-education that should be reviewed. Some to highlight are a blog (blog.roompact.com) 


\section{LEARNING ORGANIZATIONS}

and an interactive Facebook group, Residential Curriculum and Curricular Approaches (www.facebook.com/groups/1158687560864734).

Upper-level administrators and the lead curriculum coordinator (depending on where this position sits in the organizational structure) need to assess what the resident assistant and hall director staff are spending time on. An assessment of workload can assist in streamlining and simplifying it to shift and change to ensure the curricular model is well resourced. As technology becomes more prevalent, shifting to online platforms can simplify workload. Adding positions to support the curricular approach is another best practice to support outputs. Understanding what work no longer is fiscally responsible is an additional option for assessing workload; performing a cost analysis to see how to free up time from hall directors and resident assistants is an added best practice to see how work can shift to other areas or be removed if it is not needed. Centralizing budgets is another opportunity for organizations to allocate money around their learning outcomes, as some institutions that were a part of this study typically spent less money after moving to a curricular model.

Strategic Design. Strategic design implementation includes stakeholders collaborating on curricular model outputs. Structurally, there needs to be a strategic design and intentional approach to curriculum integration, which includes making goals, processes, and timelines for workflow. Every organization has a culture, and people in organizations have different lived experiences that impact how they engage in the culture (Tierney, 2008). Moving culture to a strategic design phase needs to have explicit 


\section{LEARNING ORGANIZATIONS}

elements of the culture shared with the members of the organization (Tierney, 2008).

Institutions who have a curricular model should familiarize themselves with research and factors that facilitate student learning and success and infuse them in the curricular model. Every institution has a different demographic of students, and it is vital for staff to understand their students and current trends, student demographics, and the culture of incoming students.

As organizations implement curriculum, it needs to become everyone's work. Institutions should change current department structures to be learning centric (e.g., department or divisional meetings, supervision meetings, committee meetings, etc.) and talk about the curricular model and relevant information related to the $10 \mathrm{EE}$, being a scholar-practitioner, and student learning. Every person in the organization should be creating the curriculum's content (e.g., facilitation guides, assessment plans, etc.), and there should be a very small group of people who vet the content to ensure consistency and clarity, flow, and the same voice. This is a very important first step in creating the structure and cultural environment for sustaining the curricular model. Additionally, some institutions have a smaller committee (and not the full department) who create the curricular content; if this is the structure, there should be multiple people from different hierarchical layers in the organization represented on the committee.

Campus Integration. Campus integration is needed so that student affairs staff and faculty can understand priorities and progress and connect engagement with meaningful ways to do their work. According to Kuh (2008), "Student development is a 


\section{LEARNING ORGANIZATIONS}

cumulative process shaped by many events and experience, inside and outside of the classroom" (p. 23). Kuh outlined high-impact practices, which include multiple campus resources and departments; therefore, it is vital when implementing a curricular model to include multiple campus partners.

The history of the curricular approach started in residence life, and some campuses are expanding the model to departments outside of residence life and even to a divisional approach in student affairs. This study researched institutions who have a firstyear live-on requirement; if the curricular model is for first-year students, then it should integrate the required elements for first-year students to support the programs and education that the institution would like students to participate in. Organizations should integrate campus partners intentionally with outputs of their unique institution's curriculum; this will assist in simplifying what they want students to learn. The hall director, lead curriculum coordinator, and upper-level administrators/director should be sharing assessment and data with campus partners to highlight what students are learning. Campus partner data and information should also be utilized when creating and editing the curricular model.

Each curricular model has learning outcomes that are relevant to departments or a division on a college campus. Campus experts should be utilized when creating content in the facilitation guides or integrate them to vet and edit the curriculum outputs. This will ensure that optimal learning is created. Partnerships should be mutually beneficial, and organizations should methodically and strategically build partnerships where both are 


\section{LEARNING ORGANIZATIONS}

able to fully focus on student learning and success. Institutions should think strategically of who should vet their curricular model; most institutions have a small committee vet the content, and one institution had their curricular model for the next year approved by the faculty senate.

Some departments of residence life have academic living-learning communities, and there needs to be intentionality when creating the curricular model for these communities. Depending on the structure of the academic living-learning communities, there can be several options of integration of the curricular model. For each strategy, there can be an additional layer that is relevant to the academic learning community; for example, if a resident assistant is facilitating a one-on-one meeting, there should be structured questions for all residents and one additional question per the academic livinglearning community. If part of the curricular model is a newsletter sent by hall director staff, then there should be a section created for each academic living-learning community relevant to that particular student group. This content can be co-constructed by faculty and academic partners.

Assessment Processes. An assessment process is needed, where data-informed feedback informs decision making to keep the curricular model process responsible, accountable, and effective in outputs. Learning environments that are student centered require assessment of the measured intended learning outcomes to determine if the outputs are contributing to student learning (Keeling, 2004). The cycle of assessment for student learning and educational strategies is one of the 10EE; Kerr et al. (2017) asserted: 


\section{LEARNING ORGANIZATIONS}

"Assessment structures also helps institutions maintain the gains and minimize the need to start over when there is staff turnover" (p. 26).

Assessment is important for the longevity of the curricular model. Each curricular model needs to have a clear assessment process and use data to inform revisions. Annually, the organization should assess student learning, then use its findings to update its curricular model. Assessment should be the job of everyone who facilitates and implements the curricular model, not just the lead curriculum coordinator. Staff implementing and overseeing the curricular model in their respective areas should be in charge of assessing student learning in their area. Additionally, staff who manage databases should be tasked with pulling reports to share data. Some departments have shifted to hire full-time staff who facilitate assessment. Departments should create a structured time for staff to highlight and share what students are learning in their areas. This can be built into a department meeting's structure and happen throughout the academic year.

Based on their organizational structure, departments can have an assessment committee in addition to adding assessment to everyone's job; additionally, they can hire full-time staff to assist with assessment and curricular model implementation. The lead curriculum coordinator, assessment committee, or the staff whose full-time role is assessment should educate others on best practices of assessment, including classroom assessment techniques, creating survey questions, facilitating focus groups interpreting data, etc. Many institutions utilize faculty, their assessment office, or the teaching and 


\section{LEARNING ORGANIZATIONS}

learning center on their campus as a resource for staff education; experts on campus can educate others on assessment in the organization. Having an established assessment culture and/or an assessment committee can reinforce an assessment culture for staff members (Kerr et al., 2017).

Organizations do not need to assess everything in their curricular model on an annual basis; a best practice is to take one to two learning outcomes or learning goals and assess them heavily on an annual basis throughout the academic year. Organizations should create a feedback loop based on the guides, and it is encouraged after each facilitation guide has been facilitated that there is an opportunity for feedback. There are multiple ways feedback can be gathered, including a survey that each facilitator fills out after they use a facilitation guide, during a department meeting, during a resident assistant weekly meeting where people share their thoughts through a SWOT (strengths, weaknesses, opportunities, and threats) analysis, or at the curricular committee's recurring meeting. Organizations should also utilize this feedback along with relevant data from the institution and research based on current students to inform their curricular model revisions. As institutions develop their curricular model, it is a best practice to keep the educational priority and learning goals for multiple years. Among the institutions that were a part of this research, it was encouraged to go back to facilitate an archaeological dig every four years or whenever there is a drastic change with the institutional and/or divisional mission.

These four components outline how organizations can create a structure through 


\section{LEARNING ORGANIZATIONS}

the positional leader; plan for curricular implementation, integration, and collaboration;

and partner with others on campus to create an assessment plan. The next section reviews the second theme, organizational culture, and highlights the next four critical components.

\section{Organizational Culture}

Organizational culture is the second theme for supporting a curricular model; it involves infusing culture with a learning-centered approach. The next section reviews how learning-centric foundations should be infused, reviews learning organizations, and enhancing professional development by encouraging staff to become scholar-practitioners and educators, communicating effectively, and lastly, embracing iterative adaptation.

Learner Centric. Having a learner-centered approach is pivotal to organizations having curricular approach; it allows departments to operate a learning organization and focus efforts on learning for staff. A learner-centric organization culture is focused on both integrating and facilitating student learning and success and adopting a learnercentered approach for staff development. Senge (2006) claimed that learning organizations are those that facilitate learning for all members and continuously seek to adapt to the needs of the student population they serve. Being learning centered is a personal commitment, and in order to create learning environments for students, full-time staff members need to be aware of theory and learning development (Smith \& Rodgers, 2005). In other words, organizations become learning ones because they have a learnercentric frame. Being learner centric happens during hiring, training, and the execution of 


\section{LEARNING ORGANIZATIONS}

job roles and responsibilities. Being learner centric comes first, followed by becoming a learning organization.

There have been positive gains when departments shift to the curricular approach: their conduct numbers dropped, staff had more time to be educators, and they spent less time doing administrative work. The curricular model enhances the overall learning of the student (Kerr et al., 2017). The role of residence hall staff, including hall directors and resident assistants, must shift to be centered on learning. Curricular model organizations become more proactive rather than reactive (addressing student learning and integrating the curricular model); being proactive has assisted with the reactive side of residence life, which is inevitable.

Curricular model organizations should shift their focus on learning. They should be reviewing data and information about their student population and creating a curriculum model to address behaviors and trends they have noticed. Being learner centric will ideally help departments who are reactive in nature. Being learner centric centers student learning, and its approach is focused on educating students and building a community that will help students make better-informed decisions. This will help organizations be less reactive because students are more educated based on the organization's proactive approach to education. Additionally, organizations should have plans and processes in place (that can be curricular in nature) to handle things they need to respond to because the day-to-day operation of residence life is unpredictable. Some of these plans can be related to leading a conduct meeting, key lock outs, and/or other 


\section{LEARNING ORGANIZATIONS}

operational tasks that can be a learning opportunity.

Hiring and training are core parts of student affairs, and these processes should shift to be educational in their approach and be used as a platform to talk and educate candidates about the curricular model. Position descriptions should shift to talk about the curricular model and the role the position will play in the curricular approach. Hiring authorities should evaluate their minimum and preferred qualifications to see if they are yielding the candidates they need to support their curricular model. During the recruitment process, candidates should receive information about the curricular model, educational priorities, and learning goals and outcomes. Interview questions should be revamped to incorporate the learning outcomes and the knowledge, skills, and abilities needed for the specific position and how it relates to the curricular model. Other ways the curricular approach can be implemented in the recruitment and hiring processes are as follows: have candidates read articles related to the curricular approach and/or the theoretical framework the institution utilizes, then ask them about the articles during the interview, have the candidates present or lead a small group discussion on one aspect of the curricular model or learning goals and outcomes, have candidates design a learning opportunity (strategy) while they are on campus related to a learning outcome, etc. The recruitment and hiring process is an excellent way to train candidates on the curricular model and their potential job. Most institutions interviewed in this study shared that having a learner mindset is not teachable, so it is imperative for curricular model organizations to hire staff with this mindset. 


\section{LEARNING ORGANIZATIONS}

Once hired, new staff (and returning ones) should be expected to understand the history of the organization's curricular model and how it has been implemented. Training schedules should set aside a minimum of one day to go over aspects taught at ICA, where the lead curriculum coordinator and curriculum committee (if there is one) review all aspects of the curricular model, the assessment facilitated, what students have learned, educational priorities, and learning goals and outcomes. They should also go over in detail changes for the upcoming academic year. Additionally, what is vital is to ensure that staff see themselves as educators and encourage their ability to be scholarpractitioners. Training that is skill based and incorporates articles, books, and intentional discussions. Carving out time for additional training throughout the year is a needed practice for staff, which is explained later in this chapter.

Learning Organization. Learning organizations develop cultures that are conducive to learning and allow people to expand their thinking, become more creative, embody a team approach, and work collaboratively toward the processes of learning and creating (Caldwell, 2005; Garvin, 1993; Henning, 2018; Senge, 2006). Learning organizations with a curricular approach need to integrate employee and organizational performance. Kezar at el. (2006) urged positional leaders to embrace collaboration and move the organization from learner centric to a collaborative process that is processes focused. Professional development along with being a scholar practitioner are framed by being a learning organization.

The approach of a learning-focused organization requires staff to be learning 


\section{LEARNING ORGANIZATIONS}

focused with an openness to new information and a tolerance for failure and feedback that may be critically constructive. Curricular model departments must continually be engaged in professional development, including participation in ICA, departmental meetings, and ongoing professional development. Departments that have a curricular model should be encouraged to be creative, learn by researching, and understand how organizational structures and cultures support their curricular model.

Organizations should build a culture, set an expectation, and provide structured development for their staff to be scholar-practitioners and educators. There should be an expectation for staff to think and behave like scholar-practitioners. There should be reflection activities and professional development activities incorporated into existing structures that create new opportunities for staff; the result is that staff come to realize a sense of purpose and joy. All hall director staff from this research viewed themselves as an educator and found joy in the curricular model. Additionally, all five of the institutions had a minimum of one staff member who served as a faculty member on ICA.

A scholar-practitioner is someone who engages in research to improve outcomes and effectiveness; they are administrators who engage in research to better their practice (Kupo, 2014). Additionally, being a scholar-practitioner is a mindset in which professional staff are grounded in learning and developmental theory and research (McClintock, 2004). Staff who manage the curricular model in their areas should be expected to share information related to student learning, create resources, and utilize their supervision meetings and student team meetings (e.g., resident assistant weekly 


\section{LEARNING ORGANIZATIONS}

meetings) to ensure their staff are ready to execute the facilitation guide. For example, if there is an upcoming one-on-one interaction, a resident director should model this interaction in their supervision meetings with their resident assistant and ensure they are ready to facilitate the conversation, or if there is a community meeting, the hall director should facilitate this activity in their resident assistant weekly meetings to ensure resident assistants are ready to facilitate it in their community. Additionally, hall directors have amazing experience and should be researching and creating learning moments for their supervisees and being creative in their approach to best support student learning.

Empowered Communication. Integrating inclusive practices that support equity and capacity building is how empowered communication manifests itself in organizations. Empowerment is defined by Kezar et al. (2006) as, "the practice of sharing power and enabling organizational constituents to act on issues they feel are important and relevant" (p. 77). Kezar at el. synthesized empowerment to "provide techniques and models for breaking down hierarchical structures through the delegation of authority, creation of teams, and destruction of political cultures" (p. 78). They outlined: "Leaders create empowerment by encouraging and rewarding participation, collecting and disseminating data of interest to constituents, providing forum for constitutes to talk together, and promoting a campus climate of openness" (Kezar at el., 2006, p. 140). In other words, communication is not just top town; rather, good communication is inclusive of all members in a curricular-based approach. 


\section{LEARNING ORGANIZATIONS}

Communication is central to integrating and sustaining the curricular model. It is pivotal to focus on learning and infuse it into the culture and structures of the organization. What people ask and say communicates volumes, and focusing on learning in communication is one way cultures can be created to support learning-centric environments and being scholar-practitioners. There are many ways communicating about learning can happen; one example is to ask at the beginning of each staff meeting, "What is something you have learned recently?"

For buy-in and to best develop a curricular model that is centered on student learning, organizations should incorporate multiple voices. If decision-making excludes voices and perspectives, then misunderstanding and conflict are likely to arise. The positional leader plays a pivotal role, which was addressed in this chapter's first section, Leader Legitimization; it is vital for upper-level leaders to have a clear directive, vision, and expectations related to communication and feedback. Conflict will happen in every organization, and it is everyone's responsibility to address conflict and move towards a resolution. In learning-centric curricular model organizations, communication should be centered on student learning, the learning goals, and the educational priority of the curricular model. Decisions should be based on these elements and clearly communicated. Formal and informal communication, navigating conflict, and alignment of vision is needed to support staff's understanding and buy-in.

Iterative Adaptation. Iterative adaptation is the ability to integrate the culture of the department and institution in ways that are socially and academically responsive. In 


\section{LEARNING ORGANIZATIONS}

order to initiate and sustain the curricular model, each organization must adapt the key elements into their organization and be consistently vigilant in making appropriate iterative changes to develop learning moments for the changing culture of students. The organizations that were a part of this research tried new things, learned, thoughtfully implemented the 10EE, and adapted their outputs to better support the learner-centered approach. As the organizations' curricular models evolved, their outputs also changed based on the research and assessment they facilitated.

In addition, when mistakes are made it is important that organizations learn and grow from them; this was a key cornerstone of the institutions interviewed. People in organizations should also learn from one another and be open to feedback. Supervision is a structural piece in any organization, and staff at all levels need to be bought into the curricular model. The role of a supervisor in the success of the curricular model cannot be understated.

Part of integrating an organizational curricular approach is about getting individuals on board. Rogers (2003) outlined five ways organizations can move individuals to adapt to change through the diffusion of integration theory: perceived attributes to innovation (relative advantage, compatibility, complexity, trialability, and observability); type of innovation decision (optional, collective, and authority); communication channels (mass media or interpersonal); nature of social systems (its norms, degree of network interconnectedness); and extent of change agents' promotion efforts. Getting people on board is an iterative adaptation process, just like making 


\section{LEARNING ORGANIZATIONS}

changes to the curricular model. The next section reviews the eight critical concepts on how organizations can integrate the curricular approach.

\section{Curricular Integration Model}

The goal of the curricular model is to build student learning and success outside of the classroom. In order to sustain the curricular model, organizations must adapt to new changes; they can structure and build a culture that centers student learning and success. Figure 3 is a model that encompasses the eight findings from this research to encourage organizations to understand the structural and cultural needs for integrating the curricular approach. When an organization can embed the eight critical concepts into their organizational structure and culture, the curricular model integration can be supported along with student learning and success as the core outputs of what happens within their organization.

Figure 3

\section{Kropf Curricular Integration Model}

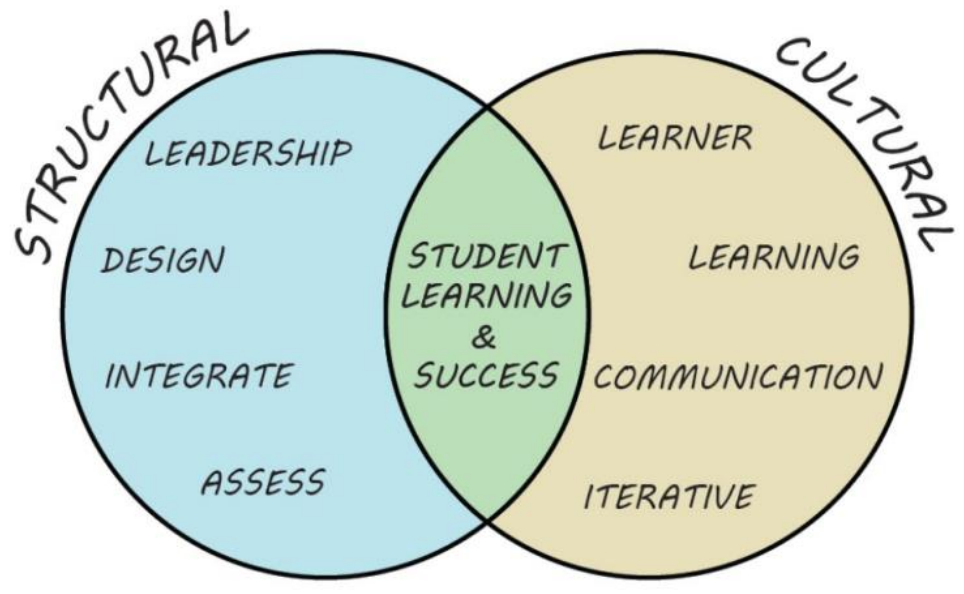

Note. Derived from data from this dissertation 


\section{LEARNING ORGANIZATIONS}

\section{Strategic Steps to Curricular Model Integration: Initiating, Sustaining, and Thriving}

Developing a curricular approach can take multiple years, and shifting to the curricular approach is as much about building the curricular model as it is about cultural and organizational change (Brown, 2017, 2019). The shift to requires a learning-centric approach in an organization, and it is vital to sustaining the curricular model. It can take nearly 2-3 years to put in place the basis of a curricular model in each organization (Brown, 2017, 2019). Shifting cultures and structures in organizations takes multiple years.

The curricular approach is not a static model; rather, it is a dynamic model, and the eight key elements that are defined in this study are in concert with each other to make the best outputs for organizational curricular model integration. Table 4 outlines the eight critical concepts in relation to a three-step process: how organizations initiate, sustain, and ultimately have a thriving structure and culture to support the curricular model. 


\section{LEARNING ORGANIZATIONS}

Table 4

Eight Critical Concepts for Integration of an Organizational Curricular Approach

\begin{tabular}{|c|c|c|c|}
\hline Integrating & Structural & Cultural & Relevant Literature \\
\hline Initiating & $\begin{array}{l}\text { Leader } \\
\text { Legitimized }\end{array}$ & Learner Centric & $\begin{array}{l}\text { Bolman \& Deal, 2017; Brown, 2017, } 2019 \\
\text { Keeling, 2004; Lichterman, 2015; } \\
\text { Lichterman \& Bloom, 2019; Kezar, 2018; } \\
\text { Kezar at el., 2006; Senge, 2006; Smith \& } \\
\text { Rodgers, 2003; Tierney, } 2008\end{array}$ \\
\hline Initiating & $\begin{array}{l}\text { Strategic } \\
\text { Design }\end{array}$ & $\begin{array}{l}\text { Learning } \\
\text { Organization }\end{array}$ & $\begin{array}{l}\text { Brown, 2017, 2019; Kerr et al., 2017; Kuh, } \\
\text { 1996; Kupo, 2014; McClintock, 2004; } \\
\text { Senge, 2006; Tierney, 2008; }\end{array}$ \\
\hline Sustaining & $\begin{array}{l}\text { Campus } \\
\text { Integration }\end{array}$ & $\begin{array}{l}\text { Empowered } \\
\text { Communication }\end{array}$ & $\begin{array}{l}\text { Kerr et al., 2017; Kezar at el., 2006; Kuh, } \\
2008\end{array}$ \\
\hline Thriving & $\begin{array}{l}\text { Assessment } \\
\text { Process }\end{array}$ & $\begin{array}{l}\text { Iterative } \\
\text { Adaptation }\end{array}$ & $\begin{array}{l}\text { Kerr et al., 2017; Brown, 2017, 2019; } \\
\text { Maki, 2004; Keeling, 2004; Kerr \& } \\
\text { Tweedy, } 2006\end{array}$ \\
\hline
\end{tabular}

The eight components to the curricular integration model is an iterative process in that organizations might not be able to implement all components immediately; rather, an organization might begin with the first four critical components, then implement the others, which is described next.

Initiating. Four components outline how organizations should initiate the curricular model based on their structural and cultural components. There are four elements, including two structural components, leaders legitimizing the outputs and formulating a strategic design. Of the two cultural aspects, one, creating learner-centric outputs, first moves the organization forward to the second, being a learning 


\section{LEARNING ORGANIZATIONS}

organization; this is how the curricular model is initiated. Without these elements, it would be very difficult to initiate the integration of the curricular model and move to the sustaining and thriving stages. Shifting from a traditional residence life student development model to a curricular approach requires a mindset change for staff and a cultural and organizational shift (Brown, 2017, 2019).

Organizations need leaders who articulate the vision and provide resources for staff to engage in learning about the curricular model. Change is needed from positional leaders (Kezar, 2018), and they should be given a clear directive, vision, and ongoing support to structurally support the curricular model (Lichterman, 2015; Lichterman \& Bloom, 2019). There should be one lead curriculum coordinator whose primary role is to oversee the development and execution of the curricular model in their organization, and this position should not manage the day-to-day operations of the residence halls. Additionally, resources need to be provided for ongoing training and support of staff on the curricular approach; a strategy institutions use is to attend ICA or host faculty on their campus. Positional leaders should assess the workload of their staff members (mostly live-in hall director and resident assistants) to ensure there is adequate time to implement the curriculum model. Depending on the organization, positional leaders need to be aware of how they enact their vision (Bolman \& Deal, 2017), and they need to approach the organization by analyzing the structure in place to implement the best action steps (Kezar at el., 2006). 


\section{LEARNING ORGANIZATIONS}

Leader legitimization is the primary way organizations can initiate the curricular model, followed by strategic design, which needs stakeholders to collaborate on the outputs of the curricular model. The organization needs to have process for integrating the curricular model. Every organization is made up of people with different lived experiences, and how they engage in the culture is different; therefore, moving the culture to have a strategic design for implementation is needed so that it can be shared with the organization (Tierney, 2008). The design should include well-researched practices for student learning, including the curricular model creation. The creation should be inclusive of all professional staff and should either have a model where all staff write lesson plans for the curricular model and a small group or committee from different hierarchical layers in the organization (not the full department) vets the content.

Culturally, organizations need to be learner centric, which can then be followed by becoming a learning organization, which means that the culture needs to shift to being focused on facilitating student learning and success. Learning Reconsidered (Keeling, 2004) defined learning as "a comprehensive, holistic, transformative activity that integrates academic learning and student development” (p. 2). Being learner centered is a personal commitment, and in order to create learning for students, staff must first be learners of theory, research, and development (Smith \& Rodgers, 2005). Organizations need to assess their outputs to be learner centric in their hiring and training outputs and focus on education around the curricular model; ideally, they should hire staff with a learner mindset. Additionally, onboarding training needs to be rooted in the curricular 


\section{LEARNING ORGANIZATIONS}

model as well as relevant readings related to student learning and assessment (Lichterman, 2015; Lichterman \& Bloom, 2019). The first step to becoming a learning organization is to have a culture that is learner centric (Senge, 2006).

Learning organizations integrate learning that allows staff to expand their thinking and adapt to meet the needs of the students they serve (Senge, 2006). Curricular model departments should be open to new information and build a culture that expects staff to be educators and scholar-practitioners. Being a scholar-practitioner is a mindset where professionals are grounded in learning, research, and developmental theory to better inform their practice (Kupo, 2014; McClintock, 2004). Learning organizations produce high-quality work and outputs (Kuh, 1996). Kerr et al. (2017) asserted: "With a decision to make student learning the center point of the student affairs unit and define operational success through the lens of student learning assessment, every element of our organization transformed" (p. 30). It is vital to remember that the shift requires a learning-centric approach in an organization, and it is vital to sustaining the curricular model (Brown, 2017, 2019). Without these elements, it would be very difficult for an organization to move on to the next stage: sustaining the curricular approach.

Sustaining. Once the curricular model has been initiated, organizations can move to sustaining it; this includes the structural outputs of campus integration and the cultural outputs of empowered communication. Sustaining campus relationships and internal communication is needed to sustain the curricular model. Campus integration is rooted in the need for other departments, the division of student affairs, and academic partners to 


\section{LEARNING ORGANIZATIONS}

understand curricular model priorities and its progress so they can connect it with their engagement in meaningful ways. According to Keer et al. (2017), “The curricular model invokes a commitment to holistic learning, high-impact practices, and collaborations between student affairs and academic affairs" (p. 28). One high-impact practice is to include multiple campus partners when researching the curricular model (Kuh, 2008). Kezar at el. (2006) urged positional leaders to embrace collaboration and move the organization from a learner-centric process to a collaborative process that is learning focused. Organizations that have a curricular approach should utilize campus partners in multiple ways to co-design training and create the curricular model. Additionally, organizations should share their curricular model outputs and assessment on what students are learning. Some institutions are shifting to a full curricular model for their division of student affairs. One institution that was a part of this research utilized the faculty senate to vet and approve their curricular model for the next year. These collaborations are built on communication within the organization.

Empowered communication is the next way organizations sustain the curricular model, the goal of which is to center inclusive practices that support equity and capacity building. Empowerment is a sharing of power and enables organizations to act on important and relevant outputs (Kezar at el., 2006). Organizations that have empowered communication breakdown their hierarchical structures, and all members are encouraged to talk with one another and create an open culture (Kezar at el, 2006), ideally making communication not just top down but a shared experience of all members in the curricular 


\section{LEARNING ORGANIZATIONS}

approach. Formal and informal communication should happen in the organization to sustain the curricular model, and communication should be inclusive of all members. As organizations move to sustaining the curricular approach, they need to create ways staff can understand and have buy-in for the curricular model. This communication can happen in many avenues, including department meetings and supervision meetings, just to name a few. The positional leader needs to clearly communicate the vision, clear directive, and expectations regarding the curricular model; if this leadership is not present, conflict can occur. Additionally, organizations should focus their communication, outputs, and decisions on the learning goals and outcomes of their curricular model. Moving to the last stage of integration is how departments can thrive with the curricular approach.

Thriving. Lastly, an organization with a thriving curricular model is sustained by the structural components of an assessment process and a cultural aspect of iterative adaptation. Assessment and adaptation are needed to create a thriving organization that both supports and sustains the curricular model. Student-centered learning environments require assessment of intended learning outcomes to determine if they are contributing to student learning (Keeling, 2004). The assessment process should be rooted in datafeedback and decision making to keep the curricular model responsible, accountable, and effective in its outputs. It is important for the longevity of the organization to have everyone involved in assessment and have people report out and present on assessment findings. Assessment of student learning should be evaluated in multiple ways (Keer \& 


\section{LEARNING ORGANIZATIONS}

Tweedy, 2006). Kerr at el. (2017) outlined the 10th element of the 10EE being a cycle of assessment that is "focused on student attainment of learning outcomes and the effectiveness of strategies in a cycle of continuous improvement" (p. 25).

Iterative adaptation is the last component of how an organization can have a thriving curricular approach. It is vital for organizations to be mindful that developing a curricular approach can take multiple years before the basis of a curricular model will be in place, and shifting to the curricular approach is as much about building the curricular model as it is cultural and organizational change (Brown, 2017, 2019). As organizations create learning environments, it is important to remember that "learning is a process of constructing meaning, framing issues, drawing on strategies and abilities honed over time, reconceptualizing understanding, repositioning oneself in relation to a problem, or issue, and connecting thinking and knowing to action” (Maki, 2004, p. 2). Shifting cultures and structures takes organizations multiple years, and when the eight critical concepts are well integrated, the curricular model can thrive.

People in organizations will make mistakes. People will need to learn to adapt and grow to support student learning and the curricular model. People in organizations should learn from one another and understand that they are responsible for student learning. The role of a supervisor cannot be understated, as their understanding of and commitment to the curricular approach will guide the success of the curricular model outputs. Keer et al. (2017) asserted that after 10 years of having a curricular model, staff know more about 


\section{LEARNING ORGANIZATIONS}

student learning, student population, and the curricular model, and the 10EE are a vital tool to educating students outside of the classroom. Keer et al. stated:

The fact that everything changes does not mean everything changes at once. The first change for everyone involved in this transformation is deciding unequivocally that we are educators. That assertion requires that we have a clear view of what students should learn and a set of informed strategies about how students best learn in our unique learning environments. When we develop ways to assess these areas, the dominoes begin to fall in sequence as the organization and the individuals transform practices. (p. 30)

\section{Model of Strategic Steps to Curricular Model Integration}

The eight critical components are interactive and need to work together in order to create a structure and culture that supports a thriving curricular model. Figure 4 outlines how the eight critical components are interactive and need to work together in order to guide the organization's strategic steps. This model is supplemental to the 10EE of a curricular model for learning beyond the classroom, as the 10EE is focused on how organizations create and implement the actual curricular model (Keer at el., 2017). Figure 4 demonstrates how the organization can initiate, sustain, and have a thriving organizational structure and culture to support the curricular model outputs. 


\section{LEARNING ORGANIZATIONS}

Figure 4

Kropf Curricular Integration Model with Temporal Considerations

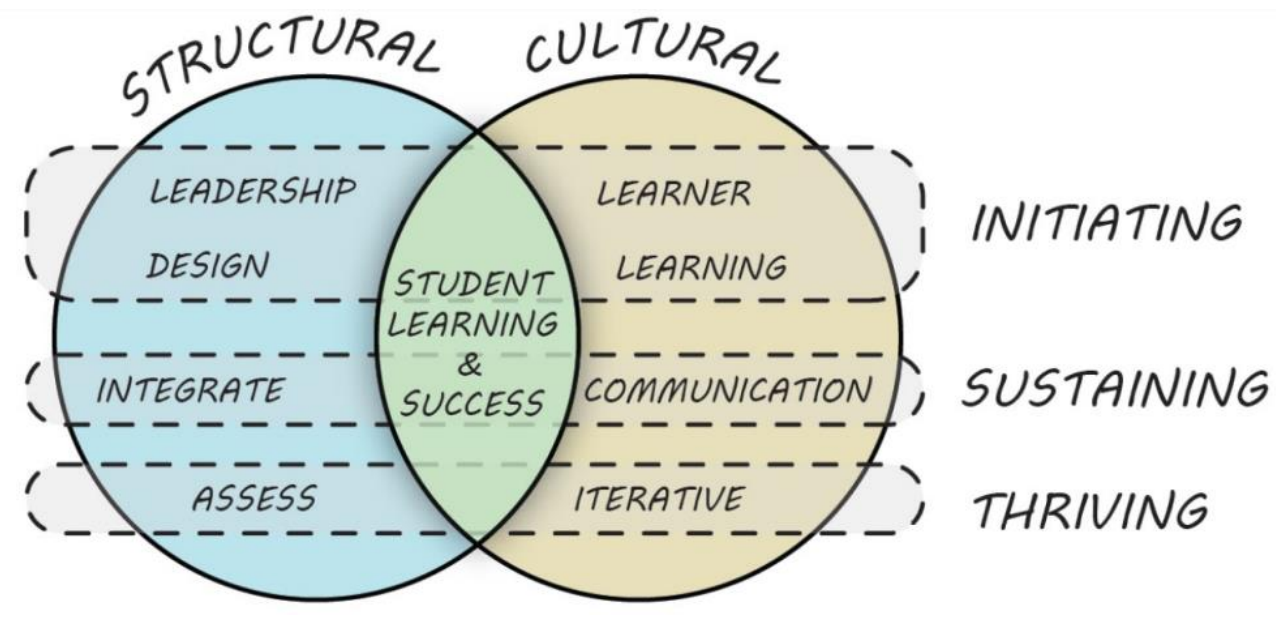

Note. Derived from data from this dissertation

To operationalize this model, there is a three-step process to initiate, sustain and move towards a thriving organizational structure and culture that supports an organization's curricular model through the eight components. This is not a stagnate model but one where the eight components are interacting with one another in order to have the optimal organizational structure and culture to allow the curricular model to thrive. The next section reviews future research.

\section{Future Research}

This study focused on five state institutions with a first-year live-on requirement who had a curricular model for a minimum of four years and were integrating the 10EE. Future research could be replicated at small, private, liberal arts institutions to learn more about their structure and learning-centric environment. This study could additionally be 


\section{LEARNING ORGANIZATIONS}

replicated at institutions that have a divisional curricular model. The research criteria were state institutions with a first-year live-on requirement, minimum of a curricular model for four years, and integrating the 10EE; in addition, all institutions surprisingly had a higher education master's program and utilized graduate students. Knowing this, future research could focus on interviewing participants at similar institutions that do not have an education graduate program and/or graduate assistants as a part of their organizational structure. These three added studies could highlight the differences of the support and learning environment in student affairs divisions and/or small private institutions or institutions without graduate programs and graduate students. In addition, this study could be replicated with departments that are outside of residence life who have adopted a curricular approach, including orientation or first-year programs, leadership offices, civic engagement, multicultural offices, and others, to understand their curricular model and the success of a learning-centered approach in their organization.

This study interviewed two people at five different institutions; therefore, a future study could interview all staff at one institution to gain deeper understanding from multiple perspectives about their organizational structure and culture. This study was primarily focused on live-in hall director staff hiring and training; another study could fully focus on student staff hiring and training. Additional research could focus specifically on the actual elements of the curricular model implementation and strategies and/or best-used and unique assessment strategies. Another study could be a quantitative study with multiple institutions, where the survey is created to have staff self-select 


\section{LEARNING ORGANIZATIONS}

which of the 10EE they do well and do not do well, then highlight ways they have executed their curricular model. In addition, a quantitative study could have additional questions based on strategy implementation, learning theory used, and/or assessment techniques. This research could highlight the best practices in curricular model outputs. As institutions continue to grow and develop their curricular model, another future study could be based on an institution's review cycle since two institutions interviewed in this research have them. One institution shared they have their review cycle every four years, and the second institution shared they are going through their first review cycle 10 years after their curricular model integration. There could be a study to review these processes and share best practices. Lastly, the researcher outlined key concepts and highlighted the Kropf Curricular Integration Model. Future research could investigate institutions and understand how organizations have initiated, sustained, and created an organizational structure and culture to support the curricular model.

\section{Conclusion}

As student cultures and higher education shift, it is now more important for student affairs practitioners to shift their efforts to support the institutional mission and student learning and success through a curricular approach. Residential curriculum, curricular approach, and curricular model are terms used to describe the "intentional specifically structured way of promoting learning in college and university student affairs programs" (Brown, 2019, p. 9). Historically, what we know is that developing a curricular approach can take multiple years, and shifting to the curricular approach is as 


\section{LEARNING ORGANIZATIONS}

much about building the curricular model as it is cultural and organizational change (Brown, 2017, 2019). Some residence life departments have a thriving curricular model, and others have been struggling to adapt to the curricular model because of their organizational structure and culture. The shift to requires a learning-centric approach in an organization, and it is vital to sustaining the curricular model; it can take nearly two to three years before the basis of a curricular model will be in place in each organization (Brown, 2017, 2019).

This study interviewed 10 people from five different institutions to investigate how their organizational structure and culture supports their thriving curricular model; eight components were found. The eight critical components for integration of an organizational curricular approach can be adapted to any department and/or division of student affairs. The Kropf Curricular Integration Model is a way to operationalize integration of a curricular approach so that the organization ultimately can initiate, sustain, and thrive in facilitating student learning and success through their curricular model. All of the eight critical components are interactive and need to work together; the model is a guide for organizations to take strategic steps, not only ones who are new to integrating the model but also ones who might already have a curricular approach and want to better support how it is sustained and thrives in their organization. The Kropf Curricular Integration Model outlines eight critical components with which organizations integrate the curricular model to allow student learning and success to be the core of their organizational outputs. 


\section{LEARNING ORGANIZATIONS}

\section{References}

American College Personnel Association. (1994). The student learning imperative. Author.

American Council on Education. (1987). The student personnel point of view. Series vistudent personnel work-number 13. Author.

Bendermacher, G., Egbrink, M., Wolfhagen, I., \& Dolmans, D. (2017). Unravelling quality culture in higher education: A realist review. Higher Education, 73(1), 39-60.

Blimling, G. (2015). Student learning in college residence halls: What works, what doesn't, and why. Jossey-Bass.

Bolman, L. G., \& Deal, T. E. (2017). Reframing organizations: Artistry, choice, and leadership. Jossey-Bass.

Brown, P. (2017). Developing a co-curricular learning model (2nd edition). Roompact. https://blog.roompact.com/resources

Brown, P. (2019). Developing a co-curricular learning model (3rd edition). Roompact. https://blog.roompact.com/resoures

Caldwell, J. (2005). Things fall apart: Discourse on agency and change in organizations. Human Relations, 58(1), 83-114. https://doi.org/10.1177/0018726705050937

Creswell, J. W., \& Creswell, J. D. (2018). Research design: Qualitative, quantitative, and mixed methods approaches (5th ed.). Sage.

Cress, C. (2008). Creating inclusive learning communities: The role of student-faculty relationships in mitigating negative campus climate. Learning Inquiry, 2(2), 95111. https://doi.org/10.1007/s11519-008-0028-2

De Araujo, P., \& Murray, J. (2010). Channels for improved performance from living on campus. American Journal of Business Education, 3(12), 57-64. https://doi.org/10.19030/ ajbe.v3i12.965

Garvin, D. (1993). Building a learning organization. Harvard Business Review, 71(4), 7891. https://hbr.org/1993/07/building-a-learning-organization 


\section{LEARNING ORGANIZATIONS}

Graham, P., Hurtado, S., \& Gonyea, R. (2018). The benefits of living on campus: Do residence halls provide distinctive environments of engagement? Journal of Student Affairs Research and Practice, 55(3), 255-69. https://doi.org/10.1080/ 19496591.2018.1474752

Henning, G. (2018, February 5). Organized anarchies: 13 steps to building a learning organization [Blog post]. New England Board of Higher Education Journal. https://nebhe.org/journal/organized-anarchies-13-steps-to-building-a-learningorganization/

Hurtado, S. (2007). Linking diversity with the educational and civic missions of higher education. The Review of Higher Education, 30(2), 185-96. https://doi.org/ 10.1353/rhe.2006.0070

Keeling, K. P. (2004). Learning reconsidered: A campus-wide focus on the student experience. National Association of Student Personnel Administrators.

Kerr, K. G., \& Tweedy, J. (2006). Beyond seat time and student satisfaction: A curricular approach to residential education. About Campus, 11(5), 9-15. https://doi.org/ 10.1002/abc. 181

Kerr, K. G., Tweedy, J., Edwards, K. E., \& Kimmel, D. (2017). Shifting to curricular approaches to learning beyond the classroom. About Campus, 22, 22-31. https://doi.org/10.1002/ abc.21279

Kezar, A. (2018). How colleges change: understanding, leading, and enacting change. Routledge.

Kezar, A. J., \& Kinzie, J. (2006). Examining the ways institutions create student engagement: The role of mission. Journal of College Student Development, $47(2), 149-72$.

Kezar, A., Carducci, R., \& Contreras-McGavin, M. (2006). Rethinking the “L” word in higher education: The revolution in research on leadership. Jossey-Bass.

Kotter, J.P. (1985). Power and influences: Beyond formal authority. Free Press.

Kuh, G. (1996). Guiding principles for creating seamless learning environments for undergraduates. Journal of College Student Development, 37(2), 135-148.

Kuh, G. (2008). High-impact educational practices. Association of American Colleges and Universities. 


\section{LEARNING ORGANIZATIONS}

Kuk, L., \& Banning, J. (2009). Designing student affairs organizational structures: Perceptions of senior student affairs officers. NASPA Journal, 46(1), 94-117. https://doi.org/10.2202/ 1949-6605.5007

Kupo, V. L. (2014). Becoming a scholar-practitioner in student affairs. New Directions for Student Services, 147, 89-98. https://doi.org/10.1002/ss.20103

Lenz, B. (2015, June 8). The 80/20 rule: Changing mindsets about the where of learning. Partnerships for 21 st century learning, 2(7). http://www.p21.org/newsevents/p21blog/1682-the-8020-rule-changing-mindsets-about-the-where-oflearning

Lichterman, H. L. (2015). Organizational perspective on implementing the residential curriculum approach: An ethnographic case study (Doctoral dissertation). South Carolina Scholar Commons. (3817). https://scholarcommons.sc.edu/etd/3817

Lichterman, H., \& Bloom, J. L. (2019). The curricular approach to residential education: Lessons for student affairs practice. College Student Affairs Journal, 37(1), 54-67. https://doi:10.1353/csj.2019.0004

Long, L. (2014). Does it matter where college students live? Differences in satisfaction and outcomes as a function of students' living arrangement and gender. Journal of College and University Student Housing, 40(2), 66-85.

Maki, P. L. (2004). Maps and inventories: Anchoring efforts to track student learning. About Campus, 9(4), 2-9. https://doi.org/10.1002/abc.99

Mann, B. J. (2010). Preserving the history of a student affairs association. College Student Affairs Journal, 28(2), 164-83.

Manning, K. (2018). Organizational theory in higher education. Routledge.

Martin, G., \& Seifert, T. A. (2011). The relationship between students' interactions with student affairs professionals and cognitive outcomes in the first year of college. Journal of Student Affairs Research and Practice, 48(4), 389-410. https://doi.org/10.2202/1949-6605.6198

Maxwell, J. A. (2013). Qualitative research design: An interactive approach (3rd ed.). Sage.

Mayhew, M. J., Rockenbach, A. N., Bowman, N. A., Seifert, T. A., Wolniak, G. C., Pascarella, E. T., \& Terenzini, P. T. (2016). How college affects students: 21 st century evidence that higher education works. Jossey-Bass. 


\section{LEARNING ORGANIZATIONS}

McClintock, C. (2004). Scholar-practitioner model. In A. DiStefano, K. E. Rudestam, \& R. Silverman (Eds.), Encyclopedia of distributed learning (pp. 440-396). Sage. http://sk.sagepub.com/reference/distributedlearning/ n134.xml

Merriam, S. B., \& Bierema, L. L. (2014). Adult learning: Linking theory and practice. Jossey-Bass.

Merriam, S. B., \& Tisdell, E. J. (2016). Qualitative research: A guide to design and implementation (4th ed.). Jossey-Bass.

Mintzberg, H. (1978). Strategy formation in an adhocracy. Management Science, 24(9), 934-948. https://www.jstor.org/stable/2630633

Mintzberg, H. (1987). The strategy concept II: Another look at why organizations need strategies. California Management Review, 30(1), 25-32. https://doi.org/ $10.2307 / 41165264$

National Association of Student Personnel Administrators. (1987). Points of view: A perspective on student affairs. Author.

National Center for Education Statistics. (2018a). The condition of education. Author. https://nces.ed.gov/programs/coe/ indicator_ctr.asp

National Center for Education Statistics. (2018b). Institutions of higher educationaverage charges: 1985 to 2017 (per student tuition and fees, board rates, and dormitory charges, by type of school, selected academic years). In ProQuest (Ed.), Statistical abstract of the U.S. 2019: The national data book (p. 330). Rowman \& Littlefield.

National Survey of Student Engagement. (2014). The relationship of residence life with selected engagement measures. Author. http://nsse.indiana.edu/ html/sample_analyses/relationship.cfm

Pascarella, E., \& Terenzini, P. (2005). How college affects students: A third decade of research. Jossey-Bass.

Patton, L., McEwen, M., Rendón, R., \& Howard-Hamilton, M. (2007). Critical race perspectives on theory in student affairs. New Directions for Student Services, 120, 39-53. https://doi.org/10.1002/ss.256

Porterfield, K. T., Roper, L.D., \& Whitt, E. J. (2011). Redefining our mission: What does higher education need from student affairs? Journal of College and Character, 12(4), 1-7. 


\section{LEARNING ORGANIZATIONS}

Rogers, E. (2003). Diffusion of innovations. Free Press.

Ruben, B., \& De Lisi, R., \& Gigliotti, R. (2017). A guide for leaders in higher education: Core concepts, competencies, and tools. Stylus.

Saldaña, J. (2013). The coding manual for qualitative researchers. Sage.

Sandeen, A. (2004). Educating the whole student. Change, 36(3), 28-33. https://doi.org/ $10.1080 / 00091380409605577$

Sanders, L. (2018). The influence of residential curriculum on first-year residential students in higher education. http://ir.ua.edu/handle/123456789/3662

Schudde, L. (2011). The causal effect of campus residency on college student retention. The Review of Higher Education, 34(4), 581-610. https://doi.org/10.1353/rhe.2011.0023

Scott, W. R., \& Davis, G. F. (2007). Organizations and organizing: Rational, natural, and open system perspectives. Pearson.

Senge, P. (2006). The fifth discipline: The art and practice of the learning organization. Random House.

Seidman, I. (2013). Interviewing as qualitative research: A guide for researchers in education and the social sciences. Teachers College Press.

Skyfactor Benchworks. (2017). How does the housing experience contribute to learning outcomes? Author. http://skyfactor.com/wp-content/uploads/2017/07/2017Housing-Learning-Research-Note.pdf

Smith, S., \& Rodgers, R. (2005). Student learning community of practice: Making meaning of the student learning imperative and principles of good practice in student affairs. Journal of College Student Development, 46(5), 472-86. https://doi.org/10.1353/csd.2005.0056

Stamm, L. (2011). Leading the learner-centered campus. Journal of College and Character, 12(4), 1-5.

Tierney, W. G. (2008). The impact of culture on organizational decision-making: Theory and practice in higher education. Stylus.

Tinto, V. (1987). Leaving college: Rethinking the causes and cures of student attrition. University of Chicago Press. 


\section{LEARNING ORGANIZATIONS}

Tull, A., \& Kuk, L. (2012). New realities in the management of student affairs: Emerging specialist roles and structures for changing times. Stylus.

U.S. Department of Housing and Urban Development, Office of Policy Development and Research. (2015). Barriers to success: Housing insecurity for U.S. college students. Author. https://www.huduser.gov/ portal/periodicals/ insight/insight_2.pdf

Webber, K., Krylow, R. B., \& Zhang, Q. (2013). Does involvement really matter? Indicators of college student success and satisfaction. Journal of College Student Development, 54(6), 591-611. https://doi.org/10.1353/csd.2013.0090

Weiss, R. S. (1995). Learning from strangers: The art and method of qualitative interview studies. Free Press.

Whitt, E. J. (2006). Are all of your educators educating? About Campus, 10(6), 2-9. https://doi.org/10.1002/abc.148

Wiggins, G., \& McTighe, J. (2005). Understanding by design (2nd ed.). ASCD. 


\section{LEARNING ORGANIZATIONS}

\section{Appendix A: IRB Approval}

\section{P Portland State \\ UN I VER S T Y \\ Office of Research Integrity \\ 1600 SW 4th Avenue, Suite 620 \\ Portland, OR 97201 \\ (503) 725-5484 psuirb@pdx.edu}

\section{Human Research Protection Program \\ Notice of Exempt Certification}

July 08, 2019

Dear Investigator,

The PSU Human Research Protection Program (HRPP) reviewed the following submission:

\begin{tabular}{|l|l|}
\hline Investigator(s) & Christine Cress / Heather Knopf \\
\hline HRPP \# & $196514-18$ \\
\hline Title & $\begin{array}{l}\text { Residence Life as Learning Organizations: An Inquiry into Organizational } \\
\text { Elements that Support Integration of the Residential Curriculum }\end{array}$ \\
\hline Funding Agency / Kuali \# & N/A \\
\hline Determination Date & 07/08/2019 \\
\hline Expiration Date & N/A \\
\hline Review Category(ies) & Exempt: \# 2 \\
\hline
\end{tabular}

Research Integrity determined this study qualifies as exempt and is satisfied the provisions for protecting the rights and welfare of all subjects participating in research are adequate. The study may proceed in accordance with the plans submitted (HRPP Forms enclosed). Please note the following ongoing Human Research Protection Program (HRPP) requirements:

Changes to Study Activities: Any changes to the study must be submitted to Research Integrity for review and determination prior to implementation.

Unanticipated Problems or Adverse Events: Notify Research Integrity within 5 days of any unanticipated problems or adverse events that occur as a result of the study.

Study Completion: Notify Research Integrity when the study is complete; Research Integrity will request annual updates on the study status. Study materials must be kept for at least three years following completion.

Compliance: The PSU IRB (FWA00000091; IRB00000903) and Research Integrity comply with 45 CFR Part 46, 21 CFR Parts 50 and 56, and other federal and Oregon laws and regulations, as applicable.

If there are any questions, please contact Research Integrity at psuirb@pdx.edu or call 503-725-5484.

Sincerely,

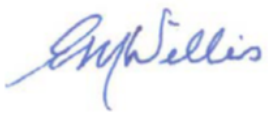

EM Willis, CIP, HRPP Admin istrator

Research Integrity 


\section{LEARNING ORGANIZATIONS}

\section{Appendix B: Email to Institutional Staff \#1}

[Note: Institutional staff is the person who oversees the implementation of the curricular model.]

Dear [staff member's name],

Hello, my name is Heather Kropf and I am a doctoral student at Portland State University and work as the Associate Director of Residence Life at the University of Oregon. I am interested in having you participate in my research study which is titled Residence Life as Learning Organizations: An Inquiry into Organizational Elements that Support Integration of the Residential Curriculum. I am interested in learning more about your organizational culture and implementation of structures that allow the curricular approach to thrive in your department.

There has been promising data and research in the past few years about the curricular model through a few dissertations and a handful of articles and resources. While the outcomes in research is proactive, what we do not know is how organizations have integrated and adapted the curricular model and built an organizational structure to support it.

Two overarching research questions frame the qualitative study:

1. How does the residence life department support the curricular model?

2. How does the residence life department infuse a learning-centric environment?

Based on nominations from select faculty at the Institute on Curricular Approach your institution has been nominated by multiple faculty. I am hopeful to interview you as the person that oversees the implementation of the curricular model and a live-in residence life hall director who is closely tied curricular approach. I plan to research 2 people at 5-7 different state institutions with a first-year live-on requirement. If you are not the person who oversees the curricular model can you kindly let me know their contact information.

The following criteria must be met to participate in the study:

1. Follow the ten essential elements of a curricular model for learning beyond the classroom

2. Have a curricular model for a minimum of 4 years 


\section{LEARNING ORGANIZATIONS}

Your department is well known in the field and will be able to provide valuable insight for how organizational structures and cultures support the curriculum model.

If you meet the criteria, I would like to confirm your participation. Part of the study is to interview two people per institutional at different hierarchical layers in the organization in order to gain rich data about the organizational structure and learning environment. The second person I would like to interview is a residence life hall director who works closely with the curricular model at your institution. Would you be willing to nominate a hall director staff by sending me their contact information? I have attached the informed consent to the research study which I will need signed prior to our interview.

Once I confirm your participation, I will send an email before with the interview questions for you to review prior to our interview. I will host a video interview that will be recorded. Please let me know the times that you're available by filling out this survey [survey link].

If you have any questions, please reach out to me at hkropf@pdx.edu. I very much appreciate your time.

Thank you, Heather Kropf 


\section{LEARNING ORGANIZATIONS}

\section{Appendix C: Email to Institutional Staff \#3}

[Note: This email was sent after confirmation of participation and one week in advance of interviews.]

Dear [staff member's name],

Thank you for your participation in my research study which is titled Residence Life as Learning Organizations: An Inquiry into Organizational Elements that Support Integration of the Residential Curriculum. I am eager to learn more about your organizational culture and implementation of structures that allow the curricular approach to thrive in your department. This email will explain more about the interview itself, review the informed consent and research questions, confirm the day and time of the interview, and request for a few preliminary documents.

The 90 minute interview will be facilitated through a video platform that will be recorded with audio recording. The interviews will be transcribed, and I may use a professional transcriber and if so; they will sign a confidentiality agreement before assessing the data. The recordings and transcriptions will be stored in a locked area in my personal residence. The dissertation and future publications will not name your institution or your name.

Attached it the informed consent that has been signed and sent to you for your records.

I wanted to give you time to prepare for the interview. Below are the questions that will guide our conversation:

[list interview protocol]

Please note there is a list of common terms (located below my signature in this email) that would be helpful for you to review before the interview.

Our interview is scheduled for: [list date and time]

Here is the website login information (video and audio link): [link to video]

You should not have to call in to talk; but if needed here is the dial-in: [phone number listed]

[Note: the following paragraph only sent to institutional staff who oversees the implementation of the curricular model.] Before our interview I am asking institutions to send me items on their curricular model for subsequent data for my research where I can learn more about your department. As you are willing, I would be interested in obtaining 


\section{LEARNING ORGANIZATIONS}

an organizational chart of your department, any training schedules or training materials as examples of how you train staff on the curricular model, job descriptions that describe the curricular model, information on the curricular model itself (strategies, educational plan, etc.), and any other materials that describe the curricular model that you would be willing to share. These materials will be part of my data analysis process to describe how the curricular model is embedded in your organizational structure and culture. I am only asking you for this information and not the live-in hall director staff you suggested.

I am eager to get to interview and learn about your organization. If you have any questions, please reach out to me at hkropf@pdx.edu. I very much appreciate your time. Thank you,

Heather Kropf

Terms to review:

Learning Organizations: learning organizations encompass a culture that creates learning environments for all people to expand their thinking and creativity, and they encourage a collaborative learning environment.

Scholar Practitioner: A scholar-practitioner is someone who engages in research to improve outcomes and effectiveness; they are administrators who engage in research to better their practice.

Ten Essential Elements of a Curricular Model for Learning Beyond the Classroom (10EE):

1. Directly connected to an institutional mission: Learning goals are tied to institutional and educational priorities such as general education, history, mission, and culture.

2. Learning goals and outcomes are derived from a defined educational priority: Educational aims of a unit are focused, interconnected, and clearly articulated.

3. Based on research and developmental theory: Educational content and strategies are grounded in student development theory and learning pedagogy.

4. Departmental learning outcomes drive development of educational strategies: Educational strategies are determined based on what can best facilitate each student achieving the department learning outcomes.

5. Traditional programs may be one type of strategy but not the only one: Strategies like international conversations, community and organizational meetings, service initiatives, social media engagement, and campus events are structured to help achieve the learning outcomes.

6. Student leaders and staff members play key roles in implementation but are not expected to be educational experts: Student leaders and staff members are considered to be facilitators rather than designers of educational strategies. 


\section{LEARNING ORGANIZATIONS}

7. Represents developmentally sequenced learning: Educational content and strategies build upon one another for coherent plans both across the academic year and the full college career.

8. Campus partners are identified and integrated into plans: Multiple units with intersecting goals work together to develop educational strategies that complement the student experience and advance the institution's mission.

9. Plan is developed through review processes: A regular review process (internal and/or external) is developed to get feedback from key partners and experts on content and pedagogy.

10. Customized student learning: Learning that is tailored to the individual student's needs and goals through multiple strategies 


\section{LEARNING ORGANIZATIONS}

\section{Appendix D: Email to Institutional Staff \#2}

[Note: Institutional staff is the person who is a live-in residence life hall director.]

Dear [staff member's name],

Hello, my name is Heather Kropf and I am a doctoral student at Portland State University and work as the Associate Director of Residence Life at the University of Oregon. I recently talked to (person who oversees the curricular model) at your institution. I am interested in having your participate in my research study which is titled Residence Life as Learning Organizations: An Inquiry into Organizational Elements that Support Integration of the Residential Curriculum. I am interested in learning more about your organizational culture and implementation of structures that allow the curricular approach to thrive in your department.

There has been promising data and research in the past few years about the curricular model through a few dissertations and a handful of articles and resources. While the outcomes in research is proactive, what we do not know is how organizations have integrated and adapted the curricular model and built an organizational structure to support it.

Two overarching research question frame this qualitative study:

1. How does the residence life department support the curricular model?

2. How does the residence life department infuse a learning-centric environment?

Based on nominations from select faculty at the Institute on Curricular Approach your institution has been nominated by multiple faculty. I will be interviewing (NAME of person who oversees the curricular model) as the person that oversees the implementation of the curricular model. I am also interviewing one live-in residence life hall director who is closely tied and has a positive regard to the curricular approach; your name was given to me by (NAME of person who oversees the implementation of the curricular model). I plan to research 2 people at 5-7 different institutions.

The following criteria has been met to participate in the study by confirmation from (NAME of person who oversees the curricular model):

1. Follow the ten essential elements of a curricular model for learning beyond the classroom

2. Have a curricular model for a minimum of 4 years

Your department is well known in the field and will be able to provide valuable insight for how organizational structures and cultures support the curriculum model. I have 


\section{LEARNING ORGANIZATIONS}

attached the informed consent to the research study which I will need signed prior to our interview.

Once I confirm your participation, I will send an email before with the interview questions for you to review prior to our interview. I will host a video interview that will be recorded. Please let me know the times that you're available by filling out this survey [link to survey].

If you have any questions, please reach out to me at hkropf@pdx.edu. I very much appreciate your time.

Thank you, Heather Kropf 


\section{LEARNING ORGANIZATIONS}

\section{Appendix E: Interview Protocol}

Interview protocol for person who oversees the implementation of the curricular model:

- How has the organizational structure changed since the implementation of the curricular model?

- Probe: What have been successful elements of your organizational structure (peoples job roles and responsibility, supervision, etc.) to allow the curricular model to thrive?

- Probe: How do your meetings support the curricular model?

- Describe how the organization created a vision for the curricular model.

- Probe: How are staff aware and knowledgeable about the goals and outcomes of the curricular model?

- Please share how funding and budgets have changed to support the curricular model.

- Can you explain how the group (committee, full department, etc.) that works on the curricular model is structured?

- Probe: How does it function within the organizational structure?

- Probe: What are the outputs of the group?

- Probe: What roles do full time hall director staff play in the curricular model?

- What is the curricular model review process like and how have you integrated the 10EE?

- Probe: How have you used mapping and sequencing in your review processes?

- Probe: How have you used and incorporated rubrics?

- Probe: What assessment strategies have been most successful?

- Probe: What theories are infused in your curricular model?

- How do you know the structural components of your organization supports an effective curricular model?

- How does the culture of the department support the curricular model?

- Probe: What have the benefits been for the organizational culture since you implemented the curricular model?

- Probe: What strategies have been effective when navigating the political nature of a curricular model?

- Tell me how your department is a learning organization. (review definition)

- Probe: How does the organization support a culture of learning?

- How does the organization learn about the changing culture of students, and how do you adopt the curricular model to support them?

- How does the organization measure student learning?

- Describe how you leverage recruitment, on-boarding, training and continued development to educate professional staff on the curricular model. 


\section{LEARNING ORGANIZATIONS}

- Probe: How does the organization motivate and engage staff in the curricular model?

- How does the organization train and empower staff to be scholarpractitioners/educators?

- What job responsibilities have shifted in order to create time for the curricular model work?

- How has the department integrated campus partners into the curricular model?

- Probe: How has the organization gained buy in from campus partners?

Wrap up questions:

- What are the positive gains with the curricular model and how do you know the curricular model is effective?

- What recommendations do you have for others about creating learning organizations?

- What recommendations do you have for others about how to sustain a curricular model?

Interview protocol for live-in residence life hall director:

- How has the organizational structure changed since the implementation of the curricular model?

- Probe: What have been successful elements of your organizational structure (peoples job roles and responsibility, supervision, etc.) to allow the curricular model to thrive?

- Probe: How do your meetings support the curricular model?

- Describe how the organization created a vision for the curricular model.

○ Probe: How are you aware and knowledgeable of the goals and outcomes of curricular model? Specifically, the goals and outcomes?

- Can you explain how the group (committee, full department, etc.) that works on the curricular model is structured?

- Probe: How does it function within the organizational structure?

- Probe: What are the outputs of the group?

- Probe: What roles do full time hall director staff play in the curricular model?

- What is the curricular model review process like and how have you integrated the10EE?

- Probe: How have you used mapping and sequencing in your review processes?

- Probe: How have you used and incorporated rubrics?

- Probe: What assessment strategies have been most successful?

- Probe: What theories are infused in your curricular model?

- How do you know the structural components of your organization supports an effective curricular model? 


\section{LEARNING ORGANIZATIONS}

- How does the culture of the department support the curricular model?

- Probe: What have the benefits been for the organizational culture since you implemented the curricular model?

- Probe: When there is conflict with the curricular model, how does the organization respond?

- Tell me how your department is a learning organization. (review definition)

○ Probe: How does the organization support a culture of learning?

- How does the organization learn about the changing culture of students, and how do you adopt the curricular model to support them?

- How does the organization measure student learning?

$\circ$ Probe: What strategies have had the most impact on student learning?

- Why were you interested in working in a department that has a curricular model?

- Describe how recruitment, on-boarding, training, and continued development throughout the year has met your needs and trained you on the curricular model.

$\circ$ Probe: How does the organization motivate and engage you in the curricular model?

- How are you a scholar-practitioner/ educator? (review definition)

- How has the department integrated campus partners into the curricular model?

- Probe: How has the organization gained buy in from campus partners?

Wrap up questions:

- How have you found joy in the curricular model?

- What are the positive gains with the curricular model and how do you know the curricular model is effective?

- What recommendations do you have for others about creating learning organizations?

- What recommendations do you have for others about how to sustain a curricular model? 


\section{LEARNING ORGANIZATIONS}

\section{Appendix F: Informed Consent \\ Consent to Participate in Research}

Project Title: Residence Life as Learning Organizations: An Inquiry into Organizational Elements that Support Integration of the Residential Curriculum

\section{Researcher:}

Christine Cress, PhD, College of Education, cressc@ pdx.edu, 503.725.4682

Heather Kropf, College of Education, hkropf@pdx.edu, 503.530.6968

You are being asked to take part in a research study. The box below highlights key information about this research for you to consider when making a decision whether or not to participate. Carefully review the information provided on this form. Please ask questions about any of the information you do not understand before you decide to participate.

\section{Key Information for You to Consider}

Voluntary Consent. You are being asked to volunteer for a research study. It is up to you

whether you choose to participate or not. There is no penalty if you choose not to participate or discontinue participation.

Purpose. The purpose of this research is understand how departments with a thriving curricular model sustain and support the curricular model through their organizational structure and infuse a learning-centric environment.

Duration. It is expected that your participation will last 90-minute through a video interview; which will be recorded. Researcher will send interview question before the schedule interview.

Procedures and Activities. You will be asked to describe your departments organizational culture and structure along with other questions related to learning environments.

Risks. There are no foreseeable potential risks associated with the study. Benefits. Some of the benefits that may be expected include an ability for other departments to understand how organizational culture and structure best supports the curricular model. Upwards to people from 5-7 institutions will be interviewed.

Alternatives. Participation is voluntary and the only alternative is to not participate. 


\section{LEARNING ORGANIZATIONS}

What happens to the information collected? The information collected will be used as research for a dissertation and potentially publications or presentations after the dissertation is complete. The institution and name of the participants will not be shared in the final dissertation. The researcher will give specifics about the institution (region, number of students enrolled, percentage of students who live on campus, public, firstyear live-on requirements, and share some specifics about the department that is shared in the interview).

How will my privacy and data confidentiality be protected? We will take measures to protect your privacy including professional transcriber signing a confidentiality agreement before they transcribe. The recordings and transcripts will be stored in a locked area in my personal residence. Despite taking steps to protect your privacy, we can never fully guarantee that your privacy or confidentiality will be protected.

What if I want to stop participating in this research? Your participation is voluntary. You do not have to take part in this study, but if you do, you may stop at any time. You have the right to choose not to participate in any study activity or completely withdraw from participation at any point without penalty or loss of benefits to which you are otherwise entitled. Your decision whether or not to participate will not affect your relationship with the researchers or Portland State University.

Will I be paid for participating in this research? Participants will receive a $\$ 20.00$ Starbucks gift card.

Who can answer my questions about this research? If you have questions, concerns, or have experienced a research related injury, contact the research team at: Christine Cress, PhD, College of Education, cressc@ pdx.edu, 503.725.4682 Heather Kropf, College of Education, hkropf @ pdx.edu, 503.530.6968

Who can I speak to about my rights as a research participant? The Portland State University Institutional Review Board ("IRB") is overseeing this research. The IRB is a group of people who independently review research studies to ensure the rights and welfare of participants are protected. The Office of Research Integrity is the office at Portland State University that supports the IRB. If you have questions about your rights, or wish to speak with someone other than the research team, you may contact:

Office of Research Integrity

PO Box 751

Portland, OR 97207-0751

Phone: (503) 725-5484

Toll Free: 1 (877) 480-4400

Email: hsrrc@pdx.edu 


\section{LEARNING ORGANIZATIONS}

Consent Statement: I have had the opportunity to read and consider the information in this form. I have asked any questions necessary to make a decision about my participation. I understand that I can ask additional questions throughout my participation.

By signing below, I understand that I am volunteering to participate in this research. I understand that I am not waiving any legal rights. I have been provided with a copy of this consent form. I understand that if my ability to consent for myself changes, either I or my legal representative may be asked to provide consent prior to me continuing in the study.

I consent to participate in this study.

Name of Adult Participant Signature of Adult Participant

Date

Researcher Signature (to be completed at time of informed consent) I have explained the research to the participant and answered all of his/her questions. I believe that he/she understands the information described in this consent form and freely consents to participate.

Name of Research Team Member Signature of Research Team Member

Date 